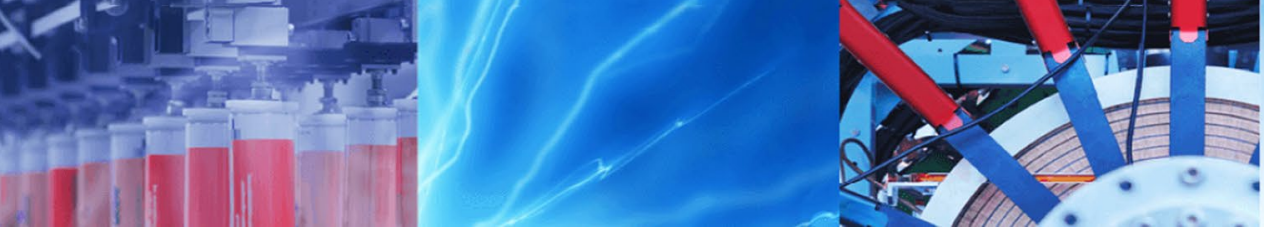

Research Article

\title{
A novel chaotic manta-ray foraging optimization algorithm for thermo-economic design optimization of an air-fin cooler
}

\author{
Oguz Emrah Turgut ${ }^{1}$ (D)
}

Received: 25 August 2020 / Accepted: 21 December 2020 / Published online: 28 December 2020

(c) The Author(s) 2020 OPEN

\begin{abstract}
This research study aims to introduce chaos theory into the Manta Ray Foraging Optimization (MRFO) Algorithm and optimize a real-world design problem through the chaos-enhanced versions of this method. Manta Ray Foraging Optimization algorithm is a bio-inspired swarm intelligence-based metaheuristic algorithm simulating the distinctive food search behaviors of the manta rays. However, MRFO suffers from some intrinsic algorithmic inefficiencies such as slow and premature convergence and unexpected entrapment to the local optimum points in the search domain like most of the metaheuristic algorithms in the literature. Recently, random numbers generated by chaos theory have been incorporated into the metaheuristic algorithms to solve these problems. More than twenty chaotic maps are applied to the base algorithm and ten best performing methods are considered for performance evaluation on high-dimensional optimization test problems. Forty test problems comprising unimodal and multimodal functions have been solved by chaotic variants of MRFO and extensive statistical analysis is performed. Furthermore, thermo-economic design optimization of an air-fin cooler is maintained by the chaotic MRFO variants to assess their optimization capabilities over complex engineering design problems. Ten decisive design variables of an air fin cooler are optimized in terms of total annual cost rates and optimum solutions obtained by five best chaotic MRFO algorithms are compared to the preliminary design. A significant improvement is observed in the objective function values when MRFO with chaotic operators is applied to this considered thermal design problem.
\end{abstract}

Keywords Air-fin cooler $\cdot$ Chaos theory · Global optimization · Manta-ray optimization algorithm · Thermal design

\section{Introduction}

Optimization is a tedious iterative process based on a comprehensive search among the trial solution alternatives to obtain the optimum solution for a particular problem. Selected optimum solution vector can minimize or maximize the considered objective to provide the optimal solution to the problem. Literature optimization approaches can be generally categorized into two main branches: Deterministic and stochastic algorithms [1]. Deterministic methods converge to the optimal solutions in a finite time and can guarantee the global optimum solution with a negligible predefined error tolerance. Algorithms belonging to deterministic optimization methods are frequently used when locating the global best answer to the problem is a necessity or in extreme cases when it is very time-consuming and exhaustive to find a feasible solution. However, these types of algorithms can be unproductive and become useless in finding the exact solutions to NP (Non Polynomial)-hard multidimensional problems. In these cases, stochastic optimizers can be favorable alternatives, which benefit from the randomness while probing the search space with a superficial exploration. It is nearly impossible to obtain the same optimal result in the

Oguz Emrah Turgut, oeturgut@hotmail.com | ${ }^{1}$ Industrial Engineering Department, Engineering and Architecture Faculty, Izmir Bakircay University, Izmir, Turkey. 
successive algorithm runs for stochastic algorithms as their search mechanism relies on non-repeating random-walks [2]. Such algorithms can provide very efficient results without any guarantee of finding the global optimum solution. Metaheuristic algorithms are prominent members of stochastic algorithms and able to yield robust and accurate predictive results for multidimensional nonlinear optimization problems. They do not impose preconditions to the solution domain such as differentiability and continuity which eases their successful applications to various design problems [3].

Metaheuristic algorithms prove their effectivity in solving complex optimization cases and therefore draw significant interest from the research community in their applications to various design problems [4-6]. Particle Swarm Optimization [7], Differential Evolution [8], and Harmony Search [9] algorithms are the prevalent examples of the metaheuristic optimizers. Despite their different structural characteristics, all metaheuristic algorithms commence with randomly generated trial solutions within the allowable bounds. Then, candidate solutions are evolved by the algorithm-specific manipulation equations until the predefined termination condition is satisfied. Solution improvement varies according to the nature of the optimization algorithm. For instance, the Particle Swarm Optimization method uses social flocking birds whereas Crow Search [10] algorithm utilizes the characteristic pilfering behaviors of the intelligent crows. Literature also comprises recently emerged metaheuristic methods such as Barnacles Mating Optimization [11], Harris Hawks Optimization [12], Seagull Optimization [13], Slime Mould Optimization [14], Farmland Fertility Optimization [15], and Levy Flight Distribution [16] algorithms whose successful engineering applications have not been sufficiently investigated yet. There is also a new emerged metaheuristic algorithm called Heat Transfer Search [17] which is inspired form the basic principles of thermodynamics and heat transfer. The proposed optimization method is based on the molecular interactions of the systems to attain a thermal equilibrium with the surroundings. This metaheuristic optimizer is applied to thermal design optimization of a fin and tube heat exchanger with a view to minimize the total weight and total annual cost of the device [18]. Patel et al. [19] present a multi-objective thermal design optimization of a Stirling heat engine taking into account of four different optimization objectives including thermal and exergy efficiency, power output, and ecological function using Heat Transfer Search algorithm.

Metaheuristic optimizers perform the iterative calculations by dividing the search domain into two main phases to increase the possibility of finding the global optimum solution of the problem. These two conflicting but complementary search mechanisms are diversification and intensification. The diversification process is concerned with maintaining an extensive global search mostly through randomization within the search range to eliminate the possibilities of the local minima entrapment. Intensification generally occurs in the neighborhood of the successful samples to evaluate the beneficial solution information stored in the population memory. This process can be also considered as an intensive local search mechanism to exploit the fertile and promising regions in the vicinity of the current best solution. A successful metaheuristic optimizer should maintain a plausible balance between these two commanding search phases to reach favorable solutions. However, achieving harmony between these probing mechanisms maybe sometimes troublesome due to the randomized natures of the stochastic optimization algorithms. An algorithm developer should be aware that too much emphasis on one phase would weaken the intensity of the other one, which may lead to poor estimations resulted from the stagnation in the solution convergence or inefficient exploration of the search domain. There are available options discussed in the literature to improve the effectiveness of these mechanisms. Random walks [20] can be alternatively employed to diversify the search space to some extent whereas local search methods $[21,22]$ are exemplified as popular strategies for the exploitation which allows for intensification on the fertile areas obtained through the iterative process. Creating a synergy between two or more metaheuristic algorithms $[23,24]$ can also improve the solution accuracy, but this kind of hybridization burdens a significant amount of computational cost which entails evident problems in ill-defined expensive optimization problems. Apart from these alternative strategies, literature studies suggest incorporating the essentials of the chaos theory into the metaheuristic algorithms to improve the exploration and exploitation phases. Chaotic sequences have been previously employed on the tunable parameters of metaheuristic optimizers such as Krill Herd Algorithm [1], Big Bang-Big Crunch Algorithm [25], Bat Algorithm [26], Firefly Algorithm [27], Grasshopper Optimization algorithm [28], Artificial Immune System Optimization Algorithm [29], Imperialist Competitive Algorithm [30], Crow Search Algorithm [31], Atom Search Optimization [32], Salp Swarm Algorithm [33], Dragonfly Algorithm [34], and Gravitational Search Algorithm [35]. Integration with chaos theory shows a promise and can be applied if the appropriate set of chaotic maps among the alternatives is utilized. The numerical analysis made on the predictive results of the above-mentioned chaotic metaheuristic algorithms reveals that using chaotic numbers rather than a uniformly distributed Gaussian random number or fixed algorithm parameter greatly enhances the solution diversity. For this reason, this research study aims to 
introduce chaotic random numbers into a recently developed metaheuristic of the Manta Ray Foraging Optimization (MRFO) algorithm [36]. This is the first time in literature that a set of chaotic variables is applied to base the MRFO algorithm to enhance the solution effectivity and quality. This algorithm mimics the intrinsic food search behaviors of the manta-rays including cyclone foraging, chain foraging, and somersault foraging mechanisms to reach the optimal solution of the problem. There is a limited research study in the literature investigating the optimization efficiency of MRFO due to its recent emergence. Calasan et al. [37] identified the unknown model parameters of single-phase transfer through a chaotic Logistic map based MRFO. Fathy et al. [38] used the MRFO algorithm for extracting the global maximum power point from the Triple-junction solar-based array running under shadow conditions. Selem et al. [39] extracted the unidentified model parameters of PEMFC using MRFO. Three case studies regarding different PEMFC stacks were solved and comparative results were verified. El-Hameed et al. [40] utilized the MRFO algorithm to estimate three-diode model parameters of solar panels. The objective function considered as the cumulative root mean square error between the experimental data and the governing mathematical model is minimized to obtain nine design variables characterizing the I-V polarization curves of generating units. It is seen from the limited literature survey that no clear improvement has been made on the search equations of MRFO to boost up the solution accuracy and efficiency, except the research study covering experimental and theoretical analysis on single-phase transformers performed by Calasan et al. [37] in which optimization performance is enhanced by hybridizing chaotic numbers produced by Logistic map with manipulation equations of MRFO.

One of the major concerns in this study is to diversify the available literature by incorporating the merits of the chaos theory into MRFO and observe the improvements in solution accuracies acquired through various chaotic variants. Previous approaches to chaotic metaheuristic algorithms suggest that different chaotic maps lead to different algorithm characteristics, which eventually leads to different solution outcomes. Extensive numerical experiments made by the author on MRFO through high dimensional test problems with various functional features indicate that this algorithm may suffer from premature convergence for a set of benchmark cases with different characteristics. To overcome this drawback, twenty-four different chaotic maps have been replaced with uniformly distributed numbers maintaining randomization for the algorithm. Optimization efficiencies of the ten best performing chaotic maps between them are compared employing the forty multidimensional optimization unconstrained benchmark problems comprising unimodal and multimodal test functions. One novelty proposed in this research study is to integrate the generated chaotic numbers into the baseline MRFO algorithm, which has not been considered before in any published literature work. Furthermore, thermo-economic design optimization of an air fin cooler will be performed by the chaotic variants of MRFO to assess their optimization capabilities on a complex real word constrained design problem. A set of ten decision variables of the heat exchanging unit will be optimized by the proposed chaotic optimization methods to retain the minimum annual capital cost of a heat exchanger. Another impactful contribution to the literature is that this is the first application of MRFO algorithm to heat exchanger design problems.

Several theoretical attempts have been made by different researchers for thermal design optimization of air plate-fin coolers in the literature. Doodman et al. [41] utilized a metaheuristic based thermo-economic design optimization of air-cooled heat exchangers utilizing the favorable merits of global sensitivity analysis and harmony search algorithm. Global sensitivity analysis is performed to reduce the number of design variables by identifying the non-influential operating parameters. Then, the Harmony search algorithm is applied to the influential design parameters to reach the optimal value of the considered problem objective. Salimpour and Bahrami [42] investigated the influences of different tube geometries and flow configurations over the thermal performance of the heat exchanger. A parametric optimization study was conducted to obtain the optimal values of total entropy generation which is the considered problem objective for this research study. Moreover, a novel correlation was developed to obtain optimal values of Reynolds number based on the optimized decision parameters. Gonzalez et al.[43] applied the Successive Quadratic Programming nonlinear optimization method to obtain the minimum cost of an air-cooled heat exchanger, subjected to various several geometric and thermohydraulic constraints. Kashani et al. [44] put into practice NSGA-II to concurrently minimize two conflicting design objectives of an air-cooled heat exchanger namely the temperature approach and total annual cost considering ten different design variables. Karami et al. [45] proposed using the Imperialist Competitive Algorithm to optimize the amount of the heat transfer that occurred in an air-cooled heat exchanger equipped with classic twisted tape inserts. Manassaldi et al. [46] used a branch-and-bound optimization method to accomplish an optimal design of an air-cooled heat exchanger corresponding to three different optimization criteria which are minimum total annual cost, minimum heat transfer area, and minimum fan power consumption. Carvalho et al. [47] presented a design optimization case of an air cooler taking into account the limiting fan calculations which 
enables using mass flow rate of the process air as a decision variable. Three different optimization methodologies were applied to this design problem and their predictive performances were compared. Despite the plenty of contributive efforts regarding the design optimization of air fin coolers, neither of them considers the effects of various types of fin resistances over total heat transfer rates as well as total annual cost values. It is important to evaluate the contributions of all these resistances to the mathematical model that governs the heat exchange mechanism between the process air and in-tube fluid. Furthermore, neither of these abovementioned approaches perform a complete analysis as to the variational influences of decision variables on the considered design objective. This research study will take into account most of the missing discussions overlooked by the past studies and propose a more reliable and robust mathematical procedure for the thermo-economic design of an air fin cooler. The rest of the paper is organized as follows. Section 2 provides the essentials of the Manta Ray Optimization algorithm along with its detailed algorithmic procedure. Section 3 gives a brief description of the characteristic formulations of chaotic maps, presents the chaos-based MantaRay Foraging Optimization, and performs a comparative statistical analysis retained from the individual successive runs of these chaotic algorithms for each benchmark function. Section 4 provides the fundamental thermal design principles of air-fin coolers, defines the objective function, and describes the imposed design constraints. Section 5 reports the optimum operating parameters that minimize the annual capital cost of an air-fin cooler, and performs parametric analysis. Section 6 concludes this research study through remarkable comments along with some useful future works.

\section{A brief overview of the manta ray foraging optimization algorithm}

Manta Ray Foraging Optimization (MRFO) algorithm [36] is a bio-inspired swarm intelligence optimizer simulating the food search proclivities of manta rays such as chain foraging, cyclone foraging, and somersault foraging. Chain foraging simulates the intrinsic food search activity in which foraging manta-rays line up in an orderly fashion to catch the missing preys overlooked or undetected by the previous manta ray in the chain [48]. This interactive cooperation between the competing manta rays eliminates the possible loss of prey in their eyesight to some degree and improves the food rewards. Cyclone foraging takes place when the concentration amount of the prey (plankton) is significant. The tail end of the manta ray connects with its head forming a spiral to produce a vertex in the eye of a cyclone, therefore the filtered water moves towards the surface. This rather complex process enables the prey plankton to be easily caught by the predator manta ray [49]. The last foraging strategy is somersault foraging which is considered to be one of the most splendid natural activities performed by a living creature [50]. Manta rays make backward spin moves and circle around the prey planktons draws them into their open mouths. These three different foraging mechanisms form the fundamental search schemes of the MRFO. Next sections will briefly describe the mathematical models inspired by the governing foraging behaviors of the manta rays.

\subsection{Chain foraging}

As mentioned in the above section, manta-rays line up in an orderly head-to-tail fashion to form a solid chain for catching prey planktons. MRFO makes an assumption that the best solution obtained so far is the plankton with higher concentration, which is the target prey for the manta ray chain to be consumed. Algorithm updates the current position of the population individuals based on the target prey considered as the best solution and the manta ray in front of the current manta ray with using the below-given formulation

$x_{i, j}^{t+1}=\left\{\begin{array}{l}x_{i, j}^{t}+r_{1}(0,1)\left(x_{\text {best }, j}^{t}-x_{i, j}^{t}\right)+\beta\left(x_{\text {best }, j}^{t}-x_{i, j}^{t}\right) i=1 \\ x_{i, j}^{t}+r_{2}(0,1)\left(x_{i-1, j}^{t}-x_{i, j}^{t}\right)+\beta\left(x_{\text {best }, j}^{t}-x_{i, j}^{t}\right) i=2, \ldots, N\end{array}\right.$

$\beta=2 \cdot r_{3}(0,1) \cdot \sqrt{\left|\log \left(r_{4}(0,1)\right)\right|}$

where $x_{i, j}^{t}$ is the position of the $i^{\text {th }}$ manta ray in the $j^{\text {th }}$ dimension at iteration $t ; r_{i}(0,1) i=1,2,3,4$ are random numbers defined in the range $[0,1]$ which are also different from each other; $\beta$ is the weight coefficient, and $x_{\text {best }}^{t}$ is the plankton prey with the highest concentration. One can easily see that position update mechanism in chain foraging is determined by the previous manta ray in the chain and the spatial position of the best plankton.

\subsection{Cyclone foraging}

Manta ray group forms a foraging chain and makes spiral movements while approaching the food source when they recognize the position of a school of plankton in the deep water. Flocked manta rays in the cyclone foraging phase not only follow the manta ray in front of the previous one to ensure the consistency of the formed chain but also chase a spiral pathway to move towards the target prey. This characteristic spiral shape movement of the manta ray 
chain is mathematically modeled in $D$ dimensional search space by the following formulation

$x_{i, j}^{t}=\left\{\begin{array}{l}x_{\text {best }, j}^{t}+r_{5}(0,1)\left(x_{\text {best }, j}^{t}-x_{i, j}^{t}\right)+\alpha\left(x_{\text {best }, j}^{t}-x_{i, j}^{t}\right) i=1 \\ x_{\text {best }, j}^{t}+r_{6}(0,1)\left(x_{i-1, j}^{t}-x_{i, j}^{t}\right)+\alpha\left(x_{\text {best }, j}^{t}-x_{i, j}^{t}\right) i=2, \ldots, N\end{array}\right.$

$\alpha=2 e^{r_{7}(0,1)\left(\frac{\text { maxiter-iter+1 }}{\text { maxiter }}\right)} \cdot \sin \left(2 \pi r_{8}(0,1)\right)$

where $\alpha$ is the weight coefficient; maxiter and iter respectively represent the maximum number of iteration and the current iteration; and $r_{i}(0,1) i=5,6,7,8$ are different random numbers defined in the range between 0 and 1. The cyclone foraging phase of the algorithm plays an important role in performing two different main driving mechanisms of metaheuristic algorithms including exploitation and exploration. Utilizing the best plankton as a reference point in this foraging phase paves the way for intensifying the fertile regions around the current best solution and gives rise to exploitation capabilities of the algorithm. Cyclone foraging also provides a significant contribution to the exploration phase by enforcing the population individuals to move a random position in the search space which should be far away from their current position as well as the best prey position. This exploration mechanism promotes an extensive diversification on the global search space and enables the algorithm to guide the population individuals through the unvisited paths of the search domain. Mathematical model of the proposed exploration mechanism is given below

$x_{\text {rand }}^{t}=\operatorname{lower}_{j}+r_{9}(0,1)\left(\right.$ upper $_{j}-$ lower $\left._{j}\right)$

$x_{i, j}^{t+1}=\left\{\begin{array}{l}x_{\text {rand }}^{t}+r_{10}(0,1)\left(x_{\text {rand }}^{t}-x_{i, j}^{t}\right)+\alpha\left(x_{\text {rand }}^{t}-x_{i, j}^{t}\right) i=1 \\ x_{\text {rand }}^{t}+r_{11}(0,1)\left(x_{i-1}^{t}-x_{i, j}^{t}\right)+\alpha\left(x_{\text {rand }}^{t}-x_{i, j}^{t}\right) i=2, \ldots, N\end{array}\right.$

where $x_{\text {rand }}^{t}$ is the random position generated within the allowable bounds; lower and upper correspondingly stand for the lower and upper bounds of the search space.

\subsection{Somersault foraging}

This foraging scheme considers the best prey position as a pivot point and each manta-ray in the population probes around this point to flip back to a new position residing in the search domain. Solution update mechanism in this phase is strongly influenced the current best solution which guides the formed chain individuals through the following mathematical formulation $x_{i, j}^{t+1}=x_{i, j}^{t}+2.0 \cdot\left(r_{12}(0,1) \cdot x_{b e s t, j}^{t}-r_{13}(0,1) \cdot x_{i, j}^{t}\right)$

Similar to most of the metaheuristic algorithms, the MRFO algorithm is initialized with generating the population individuals within prescribed allowable boundaries. The position update mechanism relies on the manta ray individual in front of the current one and the considered pivot point. Shifting from exploration to exploitation phases is dependent upon the variations in the numerical value of the iter/maxiter ratio. The exploitation phase is enacted when iter/maxiter $<r(0,1)$, in which the current best position is considered to be a pivot point and plays a dominant role in perturbing the candidate solutions nearby the fertile and promising regions in the search domain. Algorithm switches to the exploration phase when iter/maxiter $>r(0,1)$, where randomly generated manta ray individuals within the allowable bounds take control and become the leading reference point. Furthermore, the algorithm can also switch between the chain foraging and cyclone foraging based on a randomly produced number. Then, summersault foraging takes action to update the current position of individuals through the current best solution. These three different foraging mechanisms are performed interchangeably to reach the global optimum solution of the optimization problem while the predefined termination is criterion is satisfied. Figure 1 provides the main steps of the Manta Ray Foraging Optimization algorithm.

\section{Chaotic maps}

Metaheuristic optimization methods benefit from the randomized parameters to reach the optimum solution of a problem. These parameters used in the algorithms are generally either drawn from uniformly distributed random numbers [7] or random walks produced by following the rules of Levy distribution [51]. Recently, chaotic numbers have been successfully embedded into metaheuristic optimizers to iteratively adjust the algorithm-specific parameters and improve the randomization effectiveness of the related algorithm. Chaos is a random-like deterministic method observed in a nonlinear and dynamical system [25]. It is a typical phenomenon that is highly sensitive to the starting conditions such that any small changes in initial values may lead to abrupt non-linear changes in the future states. A considerable amount of number sequences can be generated by only making a small modification on initial state values. Quasi-stochastic characteristics of chaotic numbers enable them to be replaced with any type of random numbers [33]. Ergodic features of the generated chaotic numbers ease their successful implementation in 


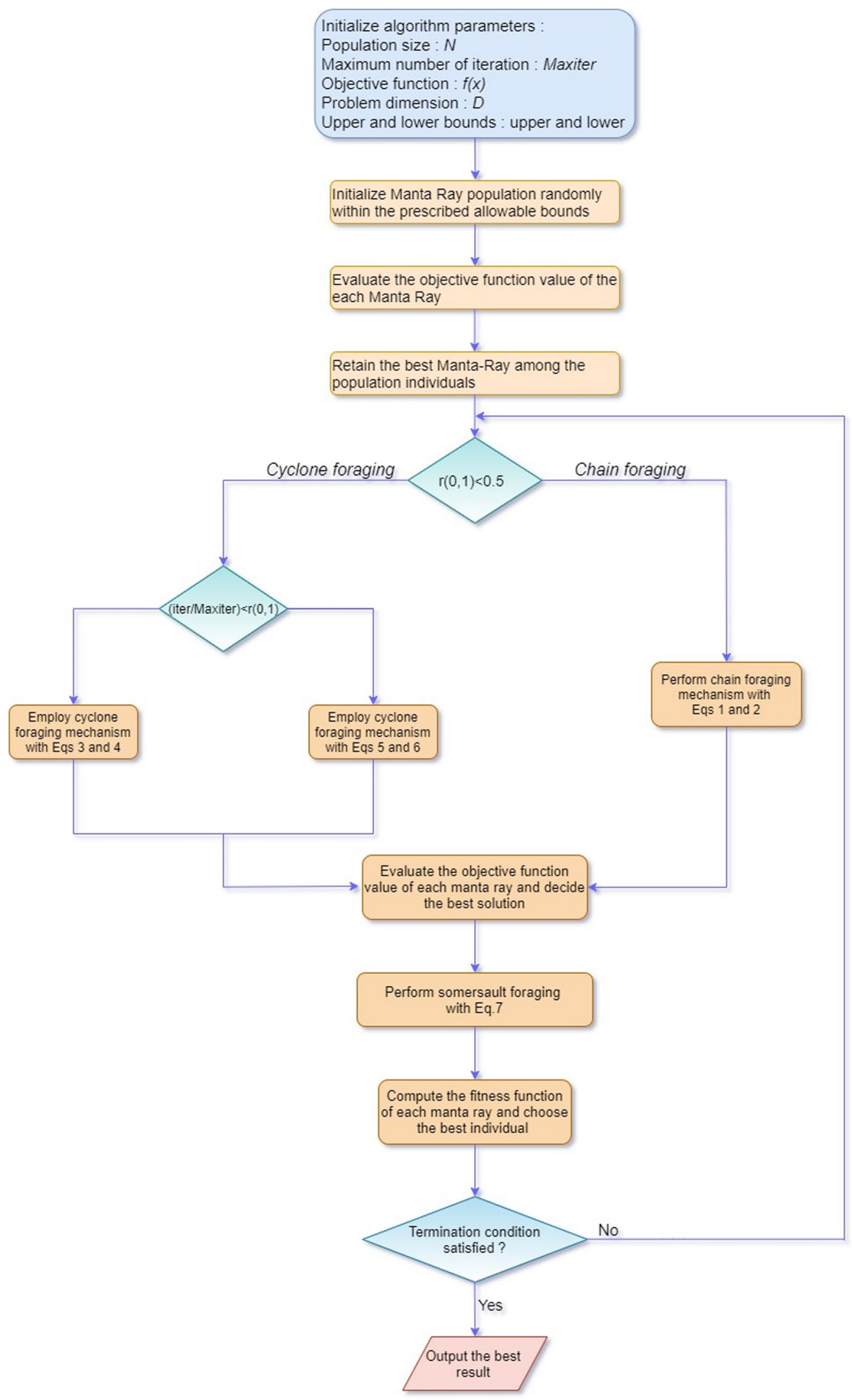

Fig. 1 Main algorithmic steps of Manta Ray Foraging Optimization Algorithm

\section{SN Applied Sciences}

A SPRINGER NATURE journal 
search conditions where all possible iterative future states should be non-repeatedly evaluated. This non-repetitive nature of the chaotic numbers not only enhances the convergence capabilities but also ameliorate the search efficiency of the base algorithm [1,29]. A combination of these characteristic properties of chaotic maps entails a significant improvement in the optimization performance of metaheuristic algorithms [52].

Some literature studies reported an enhanced solution diversity and quick avoidance of the local optimum points on the search space by utilizing the merits of the chaotic systems [53]. A typical chaotic system with $M$ dimension can be expressed by the following equation

$p_{t}^{m+1}=f\left(p_{t}^{m}\right)$

Very large and ergodic chaotic sequences can be generated in the mathematical form of $p_{t}^{m}, m=0,1,2, ., M$ by defining an initial state of $p_{t}^{0}$. Various types of chaotic maps are available in the literature. In this study, ten best performing chaotic sequences out of twenty-four noninvertible chaotic maps with different functional characteristics have been considered. Table 1 reports the mathematical formulations of the ten best performing chaotic maps where $x_{t}\left(y_{t}\right)$ denotes the $t^{\text {th }}$ number of member $x$ $(y)$ in the chaotic sequence and $t$ represents the current index of the chaotic variable in the sequence. To make a fair comparison between alternative maps, the initial value of all chaotic sequences is set to 0.7 as it was previously suggested in $[33,47]$. Figure 2 visualizes the sequential signals generated by the chaotic maps reported in Table 1 .

\subsection{Chaotic manta-ray foraging optimization algorithm}

This section will give a brief and concise instruction on the proposed chaotic Manta-Ray Foraging Optimization Algorithm. Despite a limited useful information is available in the literature approaches concerning with optimization performance of this algorithm, extensive numerical
Table 1 Mathematical formulations of the chaotic maps

\begin{tabular}{|c|c|c|c|}
\hline Name & No & Definition & Range \\
\hline Arnold [57] & CM01 & $\begin{array}{l}x_{t+1}=\bmod \left(\left(x_{t}+y_{t}\right), 1\right) \\
y_{t+1}=\bmod \left(\left(x_{t}+0.1 y_{t}\right), 1\right)\end{array}$ & $(-1,1)$ \\
\hline Chebychev [58] & CM02 & $x_{t+1}=\cos \left(t \cdot \cos ^{-1}\left(x_{t}\right)\right)$ & $(-1,1)$ \\
\hline Chirikov [59] & CM03 & $\begin{array}{l}x_{t+1}=\bmod \left(\left(x_{t}+10 \sin \left(y_{t}\right)\right), 2 \pi\right) \\
y_{t+1}=\bmod \left(\left(y_{t}+x_{t}\right), 2 \pi\right)\end{array}$ & $(-1,1)$ \\
\hline Gauss/Mouse [60] & CM04 & $x_{t+1}=\left\{\begin{array}{l}1, x_{t}=0 \\
\frac{1}{\bmod \left(x_{t}, 1\right)}, \text { otherwise }\end{array}\right.$ & $(0,1)$ \\
\hline Kent [61] & CM05 & $x_{t+1}=\left\{\begin{array}{l}\frac{x_{t}}{m}, 0<x_{t} \leq m \\
\frac{1-x_{t}}{1-m}, m<x_{t}<10<m<1\end{array}\right.$ & $(0,1)$ \\
\hline Logistic [62] & CM06 & $x_{t+1}=4.0 x_{t}\left(1-x_{t}\right)$ & $(0,1)$ \\
\hline Lozi [63] & CM07 & $\begin{array}{l}y_{t+1}=1-1.7\left|y_{t}\right|+x_{t} \\
x_{t+1}=0.5 y_{t}\end{array}$ & $(-1,1)$ \\
\hline Piecewise [54] & CM08 & $x_{t+1}=\left\{\begin{array}{l}\frac{x_{t}}{m}, 0 \leq x_{t}<m \\
\frac{x_{t}-m}{0.5-m}, m \leq x<0.5 \\
\frac{1-m-x_{t}}{0.5-m}, 0.5 \leq x_{t}<1-m \\
\frac{1-x_{t}}{m}, 1-m \leq x_{t}<1\end{array} m=0.3\right.$ & $(0.1)$ \\
\hline Standard [64] & CM09 & $\begin{array}{l}y_{t+1}=\bmod \left(0.6 y_{t}+8.8 \sin \left(x_{t}\right), 2 \pi\right) \\
x_{t+1}=\bmod \left(\left(x_{t}+y_{t+1}\right), 2 \pi\right)\end{array}$ & $(-1,1)$ \\
\hline Zaslavsky [65] & CM10 & $\begin{array}{l}x_{t+1}=\bmod \left(\left(400+x_{t}+12.6695 y_{t}+1\right), 1\right) \\
y_{t+1}=\cos \left(2 \pi x_{t}\right)+e^{-3} y_{t}\end{array}$ & $(-1,1)$ \\
\hline
\end{tabular}



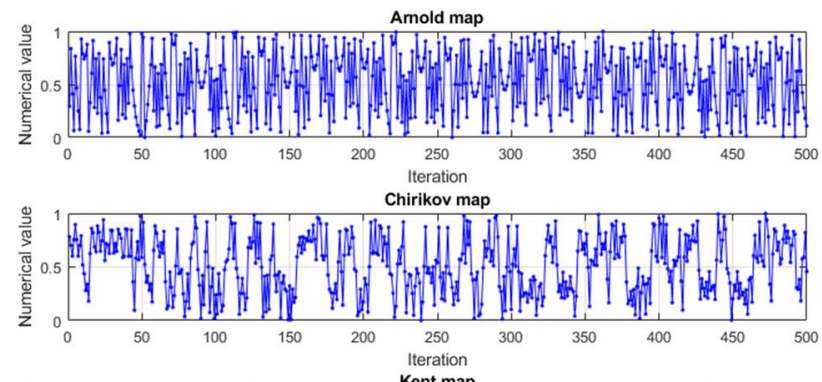

Kent map

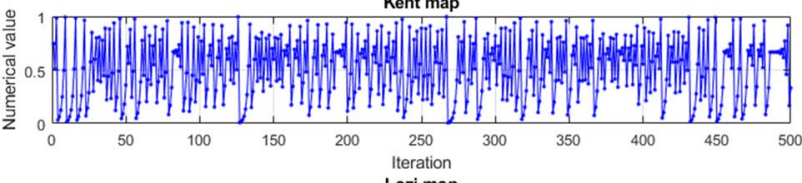

Lozi map
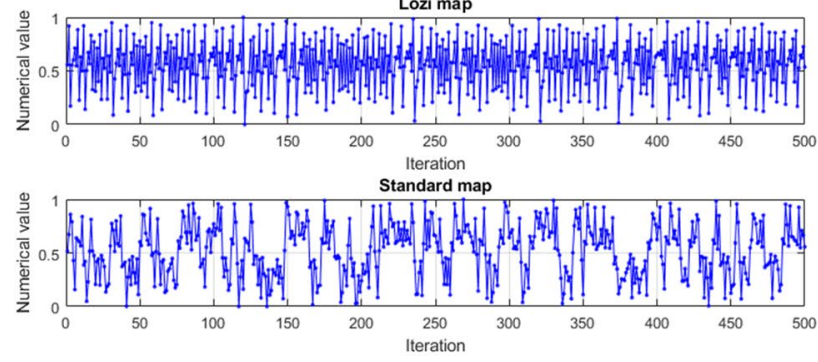

Fig. 2 Chaotic sequences produced by different chaotic maps

experiments made on the constrained and unconstrained optimization benchmark problems by the author himself reveal that premature convergence to the local optimum points due to the insufficient exploration and exploitation capabilities is obvious and this algorithmic deficiency should be resolved. MRFO has no tunable algorithm parameters which eliminate the exhaustive parameter tuning process for a specified type of optimization problem. It is one of the advantages of this metaheuristic algorithm. Most of the literature metaheuristic methods whose search equations are enhanced by the chaotic numbers either have two options for the possible replacement. One option is to replace the chaotic sequences with an algorithm-specific fixed tunable parameter, and the other one is to utilize chaotic sequences rather than uniformly distributed random numbers to improve the solution efficiency. It is also known that reducing the number of constants or iteratively adjusting parameters improve the exploration and exploitation performance [55]. As there are no fixed algorithm parameters in MRFO, uniformly generated random numbers are only the variables that posing a commanding influence on the position update mechanism and the balance between the exploration and exploitation phases. At the early phases of the iterations, it is important to diversify the search space as much as possible to explore the unreached regions over the solution domain which prevents premature convergence. As the iterative process proceeds, the algorithm shifts into
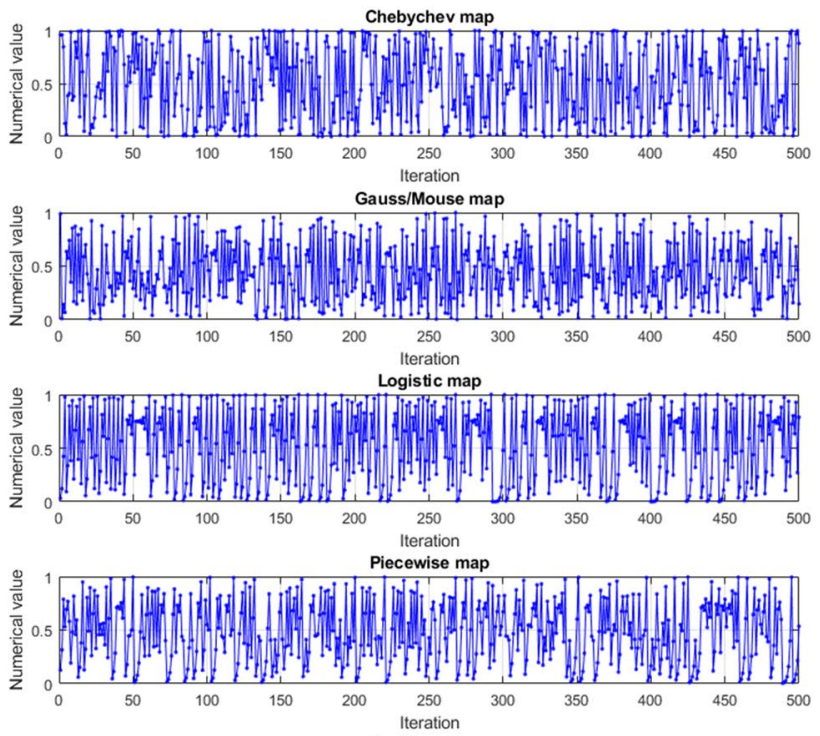

Zaslavsky map

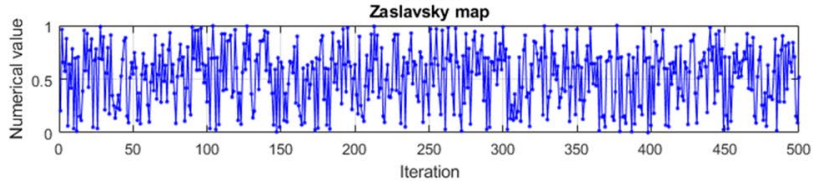

the exploitation phase which focuses on the promising regions obtained through the course of iterations. It is comprehended from the exhaustive literature survey over chaotic metaheuristic algorithms that chaotic sequences can maintain a balanced probing mechanism between these two phases and improve the overall search efficiency in terms of convergence speed and solution accuracy. Relying on the abovementioned discussions and deductions from the previous research studies, chaotic sequences generated from different chaotic maps have been replaced with the Gaussian random numbers defined in $[0,1]$. It is aimed to obtain different diversification and intensification patterns from the chaotic signals with various characteristics, which eventually entails a solution improvement. Table 2 gives the pseudo-code of the proposed chaotic Manta-Ray Foraging Optimization algorithm. The below given conclusive terms can provide meaningful insights on the efficacy of the proposed chaotic variants of MRFO.

- Generated chaotic signals enable the algorithm to focus on the exploration at first steps then gradually switch into the exploitation phase with an increasing number of iterations.

- In the case of quick convergence to regional best solutions during the optimization process, chaotic variables retained from different operators help the algorithm to circumvent these unfertile areas on the search space. 
Table 2 Pseudo-code of the proposed chaotic MRFO algorithm

$f(x)=$ Objective function

$N=$ Population size

$D=$ Problem dimension

Lower and upper $=$ Allowable lower and upper bounds

Maxiter $=$ Maximum number of iterations

Initialize the Manta ray population individuals within the prescribed boundaries

for $\mathrm{i}=1$ to $N x_{i}=x_{\text {lower }, i}+\mathrm{r}(0,1)\left(x_{\text {upper }, i}-x_{\text {lower }, i}\right)$

Calculate the fitness quality of each manta ray in the population for $\mathrm{i}=1$ to $N \quad f_{i}=f\left(x_{i}\right)$

Determine the current best solution $\left(x_{\text {best }}\right)$ by the plankton with the highest concentration

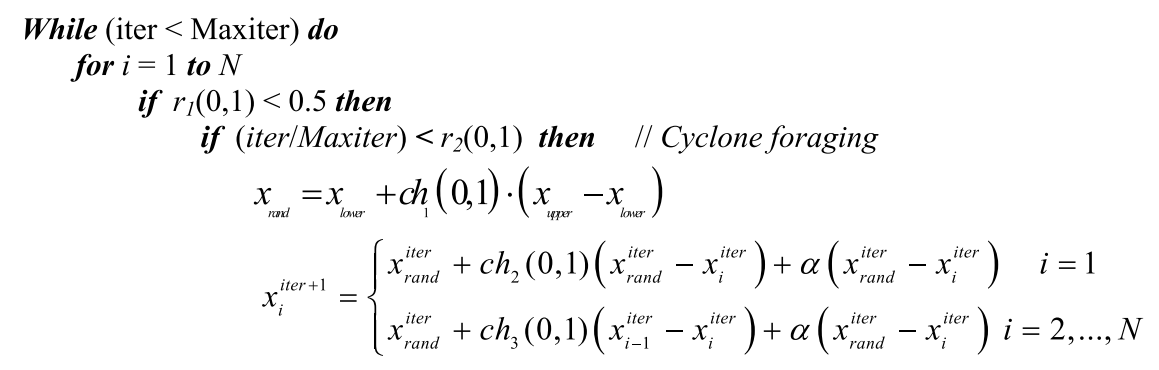

else

$$
x_{i}^{i t e r+1}=\left\{\begin{array}{l}
x_{\text {best }}^{\text {iter }}+c h_{4}(0,1)\left(x_{\text {best }}^{\text {iter }}-x_{i}^{\text {iter }}\right)+\alpha\left(x_{\text {best }}^{\text {iter }}-x_{i}^{\text {iter }}\right) \quad i=1 \\
x_{\text {best }}^{\text {iter }}+c h_{5}(0,1)\left(x_{i-1}^{i t e r}-x_{i}^{i t e r}\right)+\alpha\left(x_{\text {best }}^{\text {iter }}-x_{i}^{\text {iter }}\right) i=2, \ldots, N
\end{array}\right.
$$

end

else

$$
x_{i}^{i t e r+1}= \begin{cases}x_{i}^{i t e r}+c h_{6}(0,1)\left(x_{\text {best }}^{\text {iter }}-x_{i}^{i t e r}\right)+\beta\left(x_{\text {best }}^{\text {iter }}-x_{i}^{\text {iter }}\right) & i=1 \\ x_{i}^{i t e r}+c h_{7}(0,1)\left(x_{i-1}^{i t e r}-x_{i}^{i t e r}\right)+\beta\left(x_{\text {best }}^{\text {iter }}-x_{i}^{i t e r}\right) & i=2, \ldots, N\end{cases}
$$

end

// Employ boundary check

// Perform the position update mechanism

$$
\begin{gathered}
f_{i}^{i t e r+1}=f\left(x_{i}^{i t e r}\right) \\
\text { if } f_{i}^{i t e r+1}<f\left(x_{\text {best }}^{\text {iter }}\right) \text { then } \\
x_{\text {best }}^{\text {iter }+1}=x_{i}^{\text {iter }+1}
\end{gathered}
$$

end

// Replace the worse quality individuals with the better ones employing the greedy selection mechanism

//Somersault foraging

$$
x_{i}^{i t e r+1}=x_{i}^{\text {iter }}+2.0\left(c h_{8}(0,1) \cdot x_{\text {best }}^{\text {iter }}-c h_{9}(0,1) \cdot x_{i}^{\text {iter }}\right)
$$

// Employ boundary check

// Perform the position update mechanism

$f_{i}^{i t e r+1}=f\left(x_{i}^{i t e r+1}\right)$

if $f_{i}^{\text {iter }+1}<f\left(x_{\text {best }}^{\text {iter }}\right)$ then

$$
x_{\text {best }}^{\text {iter }+1}=x_{i}^{i t e r+1}
$$

end

// Replace the worse quality individuals with the better ones employing the greedy selection mechanism

// Update chaotic sequences $c_{1, . ., 9}$ for the upcoming iteration end

end 
- Unpredictable chaotic movements over the solution domain can also maintain swift shifts between the exploration and exploitation phases.

- Produced chaotic variables can help the algorithm to enhance the intensification process on the promising areas in the case of location a favorable solution neighborhood

\subsection{Experimental results for different chaotic variants}

This section appraises the proposed chaotic variants of the MRFO algorithm with regards to the solution accuracy and robustness through forty different unconstrained optimization benchmark problems. Thirtydimensional test problems used for benchmarking the search efficiencies of the chaotic algorithms are divided into two sub-categories: multimodal and unimodal test functions. The former is suitable for assessing the capabilities of the related algorithm for exploration whereas the latter is applicable for evaluating the exploitation performance [56]. Exact formulations of the multimodal and unimodal test functions are correspondingly given in Tables 3 and 4. A comprehensive statistical analysis is performed for each chaotic variant and optimization efficiency of each chaotic algorithm is compared in terms of mean and standard deviation results. A total number of 50 successive independent algorithm runs along with 2000 function evaluations have been performed due to the stochastic natures of the chaotic optimizers. Algorithms have been developed in Java environment and run on a personal computer with the Intel Core processor having $6.0 \mathrm{~GB}$ RAM at $2.0 \mathrm{GHz}$ CPU. Tables 5 and 6 report the statistical results for multimodal benchmark functions obtained by the chaotic algorithms along with recently developed metaheuristics of Barnacles Mating Optimizer (BMO) [11], Harris Hawks Optimization (HHO) [12], and Seagull Optimization Algorithm (SGULL) [13]. CM01 to CM10 respectively stand for Arnold (CM01) [57], Chebychev (CM02) [58], Chirikov (CM03) [59], Gauss/Mouse (CM04) [60], Kent (CM05) [61], Logistic (CM06) [62], Lozi (CM07) [63], Piecewise (CM08) [54], Standard (CM09) [64], and Zaslavsky (CM09) [65] chaotic operators. CM02 gives the best predictions while CM05, CM08, and CM10 are outperformed by MRFO for the $f_{1}$-Levy test function. Prediction performances of $\mathrm{BMO}$ and $\mathrm{HHO}$ algorithms are much better than those of the compared chaotic algorithms for this case. Predictive results obtained by $\mathrm{CMO} 3$ and $\mathrm{CM} 09$ are much better than the other methods whereas $\mathrm{CM} 05$ reaches the optimal solution for each independent run for $f_{2}$-Ackley function. CM05 outperforms the compared chaotic algorithms along with MRFO for $f_{3}$-Griewank, $f_{4}$-Rastrigin,
$f_{5}$-Zakharov, and $f_{6}$-Alpine test functions as it reaches the global optimum point for each run for these functions. It is also worth to mention the improvements in solution qualities by $\mathrm{CMO} 3$ and $\mathrm{CM} 09$ for $f_{6}$-Alpine. For these four test functions, BMO algorithm also obtains the global best answer of the mentioned test functions in each algorithm run and proves its efficiency for these benchmar problems. The global optimum solution is obtained neither of the algorithms runs for $f_{7^{-}}$Penalized 1 test function. It is also seen that domination of the MRFO algorithm in terms of solution robustness is evident in this case. Although estimated solutions are far away from global optimum points, CM09 and CM03 slightly surpass the chaotic algorithms for $f_{8}$-Quintic function. CM05 acquires the global optimum solution for each algorithm run for $f_{9}$-Csendes. Besides, satisfactory estimations are performed by $\mathrm{CM} 03$ and $\mathrm{CM} 09$ for this test function. It is also seen that estimation results of $\mathrm{BMO}$ and $\mathrm{HHO}$ are quite promising and outperform most of the chaotic variants in terms of solution accuracy. Contrary to the previous cases, predictive results obtained for $\mathrm{CMO} 05$ are inferior to those retained by the chaotic variants and literature optimizers for $f_{10}$-Schaffer. Again, CMO3 and CM09 outperform the other methods for this case. Among them, $\mathrm{HHO}$ provides the best predictions for this benchmark function with a mean deviation of $1.85 \mathrm{E}-03$ and a standard deviation of $9.79 \mathrm{E}-04$. The global optimum point of the $f_{11}$-Inverted cosine function is obtained by $\mathrm{CM} 03, \mathrm{CM} 05$, and $\mathrm{CM} 09$ for each algorithm run. The superiority of $\mathrm{CMO} 05$ in terms of solution persistency and accuracy is evident for $f_{12^{-}}$ Wavy function. BMO also performs better estimations than those of the compared variants for this case. CM05 reaches the global optimum point of $f_{13}$-Hyperellipsoid, $f_{14}$-Pathologic, and $f_{15}$-Salomon in each run and proves its superiority for these test functions. Optimization efficiencies of $\mathrm{CMO} 3$ and $\mathrm{CM} 09$ algorithms are quite satisfactory although they do not get even close to the optimum point of $f_{16}$-AckleyN4. $\mathrm{HHO}$ algorithm provides the most accurate predictions between the compared aoptimizers for this test function. All compared chaotic variants along with MRFO perform similar estimations for $f_{17}$-Exponential, however $\mathrm{CMO} 3$ and $\mathrm{CM} 09$ again slightly outperform them in solution robustness. $\mathrm{BMO}$ and $\mathrm{HHO}$ can not find a feasible solution even in a single algorithm run for this test function. MRFO produces better optimization results for $f_{18}$-Trid 6 function compared to the other chaotic methods. However, predictive results found by $\mathrm{HHO}$ algorithm in terms of mean and standard deviation values are much bettter than the compared methods for $f_{18}$-Trid 6 function. CM03, $\mathrm{HHO}, \mathrm{CM06}$, and CM09 perform well on $f_{19}$-Styblinski-Tang test function and retain better prediction accuracies in comparison 
Table 3 Mathematical formulations of the multimodal test functions

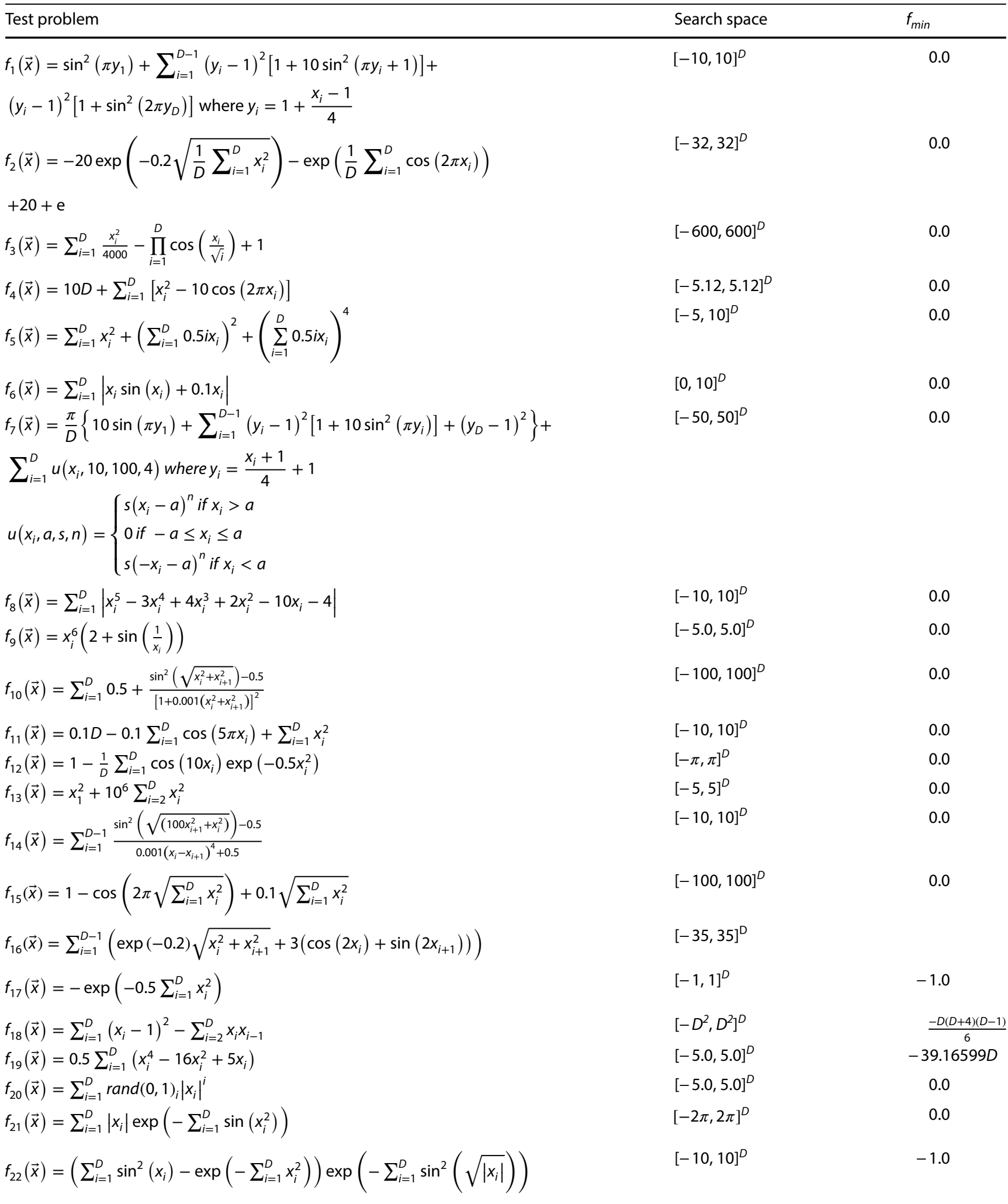

with the remaining chaotic algorithms. Considerable performance improvement is observed by CM05 for $f_{20}$-Yang $1, f_{21}$-Yang2, and $f_{22}$-Yang4 function as the same global optimum solution is found for each algorithm runs for these three test functions. 
Tables 7 and 8 report the optimum results for unimodal test functions. For $f_{23}$ - Sphere function, $\mathrm{CM} 05$ shows the best predictive performance followed by $\mathrm{CMO} 3, \mathrm{BMO}$, $\mathrm{CM} 09$, and $\mathrm{HHO}$ algorithms. Although most of the compared methods acquire similar results for $f_{24}$-Rosenbrock function, CM03 and CM09 are one step ahead of them regarding the solution robustness. Global optimum solutions of $f_{25}$-Brown, $f_{26}$-Streched sine wave, and $f_{27}$-Powell singular test functions are obtained for again $\mathrm{CM} 05$ chaotic algorithm. It is also worthwhile to mention the competitive optimization performance of $\mathrm{CMO} 3$ and $\mathrm{CM} 09$ algorithms for these test functions. BMO algorithm is not able to retain a feasible solution in any algorithm run for $f_{25}$-Brown. Very poor convergence behavior is shown by CM05 for $f_{28}$-Sum of different test function as opposed to the previous successful optimization performances. CM09 and CM03 again provide the best predictions for this benchmark problem. Promising predictions are also obtained by $\mathrm{BMO}$ and $\mathrm{HHO}$ for for $f_{28}$-Sum of different test function. $\mathrm{CM} 05$ again becomes the superior chaotic algorithm among the contestant variants for $f_{29^{-}}$Sum of squares, $f_{30}$ - Bent cigar, $f_{31}$-Discus, $f_{32}$-Different powers benchmark problems. $\mathrm{CM} 09$ and $\mathrm{CM} 03$ respectively hold the second and third seats concerning solution accuracy for these functions between the chaotic MRFO variants. Estimations of $\mathrm{BBO}$ and $\mathrm{HHO}$ are also promising and surpass most of the chaotic algorithms regarding mean and standard deviation rates for these test functions. CM09, $\mathrm{CMO3}$, and $\mathrm{CM} 05$ respectively give the best, the secondbest, and the third-best performance for $f_{33}$-Dixon-Price test function despite the optimum solution are obtained neither of the algorithm runs for each chaotic method. None of the chaotic algorithms along with MRFO obtain a feasible solution for each successive algorithm run for $f_{34}$-Yang 3. Only SGULL algorithm retains feasible during the course of algorithm runs. CM05 significantly outperforms the compared chaotic algorithms and literature optimizers in terms of solution accuracy and robustness for $f_{35}$-Schwefel 2.20, $f_{36}$-Schwefel 2.21, $f_{37}$-Schwefel 2.22, and $f_{38}$-Schwefel 2.23 test functions as it shows an intensive persistence on finding the global optimum solutions of these test functions for each algorithm run. Statistical results provided by $\mathrm{CM} 02$ for $f_{39}$-Schwefel 2.25 benchmark function are much better than those obtained by the other methods even though neither of them reaches the optimal solution in any algorithm run. CM03 and CM09 become the dominant chaotic algorithms for $f_{40}$-Dropwave function when the statistical results of the optimal solutions are evaluated. However, literature optimizers of $\mathrm{HHO}$ and $\mathrm{BMO}$ provide slightly more accurate predictions than the chaotic algorithms for $f_{40}$-Dropwave test function.

Figures 3, 4, 5, 6 visualize the convergence characteristics of the chaotic variants of the MRFO algorithm for multimodal test functions from $f_{7}$-Levy to $f_{22}$-Yang4. It can be understood from the figures that different convergence behaviors are observed for chaotic variants for multi-modal test functions. One distinctive behavior shown by the chaotic methods is performing short and gradual decreases until the end of iterations after the early stagnation period at the initial phases. The other convergence behavior is only observed for $\mathrm{CMO5}$ (Kent) whose characteristics involve sharp and abrupt declines generally at the final phases of the iterations. These sudden decreases in objective function values can be attributed to the irregular search dynamics that occurred by the quick and unpredictable shifts between exploration and exploitation phases. Similar convergence proclivities can also be observed for unimodal test functions as shown in Figs. 7, 8 , 9. Table 9 reports the Friedman test with a significance level of $5 \%(a=0.05)$ to detect the differences between multiple test runs. The p-results demonstrated in Table 9 show that $\mathrm{CM} 05$ outperforms other competing optimizers for most of the benchmark objective function optimizing tasks. Figures 10 and 11 compare the convergence characteristics of the best performing chaotic algorithm and metaheuristic methods of BMO, HHO, and SGULL for some of the test functions used for benchmarking capabilities of the contestant optimizers. Best performing chaotic algorithm outperforms the compared literature optimizers in terms of convergence speed for most of the cases and proves its superiority on solution efficiency and accuracy. Table 10 reports the statistical analysis results of the compared algorithms for the set of unconstrained test problems of the CEC 2017 competition. Optimal solutions found by the MRFO algorithm along with the three best performing chaotic algorithms of $\mathrm{CM03}, \mathrm{CM} 05$, and $\mathrm{CM} 09$ are compared with those obtained for EBOwithCMAR [66] and JSO [67] algorithms. These two algorithms respectively hold the first and second places for this competition and considered as pivot algorithms for benchmarking. Chaotic variants show similar optimization performances for $F 1$ and $F 2$ functions. Although the global optimal results are not obtained, solution quality is considerably enhanced by the chaotic methods compared to those found by the base MRFO algorithm for test functions from $F 3$ to F5. Three chaotic algorithms outperform the JSO [67] for the $F 6$ test function regarding the solution accuracy. No feasible solution is obtained for MRFO in neither of the algorithm runs for this case. A substantial improvement in convergence performance is observed for test functions from $F 7$ to $F 10$ by the chaotic algorithms however solution qualities are not as good as those obtained for CEC 2017 winners. $\mathrm{CM} 05$ and $\mathrm{CM} 03$ algorithms surpass the two best performing CEC 2017 contestants for the $F 11$ test function. Mean objective function values are greatly improved by incorporating the chaotic variables for the remaining test 
Table 4 Mathematical formulations of the unimodal benchmark functions

\begin{tabular}{|c|c|c|}
\hline Test problem & Search space & $f_{\min }$ \\
\hline$f_{23}(\vec{x})=\sum_{i=1}^{D} x_{i}^{2}$ & {$[-5.12,5.12]^{D}$} & 0.0 \\
\hline$f_{24}(\vec{x})=\sum_{i=1}^{D-1}\left[100\left(x_{i+1}-x_{i}^{2}\right)^{2}+\left(x_{i}-1\right)^{2}\right]$ & {$[-30,30]^{D}$} & 0.0 \\
\hline$f_{25}(\vec{x})=\sum_{i=1}^{D}\left(x_{i}^{2}\right)^{\left(x_{i+1}^{2}+1\right)}+\left(x_{i+1}^{2}\right)^{\left(x_{i}^{2}+1\right)}$ & {$[-1.0,4.0]^{D}$} & 0.0 \\
\hline$f_{26}(\vec{x})=\sum_{i=1}^{D-1}\left(x_{i+1}^{2}+x_{i}^{2}\right)^{0.25}\left[\sin ^{2}\left\{50\left(x_{i+1}^{2}+x_{i}^{2}\right)^{0.1}\right\}+0.1\right]$ & {$[-10,10]^{D}$} & 0.0 \\
\hline$f_{27}(\vec{x})=\sum_{i=1}^{D-2}\left(x_{i-1}+10 x_{i}\right)^{2}+5\left(x_{i+1}-x_{i+2}\right)^{2}+\left(x_{i}-2 x_{i+1}\right)^{4}+10\left(x_{i-1}-x_{i+2}\right)$ & )$^{4-4,5]^{D}}$ & 0.0 \\
\hline$f_{28}(\vec{x})=\sum_{i=1}^{D}\left|x_{i}\right|^{i+1}$ & {$[-1,1]^{D}$} & 0.0 \\
\hline$f_{29}(\vec{x})=\sum_{i=1}^{D} i x_{i}^{2}$ & {$[-10,10]^{D}$} & 0.0 \\
\hline$f_{30}(\vec{x})=\sum_{i=1}^{D} 10^{\frac{4(i-1)}{(D-1)}} x_{i}^{2}$ & {$[-5,5]^{D}$} & 0 \\
\hline$f_{31}(\vec{x})=10^{4} x_{1}^{2}+\sum_{i=2}^{D} x_{i}^{2}$ & {$[-5,5]^{D}$} & 0 \\
\hline$f_{32}(\vec{x})=\sum_{i=1}^{D}\left|x_{i}\right|^{i+2}$ & {$[-1,1]^{D}$} & 0.0 \\
\hline$f_{33}(\vec{x})=\left(x_{1}-1\right)^{2}+\sum_{i=2}^{D} i\left(2 x_{i}^{2}-x_{i-1}\right)^{2}$ & {$[-10,10]^{D}$} & 0.0 \\
\hline$f_{34}(\vec{x})=\exp \left(-\sum_{i=1}^{D}\left(x_{i} / 15\right)^{10}\right)-2 \exp \left(-\sum_{i=1}^{D} x_{i}^{2}\right) \prod_{i=1}^{D} \cos ^{2}\left(x_{i}\right)$ & {$[-2 \pi, 2 \pi]^{D}$} & -1.0 \\
\hline$f_{35}(\vec{x})=\sum_{i=1}^{D}\left|x_{i}\right|$ & {$[-100,100]^{D}$} & 0.0 \\
\hline$f_{36}(\vec{x})=\max _{i=1, \ldots, D}\left|x_{i}\right|$ & {$[-100,100]^{D}$} & 0.0 \\
\hline$f_{37}(\vec{x})=\sum_{i=1}^{D}\left|x_{i}\right|+\prod_{i=1}^{D}\left|x_{i}\right|$ & {$[-100,100]^{D}$} & 0.0 \\
\hline$f_{38}(\vec{x})=\sum_{i=1}^{D} x_{i}^{10}$ & {$[-10,10]^{D}$} & 0.0 \\
\hline$f_{39}(\vec{x})=\sum_{i=1}^{D}\left(x_{i}-1\right)^{2}+\left(x_{1}-x_{i}^{2}\right)^{2}$ & {$[0,10]^{D}$} & 0.0 \\
\hline$f_{40}(\vec{x})=-\frac{1+\cos \left(12 \sqrt{\sum_{i=1}^{D} x_{i}^{2}}\right)}{0.5\left(\sum_{i=1}^{D} x_{i}^{2}\right)+2.0}$ & {$[-5.12,5.12]^{D}$} & -1.0 \\
\hline
\end{tabular}

functions and competitive results are obtained as compared to those acquired by EBOwithCMAR [66] and JSO [67] algorithms. Based on the numerical outcomes of the experimental studies performed in this section, it is fair to conclude that convergence speed and solution accuracy are both greatly improved by incorporating chaotic random numbers in the base optimization algorithm.

\section{Thermal design and optimization of air fin coolers}

\subsection{Preliminary concepts}

Evolving interest on-air fin coolers between the heat exchanger research community is raised from the threatening concerns on increasing water costs along with water shortages, which have reduced the utilization of water-cooled heat exchangers among the industrial applications. When the applicable heat regeneration is not possible due to the structural limitations within the thermal plant, heat rejection to the surrounding environment occurs which is widely observable in refineries and chemical plants using Air Cooled Heat Exchangers (ACHEs). These types of heat exchangers are preferable in the application regions where special water treatment is required to reduce the fouling inside the tubes. ACHEs are composed of tube bundles over which cooling air is blown through one or more fans to remove the excess heat rejected from the tubes. Below described two different types of ACHES are widely applied in industrial applications. These are forced draft air coolers and induced draft air coolers. Relying on their economic advantages and versatile maintenance features, the forced draft ACHE is an advantageous, practical and the most common air cooler type where axial fans are mounted below the tube bundle to circulate the 
Table 5 Statistical results for multimodal test functions from $f_{1}$-Levy to $f_{16}$-AckleyN4

\begin{tabular}{|c|c|c|c|c|}
\hline & $\begin{array}{l}f_{1} \text {-Levy } \\
\text { Mean } \pm \text { Std.dev }\end{array}$ & $\begin{array}{l}f_{2} \text {-Ackley } \\
\text { Mean } \pm \text { Std.dev }\end{array}$ & $\begin{array}{l}f_{3}-\text { Griewank } \\
\text { Mean } \pm \text { Std.dev }\end{array}$ & $\begin{array}{l}f_{4} \text {-Rastrigin } \\
\text { Mean } \pm \text { Std.dev }\end{array}$ \\
\hline MRFO & $1.28 \mathrm{E}+00 \pm 5.38 \mathrm{E} 01$ & $2.83 \mathrm{E}-04 \pm 2.31 \mathrm{E}-04$ & $2.27 \mathrm{E}-02 \pm 7.76 \mathrm{E}-02$ & $7.08 \mathrm{E}+01 \pm 7.27 \mathrm{E}+01$ \\
\hline CM01 & $1.09 \mathrm{E}+00 \pm 3.86 \mathrm{E}-01$ & $2.05 \mathrm{E}-04 \pm 1.71 \mathrm{E}-04$ & $1.54 \mathrm{E}-02 \pm 8.36 \mathrm{E}-02$ & $3.89 \mathrm{E}+01 \pm 4.87 \mathrm{E}+01$ \\
\hline CMO2 & $2.49 \mathrm{E}-02 \pm 1.29 \mathrm{E}-01$ & $4.12 \mathrm{E}-02 \pm 2.68 \mathrm{E}-02$ & $8.12 \mathrm{E}-04 \pm 1.10 \mathrm{E}-03$ & $2.86 \mathrm{E}+01 \pm 8.76 \mathrm{E}-01$ \\
\hline CM03 & $9.26 \mathrm{E}-01 \pm 1.54 \mathrm{E}-01$ & $4.21 \mathrm{E}-10 \pm 4.22 \mathrm{E}-10$ & $4.81 \mathrm{E}-04 \pm 3.05 \mathrm{E}-03$ & $3.12 \mathrm{E}-02 \pm 2.16 \mathrm{E}-01$ \\
\hline CM04 & $1.02 \mathrm{E}+00 \pm 2.16 \mathrm{E}-01$ & $3.69 \mathrm{E}-05 \pm 3.90 \mathrm{E}-05$ & $1.41 \mathrm{E}-02 \pm 4.13 \mathrm{E}-02$ & $3.32 \mathrm{E}+01 \pm 5.09 \mathrm{E}+01$ \\
\hline M05 & $1.94 \mathrm{E}+00 \pm 4.29 \mathrm{E}-01$ & $4.44 \mathrm{E}-16 \pm 0.00 \mathrm{E}+00$ & $0.00 \mathrm{E}+00 \pm 0.00 \mathrm{E}+00$ & $0.00 \mathrm{E}+00 \pm 0.00 \mathrm{E}+00$ \\
\hline CM06 & $1.03 \mathrm{E}+00 \pm 1.79 \mathrm{E}-01$ & $9.32 \mathrm{E}-04 \pm 8.78 \mathrm{E}-04$ & $9.74 \mathrm{E}-03 \pm 4.18 \mathrm{E}-02$ & $2.69 \mathrm{E}+01 \pm 3.58 \mathrm{E}+01$ \\
\hline CM07 & $1.10 \mathrm{E}+00 \pm 2.44 \mathrm{E}-01$ & $2.73 \mathrm{E}-05 \pm 3.74 \mathrm{E}-05$ & $1.09 \mathrm{E}-02 \pm 3.20 \mathrm{E}-02$ & $3.02 \mathrm{E}+01 \pm 4.07 \mathrm{E}+01$ \\
\hline CM08 & $1.37 \mathrm{E}+00 \pm 3.51 \mathrm{E}-01$ & $3.37 \mathrm{E}-04 \pm 3.92 \mathrm{E}-04$ & $2.33 \mathrm{E}-02 \pm 6.49 \mathrm{E}-02$ & $6.70 \mathrm{E}+01 \pm 6.51 \mathrm{E}+01$ \\
\hline CM09 & $1.00 \mathrm{E}+00 \pm 2.18 \mathrm{E}-01$ & $3.26 \mathrm{E}-11 \pm 5.34 \mathrm{E}-11$ & $7.36 \mathrm{E}-03 \pm 2.96 \mathrm{E}-02$ & $1.21 \mathrm{E}-01 \pm 8.90 \mathrm{E}-01$ \\
\hline CM10 & $1.34 \mathrm{E}+00 \pm 3.93 \mathrm{E}-01$ & $2.06 \mathrm{E}-04 \pm 1.91 \mathrm{E}-04$ & $8.24 \mathrm{E}-03 \pm 2.56 \mathrm{E}-02$ & $5.05 \mathrm{E}+01 \pm 6.43 \mathrm{E}+01$ \\
\hline BMO & $4.57 \mathrm{E}-02 \pm 1.20 \mathrm{E}-02$ & $3.48 \mathrm{E}-10 \pm 1.69 \mathrm{E}-09$ & $0.00 \mathrm{E}+00 \pm 0.00 \mathrm{E}+00$ & $0.00 \mathrm{E}+00 \pm 0.00 \mathrm{E}+00$ \\
\hline $\mathrm{HHO}$ & $7.10 \mathrm{E}-01 \pm 2.38 \mathrm{E}-01$ & $4.49 \mathrm{E}-09 \pm 1.09 \mathrm{E}-09$ & $0.00 \mathrm{E}+00 \pm 0.00 \mathrm{E}+00$ & $3.78 \mathrm{E}-15 \pm 1.93 \mathrm{E}-14$ \\
\hline SGULL & $\begin{array}{l}4.60 \mathrm{E}+02 \pm 2.59 \mathrm{E}+03 \\
f_{5}-\text { Zakharov } \\
\text { Mean } \pm \text { Std.dev }\end{array}$ & $\begin{array}{l}3.99 \mathrm{E}-01 \pm 2.89 \mathrm{E}+00 \\
f_{6} \text {-Alpine } \\
\text { Mean } \pm \text { Std.dev }\end{array}$ & $\begin{array}{l}2.05 \mathrm{E}-02 \pm 1.90 \mathrm{E}-01 \\
f_{7}-\text { Penalized } 1 \\
\text { Mean } \pm \text { Std.dev }\end{array}$ & $\begin{array}{l}4.75 \mathrm{E}+02 \pm 4.15 \mathrm{E}+03 \\
f_{8}-\text { Quintic } \\
\text { Mean } \pm \text { Std.dev }\end{array}$ \\
\hline MRFO & $2.44 \mathrm{E}+02 \pm 1.89 \mathrm{E}+02$ & $7.09 \mathrm{E}-01 \pm 1.61 \mathrm{E}-01$ & $4.78 \mathrm{E}-03 \pm 3.23 \mathrm{E}-02$ & $5.58 \mathrm{E}+01 \pm 1.58 \mathrm{E}+01$ \\
\hline CM01 & $1.81 E+03 \pm 2.35 E+03$ & $8.05 \mathrm{E}-01 \pm 4.62 \mathrm{E}+00$ & $8.32 \mathrm{E}-02 \pm 1.22 \mathrm{E}-01$ & $4.83 \mathrm{E}+01 \pm 1.71 \mathrm{E}+01$ \\
\hline CMO2 & $1.23 \mathrm{E}+02 \pm 3.20 \mathrm{E}+00$ & $5.01 \mathrm{E}-02 \pm 2.59 \mathrm{E}-02$ & $1.12 \mathrm{E}-01 \pm 1.89 \mathrm{E}-01$ & $2.56 \mathrm{E}+01 \pm 2.05 \mathrm{E}+01$ \\
\hline CM03 & $6.78 \mathrm{E}+02 \pm 1.17 \mathrm{E}+03$ & $4.25 \mathrm{E}-10 \pm 1.83 \mathrm{E}-09$ & $1.92 \mathrm{E}-02 \pm 1.22 \mathrm{E}-02$ & $2.13 \mathrm{E}+01 \pm 5.57 \mathrm{E}+00$ \\
\hline CM04 & $1.44 \mathrm{E}+03 \pm 1.46 \mathrm{E}+03$ & $2.64 \mathrm{E}-01 \pm 1.96 \mathrm{E}+00$ & $2.80 \mathrm{E}-02 \pm 2.21 \mathrm{E}-02$ & $4.15 \mathrm{E}+01 \pm 1.54 \mathrm{E}+01$ \\
\hline CM05 & $0.00 \mathrm{E}+00 \pm 0.00 \mathrm{E}+00$ & $0.00 \mathrm{E}+00 \pm 0.0$ & $1.98 \mathrm{E}-01 \pm 1.23 \mathrm{E}$ & +01 \\
\hline CM06 & $7.07 \mathrm{E}+02 \pm 5.60 \mathrm{E}+02$ & $1.13 \mathrm{E}-02 \pm 3.36$ & $2.04 \mathrm{E}-02 \pm 1.24 \mathrm{E}-02$ & $3.64 \mathrm{E}+01 \pm 1.24 \mathrm{E}+01$ \\
\hline CM07 & $8.05 \mathrm{E}+02 \pm 1.12 \mathrm{E}+03$ & $2.87 \mathrm{E}-01 \pm 1.43 \mathrm{E}+00$ & $3.80 \mathrm{E}-02 \pm 9.55 \mathrm{E}-02$ & $3.46 \mathrm{E}+01 \pm 1.22 \mathrm{E}+01$ \\
\hline CM08 & $1.34 \mathrm{E}+03 \pm 1.42 \mathrm{E}+03$ & $9.39 \mathrm{E}-01 \pm 6.03 \mathrm{E}+00$ & $1.35 \mathrm{E}-01 \pm 3.58 \mathrm{E}-01$ & $5.57 \mathrm{E}+01 \pm 1.83 \mathrm{E}+01$ \\
\hline CM09 & $3.40 \mathrm{E}+02 \pm 7.40 \mathrm{E}+02$ & $1.75 \mathrm{E}-11 \pm 5.71 \mathrm{E}-11$ & $1.79 \mathrm{E}-02 \pm 8.28 \mathrm{E}-03$ & $2.04 \mathrm{E}+01 \pm 6.52 \mathrm{E}+00$ \\
\hline CM10 & $1.32 \mathrm{E}+03 \pm 1.28 \mathrm{E}+03$ & $1.02 \mathrm{E}-01 \pm 3.28 \mathrm{E}-01$ & $5.04 \mathrm{E}-02 \pm 4.85 \mathrm{E}-02$ & $5.35 \mathrm{E}+01 \pm 1.79 \mathrm{E}+01$ \\
\hline BMO & $1.83 \mathrm{E}+03 \pm 5.72 \mathrm{E}+03$ & $8.59 \mathrm{E}-11 \pm 3.39 \mathrm{E}-10$ & $2.93 \mathrm{E}-01 \pm 1.79 \mathrm{E}-01$ & $5.28 \mathrm{E}+01 \pm 8.73 \mathrm{E}+00$ \\
\hline $\mathrm{HHO}$ & $2.95 E+04 \pm 1.93 E+04$ & $9.72 \mathrm{E}-10 \pm 1.77 \mathrm{E}-09$ & $2.97 \mathrm{E}-02 \pm 1.61 \mathrm{E}-02$ & $2.20 \mathrm{E}+01 \pm 4.37 \mathrm{E}+00$ \\
\hline SGULL & $\begin{array}{l}1.19 \mathrm{E}+06 \pm 1.58 \mathrm{E}+07 \\
f_{9}-\text { Csendes } \\
\text { Mean } \pm \text { Std.dev }\end{array}$ & $\begin{array}{l}7.22 \mathrm{E}-04 \pm 1.93 \mathrm{E}-03 \\
f_{10} \text {-Schaffer } \\
\text { Mean } \pm \text { Std.dev }\end{array}$ & $\begin{array}{l}1.57 \mathrm{E}+07 \pm 1.36 \mathrm{E}+08 \\
f_{11} \text {-Inverted cosine } \\
\text { Mean } \pm \text { Std.dev }\end{array}$ & $\begin{array}{l}1.21 \mathrm{E}+07 \pm 9.85 \mathrm{E}+07 \\
f_{12}-\text { Wavy } \\
\text { Mean } \pm \text { Std.dev }\end{array}$ \\
\hline MRFO & $4.25 \mathrm{E}-01 \pm 1.76 \mathrm{E}+00$ & $3.05 \mathrm{E}-02 \pm 1.41 \mathrm{E}-02$ & $6.37 \mathrm{E}-06 \pm 1.59 \mathrm{E}-05$ & $3.12 \mathrm{E}-01 \pm 1.63 \mathrm{E}-01$ \\
\hline CM01 & $2.27 \mathrm{E}-02 \pm 1.44 \mathrm{E}-01$ & $3.02 \mathrm{E}-02 \pm 1.71 \mathrm{E}-02$ & $1.56 \mathrm{E}-06 \pm 2.31 \mathrm{E}-06$ & $3.21 \mathrm{E}-01 \pm 1.93 \mathrm{E}-01$ \\
\hline CMO2 & $7.52 \mathrm{E}-08 \pm 4.56 \mathrm{E}-07$ & $5.26 \mathrm{E}-03 \pm 1.38 \mathrm{E}-02$ & $4.84 \mathrm{E}-02 \pm 6.77 \mathrm{E}-02$ & $2.77 \mathrm{E}-01 \pm 2.62 \mathrm{E}-01$ \\
\hline CM03 & $5.99 \mathrm{E}-33 \pm 2.50 \mathrm{E}-32$ & $3.81 \mathrm{E}-03 \pm 2.09 \mathrm{E}-03$ & $0.00 \mathrm{E}+00 \pm 0.00 \mathrm{E}+00$ & $9.91 \mathrm{E}-02 \pm 1.48 \mathrm{E}-01$ \\
\hline CM04 & $2.71 \mathrm{E}-05 \pm 1.16 \mathrm{E}-04$ & $1.94 \mathrm{E}-02 \pm 1.21 \mathrm{E}-02$ & $3.99 \mathrm{E}-08 \pm 8.25 \mathrm{E}-08$ & $3.23 \mathrm{E}-01 \pm 2.01 \mathrm{E}-01$ \\
\hline CM05 & $0.00 \mathrm{E}+00 \pm 0.00 \mathrm{E}+00$ & $1.71 \mathrm{E}-01 \pm 1.02 \mathrm{E}-01$ & $0.00 \mathrm{E}+00 \pm 0.00 \mathrm{E}+00$ & $0.00 \mathrm{E}+00 \pm 0.00 \mathrm{E}+00$ \\
\hline CM06 & $8.19 \mathrm{E}-07 \pm 2.94 \mathrm{E}-06$ & $1.25 \mathrm{E}-02 \pm 5.86 \mathrm{E}-03$ & $1.66 \mathrm{E}-05 \pm 3.27 \mathrm{E}-05$ & $2.52 \mathrm{E}-01 \pm 1.12 \mathrm{E}-01$ \\
\hline CM07 & $2.98 \mathrm{E}-08 \pm 1.53 \mathrm{E}-07$ & $1.39 \mathrm{E}-02 \pm 7.81 \mathrm{E}-03$ & $9.22 \mathrm{E}-09 \pm 2.22 \mathrm{E}-08$ & $2.52 \mathrm{E}-01 \pm 2.04 \mathrm{E}-01$ \\
\hline CM08 & $3.00 \mathrm{E}-01 \pm 2.41 \mathrm{E}+00$ & $3.01 \mathrm{E}-02 \pm 1.75 \mathrm{E}-02$ & $4.18 \mathrm{E}-06 \pm 1.56 \mathrm{E}-05$ & $3.45 \mathrm{E}-01 \pm 1.98 \mathrm{E}-01$ \\
\hline CM09 & $8.12 \mathrm{E}-40 \pm 3.46 \mathrm{E}-39$ & $2.75 \mathrm{E}-03 \pm 1.16 \mathrm{E}-03$ & $0.00 \mathrm{E}+00 \pm 0.00 \mathrm{E}+00$ & $6.81 \mathrm{E}-02 \pm 1.44 \mathrm{E}-01$ \\
\hline CM10 & $3.73 \mathrm{E}-02 \pm 1.88 \mathrm{E}-01$ & $2.84 \mathrm{E}-02 \pm 1.60 \mathrm{E}-02$ & $2.41 \mathrm{E}-06 \pm 7.44 \mathrm{E}-06$ & $3.17 \mathrm{E}-01 \pm 1.93 \mathrm{E}-01$ \\
\hline BMO & $1.81 \mathrm{E}-46 \pm 1.46 \mathrm{E}-45$ & $2.05 \mathrm{E}-03 \pm 1.33 \mathrm{E}-03$ & $5.55 \mathrm{E}-17 \pm 2.54 \mathrm{E}-16$ & $8.55 \mathrm{E}-15 \pm 6.72 \mathrm{E}-14$ \\
\hline $\mathrm{HHO}$ & $3.90 \mathrm{E}-47 \pm 2.47 \mathrm{E}-46$ & $1.95 \mathrm{E}-03 \pm 9.79 \mathrm{E}-04$ & $8.95 \mathrm{E}-16 \pm 3.45 \mathrm{E}-15$ & $8.18 \mathrm{E}-04 \pm 6.22 \mathrm{E}-03$ \\
\hline SGULL & $\begin{array}{l}2.82 \mathrm{E}-12 \pm 2.74 \mathrm{E}-11 \\
f_{13^{-}} \text {Hyperellipsoid } \\
\text { Mean } \pm \text { Std.dev }\end{array}$ & $\begin{array}{l}1.21 \mathrm{E}-02 \pm 4.46 \mathrm{E}-02 \\
f_{14^{-}} \text {Pathologic } \\
\text { Mean } \pm \text { Std.dev }\end{array}$ & $\begin{array}{l}4.56 \mathrm{E}+02 \pm 2.96 \mathrm{E}+03 \\
f_{15}-\text { Salomon } \\
\text { Mean } \pm \text { Std.dev }\end{array}$ & $\begin{array}{l}1.94 \mathrm{E}-01 \pm 3.53 \mathrm{E}-01 \\
f_{16} \text { - AckleyN4 } \\
\text { Mean } \pm \text { Std.dev }\end{array}$ \\
\hline MRFO & $8.07 \mathrm{E}-05 \pm 1.83 \mathrm{E}-04$ & $5.39 \mathrm{E}+00 \pm 3.14 \mathrm{E}-01$ & $3.51 \mathrm{E}-01 \pm 1.03 \mathrm{E}-01$ & $-3.65 E+01 \pm 1.58 E+01$ \\
\hline CM01 & $2.13 \mathrm{E}-05 \pm 7.21 \mathrm{E}-05$ & $5.35 \mathrm{E}+00 \pm 2.96 \mathrm{E}-01$ & $2.93 \mathrm{E}-01 \pm 8.90 \mathrm{E}-02$ & $-2.97 \mathrm{E}+01 \pm 1.60 \mathrm{E}+01$ \\
\hline
\end{tabular}


Table 5 (continued)

\begin{tabular}{lllll}
\hline & $\begin{array}{l}f_{1} \text {-Levy } \\
\text { Mean } \pm \text { Std.dev }\end{array}$ & $\begin{array}{l}f_{2} \text {-Ackley } \\
\text { Mean } \pm \text { Std.dev }\end{array}$ & $\begin{array}{l}f_{3} \text {-Griewank } \\
\text { Mean } \pm \text { Std.dev }\end{array}$ & $\begin{array}{l}f_{4} \text {-Rastrigin } \\
\text { Mean } \pm \text { Std.dev }\end{array}$ \\
\hline CM02 & $1.78 \mathrm{E}+00 \pm 4.65 \mathrm{E}+00$ & $4.17 \mathrm{E}+00 \pm 1.91 \mathrm{E}+00$ & $1.82 \mathrm{E}-01 \pm 9.28 \mathrm{E}-02$ & $-1.18 \mathrm{E}+01 \pm 3.88 \mathrm{E}+01$ \\
CM03 & $9.53 \mathrm{E}-17 \pm 2.72 \mathrm{E}-16$ & $5.37 \mathrm{E}+00 \pm 3.21 \mathrm{E}-01$ & $1.02 \mathrm{E}-01 \pm 1.58 \mathrm{E}-02$ & $-5.86 \mathrm{E}+01 \pm 9.01 \mathrm{E}+00$ \\
CM04 & $3.70 \mathrm{E}-07 \pm 7.64 \mathrm{E}-07$ & $5.38 \mathrm{E}+00 \pm 2.75 \mathrm{E}-01$ & $2.36 \mathrm{E}-01 \pm 6.57 \mathrm{E}-02$ & $-5.24 \mathrm{E}+01 \pm 1.23 \mathrm{E}+01$ \\
CM05 & $0.00 \mathrm{E}+00 \pm 0.00 \mathrm{E}+00$ & $0.00 \mathrm{E}+00 \pm 0.00 \mathrm{E}+00$ & $0.00 \mathrm{E}+00 \pm 0.00 \mathrm{E}+00$ & $-1.78 \mathrm{E}+01 \pm 1.17 \mathrm{E}+01$ \\
CM06 & $1.46 \mathrm{E}-04 \pm 2.44 \mathrm{E}-04$ & $5.20 \mathrm{E}+00 \pm 2.95 \mathrm{E}-01$ & $2.17 \mathrm{E}-01 \pm 6.43 \mathrm{E}-02$ & $-5.42 \mathrm{E}+01 \pm 8.39 \mathrm{E}+00$ \\
CM07 & $7.95 \mathrm{E}-08 \pm 1.58 \mathrm{E}-07$ & $5.36 \mathrm{E}+00 \pm 3.46 \mathrm{E}-01$ & $2.24 \mathrm{E}-02 \pm 6.05 \mathrm{E}-02$ & $-5.30 \mathrm{E}+01 \pm 1.35 \mathrm{E}+01$ \\
CM08 & $3.75 \mathrm{E}-05 \pm 7.96 \mathrm{E}-05$ & $5.40 \mathrm{E}+00 \pm 3.82 \mathrm{E}-01$ & $3.12 \mathrm{E}-01 \pm 9.51 \mathrm{E}-02$ & $-3.54 \mathrm{E}+01 \pm 1.71 \mathrm{E}+01$ \\
CM09 & $4.58 \mathrm{E}-19 \pm 1.09 \mathrm{E}-19$ & $5.17 \mathrm{E}+00 \pm 3.67 \mathrm{E}-01$ & $1.02 \mathrm{E}-01 \pm 1.49 \mathrm{E}-02$ & $-6.37 \mathrm{E}+01 \pm 7.23 \mathrm{E}+00$ \\
CM10 & $2.57 \mathrm{E}-05 \pm 5.24 \mathrm{E}-05$ & $5.46 \mathrm{E}+00 \pm 3.36 \mathrm{E}-01$ & $3.07 \mathrm{E}-01 \pm 1.05 \mathrm{E}-01$ & $-3.84 \mathrm{E}+01 \pm 1.68 \mathrm{E}+01$ \\
BMO & $1.32 \mathrm{E}-15 \pm 7.07 \mathrm{E}-15$ & $5.63 \mathrm{E}+00 \pm 4.32 \mathrm{E}-01$ & $1.01 \mathrm{E}-01 \pm 6.27 \mathrm{E}-03$ & $-1.47 \mathrm{E}+01 \pm 1.73 \mathrm{E}+01$ \\
HHO & $2.13 \mathrm{E}-14 \pm 7.84 \mathrm{E}-14$ & $4.88 \mathrm{E}+00 \pm 6.29 \mathrm{E}-01$ & $9.98 \mathrm{E}-02 \pm 1.72 \mathrm{E}-16$ & $-6.58 \mathrm{E}+01 \pm 1.02 \mathrm{E}+01$ \\
SGULL & $2.62 \mathrm{E}+04 \pm 2.68 \mathrm{E}+05$ & $3.39 \mathrm{E}+02 \pm 1.92 \mathrm{E}+00$ & $7.37 \mathrm{E}-01 \pm 4.29 \mathrm{E}+00$ & $1.09 \mathrm{E}+02 \pm 3.26 \mathrm{E}+02$ \\
\hline & & & &
\end{tabular}

Table 6 Mean and standard deviation results for chaotic algorithms for multimodal test functions

\begin{tabular}{|c|c|c|c|}
\hline & $\begin{array}{l}f_{17}-\text { Exponential } \\
\text { Mean } \pm \text { Std.dev }\end{array}$ & $\begin{array}{l}f_{18}-\text { Trid } 6 \\
\text { Mean } \pm \text { Std.dev }\end{array}$ & $\begin{array}{l}f_{19^{-}} \text {Styblinski-Tang } \\
\text { Mean } \pm \text { Std.dev }\end{array}$ \\
\hline MRFO & $-9.99 \mathrm{E}-01 \pm 1.24 \mathrm{E}-06$ & $-2.15 \mathrm{E}+02 \pm 6.14 \mathrm{E}+01$ & $-8.50 \mathrm{E}+02 \pm 6.12 \mathrm{E}+01$ \\
\hline CM01 & $-9.99 \mathrm{E}-01 \pm 1.42 \mathrm{E}-07$ & $1.49 \mathrm{E}+03 \pm 6.14 \mathrm{E}+03$ & $-8.20 \mathrm{E}+02 \pm 5.77 \mathrm{E}+01$ \\
\hline CM02 & $-9.99 \mathrm{E}-01 \pm 8.45 \mathrm{E}-03$ & $-8.05 \mathrm{E}+02 \pm 1.29 \mathrm{E}+02$ & $-6.21 \mathrm{E}+02 \pm 4.74 \mathrm{E}+01$ \\
\hline CM03 & $-1.00 \mathrm{E}+00 \pm 5.01 \mathrm{E}-17$ & $-2.11 \mathrm{E}+02 \pm 7.43 \mathrm{E}+01$ & $-9.24 \mathrm{E}+02 \pm 4.08 \mathrm{E}+01$ \\
\hline CM04 & $-9.99 \mathrm{E}-01 \pm 1.71 \mathrm{E}-08$ & $3.17 \mathrm{E}+03 \pm 1.23 \mathrm{E}+04$ & $-8.76 \mathrm{E}+02 \pm 4.76 \mathrm{E}+01$ \\
\hline CM05 & $-9.99 \mathrm{E}-01 \pm 9.17 \mathrm{E}-10$ & $-9.45 \mathrm{E}+01 \pm 3.93 \mathrm{E}+01$ & $-7.56 \mathrm{E}+02 \pm 5.64 \mathrm{E}+01$ \\
\hline CM06 & $-9.99 \mathrm{E}-01 \pm 1.12 \mathrm{E}-06$ & $1.20 \mathrm{E}+03 \pm 5.54 \mathrm{E}+03$ & $-9.18 \mathrm{E}+02 \pm 4.51 \mathrm{E}+01$ \\
\hline CM07 & $-9.99 \mathrm{E}-01 \pm 1.48 \mathrm{E}-08$ & $8.08 \mathrm{E}+02 \pm 3.13 \mathrm{E}+03$ & $-8.66 \mathrm{E}+02 \pm 6.73 \mathrm{E}+01$ \\
\hline CM08 & $-9.99 \mathrm{E}-01 \pm 1.95 \mathrm{E}-06$ & $6.28 \mathrm{E}+03 \pm 1.58 \mathrm{E}+04$ & $-8.20 \mathrm{E}+02 \pm 6.49 \mathrm{E}+01$ \\
\hline CM09 & $-1.00 \mathrm{E}+00 \pm 0.00 \mathrm{E}+00$ & $-2.12 \mathrm{E}+02 \pm 7.10 \mathrm{E}+02$ & $-9.21 \mathrm{E}+02 \pm 5.41 \mathrm{E}+01$ \\
\hline CM10 & $-9.99 \mathrm{E}-01 \pm 3.44 \mathrm{E}-07$ & $6.97 \mathrm{E}+03 \pm 1.35 \mathrm{E}+04$ & $-8.51 \mathrm{E}+02 \pm 5.86 \mathrm{E}+01$ \\
\hline BMO & $\mathrm{N} / \mathrm{A}$ & $-2.39 \mathrm{E}+01 \pm 1.15 \mathrm{E}+01$ & $-5.80 \mathrm{E}+02 \pm 1.08 \mathrm{E}+02$ \\
\hline $\mathrm{HHO}$ & $\mathrm{N} / \mathrm{A}$ & $-1.89 \mathrm{E}+03 \pm 3.28 \mathrm{E}+02$ & $-9.24 \mathrm{E}+02 \pm 9.76 \mathrm{E}+01$ \\
\hline SGULL & $\begin{array}{l}-9.19 \mathrm{E}-01 \pm 2.72 \mathrm{E}-01 \\
f_{20}-\text { Yang } 1 \\
\text { Mean } \pm \text { Std.dev }\end{array}$ & $\begin{array}{l}1.13 \mathrm{E}+03 \pm 7.63 \mathrm{E}+03 \\
f_{21}-\text { Yang } 2 \\
\text { Mean } \pm \text { Std.dev }\end{array}$ & $\begin{array}{l}2.41 \mathrm{E}+06 \pm 1.40 \mathrm{E}+07 \\
f_{22^{-}} \text {Yang } 4 \\
\text { Mean } \pm \text { Std.dev }\end{array}$ \\
\hline MRFO & $1.00 \mathrm{E}+01 \pm 5.19 \mathrm{E}+01$ & $2.70 \mathrm{E}-05 \pm 4.66 \mathrm{E}-05$ & $6.70 \mathrm{E}-11 \pm 1.58 \mathrm{E}-10$ \\
\hline CM01 & $2.84 \mathrm{E}+06 \pm 1.58 \mathrm{E}+07$ & $7.77 \mathrm{E}-04 \pm 1.47 \mathrm{E}-04$ & $3.21 \mathrm{E}-09 \pm 2.16 \mathrm{E}-09$ \\
\hline CM02 & $7.72 \mathrm{E}-03 \pm 1.54 \mathrm{E}-02$ & $3.80 \mathrm{E}-06 \pm 8.37 \mathrm{E}-06$ & $-8.56 \mathrm{E}-03 \pm 4.20 \mathrm{E}-02$ \\
\hline CM03 & $1.76 \mathrm{E}-16 \pm 4.91 \mathrm{E}-16$ & $1.51 \mathrm{E}-05 \pm 2.76 \mathrm{E}-05$ & $1.85 \mathrm{E}-09 \pm 2.49 \mathrm{E}-09$ \\
\hline CM04 & $2.83 \mathrm{E}+02 \pm 1.71 \mathrm{E}+03$ & $8.14 \mathrm{E}-05 \pm 1.86 \mathrm{E}-04$ & $3.01 \mathrm{E}-11 \pm 5.98 \mathrm{E}-11$ \\
\hline CM05 & $0.00 \mathrm{E}+00 \pm 0.00 \mathrm{E}+00$ & $0.00 \mathrm{E}+00 \pm 0.00 \mathrm{E}+00$ & $-1.00 \mathrm{E}+00 \pm 0.00 \mathrm{E}+00$ \\
\hline CM06 & $1.33 \mathrm{E}+01 \pm 4.39 \mathrm{E}+01$ & $2.38 \mathrm{E}-05 \pm 4.06 \mathrm{E}-05$ & $3.46 \mathrm{E}-11 \pm 8.68 \mathrm{E}-11$ \\
\hline CM07 & $1.99 \mathrm{E}-01 \pm 6.54 \mathrm{E}-01$ & $6.79 \mathrm{E}-05 \pm 1.30 \mathrm{E}-04$ & $5.74 \mathrm{E}-12 \pm 1.02 \mathrm{E}-11$ \\
\hline CM08 & $4.88 \mathrm{E}+07 \pm 3.30 \mathrm{E}+08$ & $4.19 \mathrm{E}-05 \pm 5.95 \mathrm{E}-05$ & $4.46 \mathrm{E}-11 \pm 7.80 \mathrm{E}-11$ \\
\hline CM09 & $1.00 \mathrm{E}-17 \pm 5.64 \mathrm{E}-17$ & $3.75 \mathrm{E}-05 \pm 8.50 \mathrm{E}-05$ & $3.55 \mathrm{E}-12 \pm 4.89 \mathrm{E}-12$ \\
\hline CM10 & $2.65 \mathrm{E}+05 \pm 1.30 \mathrm{E}+06$ & $5.39 \mathrm{E}-05 \pm 7.68 \mathrm{E}-05$ & $4.20 \mathrm{E}-11 \pm 1.59 \mathrm{E}-10$ \\
\hline BMO & $1.84 \mathrm{E}-19 \pm 8.33 \mathrm{E}-19$ & $2.64 \mathrm{E}-03 \pm 4.53 \mathrm{E}-03$ & $2.42 \mathrm{E}-09 \pm 4.05 \mathrm{E}-09$ \\
\hline $\mathrm{HHO}$ & $4.04 \mathrm{E}-05 \pm 2.08 \mathrm{E}-04$ & $1.85 \mathrm{E}-04 \pm 6.02 \mathrm{E}-04$ & $4.37 \mathrm{E}-11 \pm 5.39 \mathrm{E}-11$ \\
\hline SGULL & $1.42 \mathrm{E} \pm 06 \pm 8.36 \mathrm{E}+06$ & $1.66 \mathrm{E}-03 \pm 3.52 \mathrm{E}-03$ & $-6.23 \mathrm{E}-01 \pm 4.73 \mathrm{E}-01$ \\
\hline
\end{tabular}


Table 7 Statistical performance of the chaotic MRFO algorithms for unimodal test functions

\begin{tabular}{|c|c|c|c|c|}
\hline & $\begin{array}{l}f_{23}-\text { Sphere } \\
\text { Mean } \pm \text { Std.dev }\end{array}$ & $\begin{array}{l}f_{24} \text {-Rosenbrock } \\
\text { Mean } \pm \text { Std.dev }\end{array}$ & $\begin{array}{l}f_{25}-\text { Brown } \\
\text { Mean } \pm \text { Std.dev }\end{array}$ & $\begin{array}{l}f_{26} \text {-Streched sine wave } \\
\text { Mean } \pm \text { Std.dev }\end{array}$ \\
\hline MRFO & $9.64 \mathrm{E}-07 \pm 2.59 \mathrm{E}-06$ & $4.19 E+01 \pm 9.01 E+01$ & $1.81 \mathrm{E}-02 \pm 1.02 \mathrm{E}-01$ & $3.46 \mathrm{E}-01 \pm 1.93 \mathrm{E}-01$ \\
\hline CM01 & $2.63 \mathrm{E}-07 \pm 7.00 \mathrm{E}-07$ & $3.51 \mathrm{E}+01 \pm 5.14 \mathrm{E}+01$ & $5.93 \mathrm{E}-04 \pm 2.13 \mathrm{E}-03$ & $2.24 \mathrm{E}-01 \pm 1.55 \mathrm{E}-01$ \\
\hline CM02 & $4.01 \mathrm{E}-03 \pm 9.74 \mathrm{E}-03$ & $2.89 \mathrm{E}+01 \pm 7.78 \mathrm{E}-01$ & $4.95 \mathrm{E}-03 \pm 1.59 \mathrm{E}-03$ & $5.65 \mathrm{E}+00 \pm 1.44 \mathrm{E}+00$ \\
\hline CM03 & $2.06 \mathrm{E}-17 \pm 8.96 \mathrm{E}-17$ & $2.68 \mathrm{E}+01 \pm 3.70 \mathrm{E}-01$ & $3.93 \mathrm{E}-16 \pm 1.12 \mathrm{E}-15$ & $8.52 \mathrm{E}-05 \pm 6.85 \mathrm{E}-05$ \\
\hline CM04 & $4.09 \mathrm{E}-09 \pm 6.74 \mathrm{E}-09$ & $2.80 \mathrm{E}+01 \pm 8.31 \mathrm{E}-01$ & $1.68 \mathrm{E}-04 \pm 9.17 \mathrm{E}-04$ & $9.95 \mathrm{E}-02 \pm 7.45 \mathrm{E}-02$ \\
\hline CM05 & $0.00 \mathrm{E}+00 \pm 0.00 \mathrm{E}+00$ & $2.89 \mathrm{E}+01 \pm 4.29 \mathrm{E}-02$ & $0.00 \mathrm{E}+00 \pm 0.00 \mathrm{E}+00$ & $0.00 \mathrm{E}+00 \pm 0.00 \mathrm{E}+00$ \\
\hline CM06 & $2.91 \mathrm{E}-02 \pm 9.16 \mathrm{E}-02$ & $2.82 \mathrm{E}+01 \pm 7.76 \mathrm{E}-01$ & $3.89 \mathrm{E}-05 \pm 1.00 \mathrm{E}-04$ & $5.84 \mathrm{E}-01 \pm 3.35 \mathrm{E}-01$ \\
\hline CM07 & $3.87 \mathrm{E}-09 \pm 1.87 \mathrm{E}-08$ & $2.78 \mathrm{E}+01 \pm 4.37 \mathrm{E}-01$ & $1.72 \mathrm{E}-08 \pm 6.04 \mathrm{E}-08$ & $1.21 \mathrm{E}-01 \pm 9.69 \mathrm{E}-02$ \\
\hline CM08 & $4.13 \mathrm{E}-07 \pm 8.01 \mathrm{E}-07$ & $8.43 \mathrm{E}+01 \pm 3.64 \mathrm{E}+02$ & $1.74 \mathrm{E}-03 \pm 1.05 \mathrm{E}-02$ & $2.79 \mathrm{E}-01 \pm 2.25 \mathrm{E}-01$ \\
\hline CM09 & $4.26 \mathrm{E}-21 \pm 8.79 \mathrm{E}-21$ & $2.66 \mathrm{E}+01 \pm 5.72 \mathrm{E}-01$ & $3.87 \mathrm{E}-19 \pm 1.22 \mathrm{E}-18$ & $1.56 \mathrm{E}-05 \pm 1.42 \mathrm{E}-05$ \\
\hline CM10 & $9.69 \mathrm{E}-06 \pm 1.23 \mathrm{E}-05$ & $3.70 \mathrm{E}+01 \pm 5.81 \mathrm{E}+01$ & $7.94 \mathrm{E}-05 \pm 2.49 \mathrm{E}-04$ & $2.68 \mathrm{E}-01 \pm 1.61 \mathrm{E}-01$ \\
\hline $\mathrm{BMO}$ & $3.33 \mathrm{E}-17 \pm 2.60 \mathrm{E}-16$ & $2.86 \mathrm{E}+01 \pm 2.14 \mathrm{E}-01$ & $\mathrm{~N} / \mathrm{A}$ & $5.38 \mathrm{E}-05 \pm 7.44 \mathrm{E}-05$ \\
\hline $\mathrm{HHO}$ & $1.48 \mathrm{E}-16 \pm 4.91 \mathrm{E}-16$ & $2.85 \mathrm{E}+01 \pm 2.38 \mathrm{E}-01$ & $1.25 \mathrm{E}-16 \pm 4.54 \mathrm{E}-16$ & $5.87 \mathrm{E}-04 \pm 9.21 \mathrm{E}-04$ \\
\hline \multirow[t]{3}{*}{ SGULL } & $3.58 \mathrm{E}+02 \pm 3.92 \mathrm{E}+03$ & $4.53 E+03 \pm 3.76 E+03$ & $5.67 \mathrm{E}+04 \pm 3.86 \mathrm{E}+03$ & $1.15 \mathrm{E}+01 \pm 5.35 \mathrm{E}+01$ \\
\hline & $f_{27}$-Powell singular & $f_{28}$-Sum of different powers & $f_{29}$-Sum of squares & $f_{30}$-Bent cigar \\
\hline & Mean \pm Std.dev & Mean \pm Std.dev & Mean \pm Std.dev & Mean \pm Std.dev \\
\hline MRFO & $1.27 \mathrm{E}-02 \pm 4.26 \mathrm{E}-02$ & $1.47 \mathrm{E}+04 \pm 1.31 \mathrm{E}+05$ & $1.11 \mathrm{E}-05 \pm 2.05 \mathrm{E}-05$ & $2.37 \mathrm{E}+00 \pm 1.50 \mathrm{E}+01$ \\
\hline CM01 & $4.97 \mathrm{E}-03 \pm 2.46 \mathrm{E}-02$ & $2.17 \mathrm{E}+01 \pm 1.35 \mathrm{E}+02$ & $4.39 \mathrm{E}-06 \pm 1.45 \mathrm{E}-05$ & $1.19 \mathrm{E}-01 \pm 2.38 \mathrm{E}-01$ \\
\hline CM02 & $7.25 \mathrm{E}-01 \pm 1.89 \mathrm{E}+00$ & $1.23 \mathrm{E}-02 \pm 1.12 \mathrm{E}-02$ & $1.02 \mathrm{E}-01 \pm 2.57 \mathrm{E}-01$ & $2.81 \mathrm{E}+03 \pm 8.00 \mathrm{E}+02$ \\
\hline CM03 & $1.04 \mathrm{E}-08 \pm 5.72 \mathrm{E}-08$ & $2.86 \mathrm{E}-23 \pm 1.42 \mathrm{E}-22$ & $2.62 \mathrm{E}-17 \pm 5.83 \mathrm{E}-17$ & $1.01 \mathrm{E}-12 \pm 1.72 \mathrm{E}-12$ \\
\hline CM04 & $7.17 \mathrm{E}-05 \pm 1.92 \mathrm{E}-04$ & $3.34 \mathrm{E}+00 \pm 1.59 \mathrm{E}+01$ & $4.62 \mathrm{E}-08 \pm 6.34 \mathrm{E}-08$ & $4.68 \mathrm{E}-03 \pm 1.24 \mathrm{E}-02$ \\
\hline CM05 & $0.00 \mathrm{E}+00 \pm 0.00 \mathrm{E}+00$ & $4.62 \mathrm{E}+04 \pm 1.33 \mathrm{E}+05$ & $0.00 \mathrm{E}+00 \pm 0.00 \mathrm{E}+00$ & $0.00 \mathrm{E}+00 \pm 0.00 \mathrm{E}+00$ \\
\hline CM06 & $3.43 \mathrm{E}-03 \pm 7.27 \mathrm{E}-03$ & $2.13 \mathrm{E}-03 \pm 8.52 \mathrm{E}-03$ & $5.59 \mathrm{E}-05 \pm 9.55 \mathrm{E}-05$ & $1.50 \mathrm{E}+00 \pm 4.23 \mathrm{E}+00$ \\
\hline CM07 & $1.06 \mathrm{E}-05 \pm 2.86 \mathrm{E}-05$ & $9.71 \mathrm{E}-05 \pm 5.83 \mathrm{E}-04$ & $2.26 \mathrm{E}-08 \pm 5.59 \mathrm{E}-08$ & $8.00 \mathrm{E}-04 \pm 2.05 \mathrm{E}-03$ \\
\hline CM08 & $1.16 \mathrm{E}-02 \pm 5.36 \mathrm{E}-02$ & $6.32 \mathrm{E}+01 \pm 4.22 \mathrm{E}+02$ & $3.64 \mathrm{E}-06 \pm 8.05 \mathrm{E}-06$ & $2.22 \mathrm{E}-01 \pm 2.99 \mathrm{E}-01$ \\
\hline CM09 & $2.67 \mathrm{E}-10 \pm 1.42 \mathrm{E}-09$ & $9.34 \mathrm{E}-28 \pm 5.25 \mathrm{E}-27$ & $1.33 \mathrm{E}-19 \pm 3.03 \mathrm{E}-19$ & $2.86 \mathrm{E}-15 \pm 9.24 \mathrm{E}-15$ \\
\hline CM10 & $4.85 \mathrm{E}-03 \pm 2.61 \mathrm{E}-02$ & $7.26 \mathrm{E}+00 \pm 4.21 \mathrm{E}+01$ & $2.61 \mathrm{E}-06 \pm 4.45 \mathrm{E}-06$ & $1.11 \mathrm{E}-01 \pm 1.95 \mathrm{E}-01$ \\
\hline $\mathrm{BMO}$ & $7.99 \mathrm{E}-16 \pm 5.19 \mathrm{E}-15$ & $5.51 \mathrm{E}-22 \pm 2.72 \mathrm{E}-21$ & $3.54 \mathrm{E}-17 \pm 1.91 \mathrm{E}-16$ & $1.56 \mathrm{E}-12 \pm 7.10 \mathrm{E}-12$ \\
\hline $\mathrm{HHO}$ & $8.94 \mathrm{E}-15 \pm 5.42 \mathrm{E}-14$ & $5.40 \mathrm{E}-15 \pm 2.91 \mathrm{E}-14$ & $1.26 \mathrm{E}-15 \pm 4.64 \mathrm{E}-15$ & $3.64 \mathrm{E}-09 \pm 3.57 \mathrm{E}-08$ \\
\hline \multirow[t]{3}{*}{ SGULL } & $2.03 E+03 \pm 1.42 E+03$ & $4.57 \mathrm{E}+03 \pm 2.12 \mathrm{E}+02$ & $3.18 \mathrm{E}+02 \pm 1.56 \mathrm{E}+02$ & $5.36 \mathrm{E}+03 \pm 2.13 \mathrm{E}+03$ \\
\hline & $f_{31}$-Discus & $f_{32}$ - Different powers & $f_{33}$ - Dixon-Price & $f_{34}-$ Yang 3 \\
\hline & Mean \pm Std.dev & Mean \pm Std.dev & Mean \pm Std.dev & Mean \pm Std.dev \\
\hline MRFO & $1.13 \mathrm{E}-06 \pm 2.46 \mathrm{E}-06$ & $1.42 \mathrm{E}-03 \pm 2.59 \mathrm{E}-03$ & $2.45 E+05 \pm 1.53 E+06$ & $\mathrm{~N} / \mathrm{A}$ \\
\hline CM01 & $1.56 \mathrm{E}-03 \pm 3.03 \mathrm{E}-03$ & $8.05 \mathrm{E}-04 \pm 1.75 \mathrm{E}-03$ & $4.10 \mathrm{E}+03 \pm 2.51 \mathrm{E}+04$ & N/A \\
\hline CM02 & $5.62 \mathrm{E}+05 \pm 5.84 \mathrm{E}+03$ & $3.71 \mathrm{E}-02 \pm 9.55 \mathrm{E}-02$ & $1.29 E+03 \pm 6.67 E+03$ & $\mathrm{~N} / \mathrm{A}$ \\
\hline CM03 & $2.52 \mathrm{E}-13 \pm 8.51 \mathrm{E}-13$ & $8.64 \mathrm{E}-13 \pm 3.83 \mathrm{E}-12$ & $6.66 \mathrm{E}-01 \pm 2.04 \mathrm{E}-04$ & $\mathrm{~N} / \mathrm{A}$ \\
\hline CM04 & $1.33 \mathrm{E}-04 \pm 4.04 \mathrm{E}-04$ & $3.62 \mathrm{E}-05 \pm 1.20 \mathrm{E}-04$ & $1.24 \mathrm{E}+01 \pm 4.04 \mathrm{E}+01$ & $\mathrm{~N} / \mathrm{A}$ \\
\hline CM05 & $0.00 \mathrm{E}+00 \pm 0.00 \mathrm{E}+00$ & $0.00 \mathrm{E}+00 \pm 0.00 \mathrm{E}+00$ & $9.11 \mathrm{E}-01 \pm 1.07 \mathrm{E}-01$ & $\mathrm{~N} / \mathrm{A}$ \\
\hline CM06 & $6.51 \mathrm{E}-02 \pm 1.49 \mathrm{E}-01$ & $6.88 \mathrm{E}-04 \pm 1.67 \mathrm{E}-03$ & $2.07 \mathrm{E}+02 \pm 6.39 \mathrm{E}+02$ & $\mathrm{~N} / \mathrm{A}$ \\
\hline CM07 & $1.37 \mathrm{E}-05 \pm 3.70 \mathrm{E}-05$ & $1.23 \mathrm{E}-05 \pm 3.25 \mathrm{E}-05$ & $1.51 \mathrm{E}+01 \pm 2.83 \mathrm{E}+00$ & $\mathrm{~N} / \mathrm{A}$ \\
\hline CM08 & $3.88 \mathrm{E}-03 \pm 1.40 \mathrm{E}-02$ & $2.12 \mathrm{E}-03 \pm 7.66 \mathrm{E}-03$ & $2.78 \mathrm{E}+03 \pm 7.39 \mathrm{E}+03$ & $\mathrm{~N} / \mathrm{A}$ \\
\hline CM09 & $5.21 \mathrm{E}-16 \pm 1.61 \mathrm{E}-15$ & $2.78 \mathrm{E}-15 \pm 4.38 \mathrm{E}-15$ & $6.66 \mathrm{E}-01 \pm 4.06 \mathrm{E}-05$ & $\mathrm{~N} / \mathrm{A}$ \\
\hline CM10 & $2.37 \mathrm{E}-03 \pm 4.59 \mathrm{E}-03$ & $3.77 \mathrm{E}-04 \pm 5.29 \mathrm{E}-04$ & $1.84 \mathrm{E}+03 \pm 4.00 \mathrm{E}+03$ & $\mathrm{~N} / \mathrm{A}$ \\
\hline BMO & $1.22 \mathrm{E}-16 \pm 5.92 \mathrm{E}-16$ & $1.30 \mathrm{E}-13 \pm 6.44 \mathrm{E}-13$ & $7.20 \mathrm{E}-01 \pm 1.15 \mathrm{E}-01$ & $\mathrm{~N} / \mathrm{A}$ \\
\hline $\mathrm{HHO}$ & $2.24 \mathrm{E}-15 \pm 5.31 \mathrm{E}-15$ & $1.40 \mathrm{E}-11 \pm 3.53 \mathrm{E}-11$ & $6.68 \mathrm{E}-01 \pm 2.03 \mathrm{E}-03$ & $\mathrm{~N} / \mathrm{A}$ \\
\hline SGULL & $1.67 \mathrm{E}+05 \pm 1.73 \mathrm{E}+06$ & $3.69 \mathrm{E}+03 \pm 2.32 \mathrm{E}+04$ & $2.32 \mathrm{E}+01 \pm 1.42 \mathrm{E}+00$ & $-3.07 \mathrm{E}-01 \pm 4.53 \mathrm{E}-01$ \\
\hline
\end{tabular}


Table 8 Statistical comparison between different chaotic variants for unimodal test functions

\begin{tabular}{|c|c|c|c|}
\hline & $\begin{array}{l}f_{35}-\text { Schwefel } 2.20 \\
\text { Mean } \pm \text { Std.dev }\end{array}$ & $\begin{array}{l}f_{36}-\text { Schwefel } 2.21 \\
\text { Mean } \pm \text { Std.dev }\end{array}$ & $\begin{array}{l}f_{37}-\text { Schwefel } 2.22 \\
\text { Mean } \pm \text { Std.dev }\end{array}$ \\
\hline MRFO & $3.12 \mathrm{E}-05 \pm 2.98 \mathrm{E}-05$ & $6.16 \mathrm{E}-58 \pm 5.05 \mathrm{E}-57$ & $2.99 \mathrm{E}-05 \pm 2.81 \mathrm{E}-05$ \\
\hline CM01 & $4.66 \mathrm{E}-05 \pm 5.91 \mathrm{E}-05$ & $4.28 \mathrm{E}-58 \pm 1.66 \mathrm{E}-57$ & $2.15 \mathrm{E}-05 \pm 2.83 \mathrm{E}-05$ \\
\hline CM02 & $1.51 \mathrm{E}+00 \pm 1.06 \mathrm{E}+00$ & $1.88 \mathrm{E}-13 \pm 5.73 \mathrm{E}-13$ & $7.29 \mathrm{E}-01 \pm 7.91 \mathrm{E}-01$ \\
\hline CM03 & $1.92 \mathrm{E}-10 \pm 2.88 \mathrm{E}-10$ & $6.37 \mathrm{E}-66 \pm 2.46 \mathrm{E}-65$ & $3.87 \mathrm{E}-11 \pm 5.02 \mathrm{E}-11$ \\
\hline CM04 & $9.13 \mathrm{E}-06 \pm 8.51 \mathrm{E}-06$ & $2.64 \mathrm{E}-58 \pm 6.39 \mathrm{E}-58$ & $1.93 \mathrm{E}-06 \pm 1.85 \mathrm{E}-06$ \\
\hline CM05 & $0.00 \mathrm{E}+00 \pm 0.00 \mathrm{E}+00$ & $0.00 \mathrm{E}+00 \pm 0.00 \mathrm{E}+00$ & $0.00 E+00 \pm 0.00 E+00$ \\
\hline CM06 & $1.77 \mathrm{E}-03 \pm 1.48 \mathrm{E}-03$ & $6.42 \mathrm{E}-47 \pm 2.88 \mathrm{E}-46$ & $5.74 \mathrm{E}-04 \pm 8.61 \mathrm{E}-04$ \\
\hline CM07 & $4.41 \mathrm{E}-06 \pm 7.52 \mathrm{E}-06$ & $4.26 \mathrm{E}-69 \pm 1.91 \mathrm{E}-68$ & $6.59 \mathrm{E}-07 \pm 8.32 \mathrm{E}-07$ \\
\hline CM08 & $7.04 \mathrm{E}-05 \pm 7.49 \mathrm{E}-05$ & $5.86 \mathrm{E}-59 \pm 2.94 \mathrm{E}-58$ & $1.57 \mathrm{E}-05 \pm 1.72 \mathrm{E}-05$ \\
\hline CM09 & $1.22 \mathrm{E}-11 \pm 2.82 \mathrm{E}-11$ & $1.42 \mathrm{E}-66 \pm 6.29 \mathrm{E}-66$ & $2.28 \mathrm{E}-12 \pm 3.22 \mathrm{E}-12$ \\
\hline CM10 & $6.98 \mathrm{E}-05 \pm 9.66 \mathrm{E}-05$ & $3.06 \mathrm{E}-59 \pm 1.29 \mathrm{E}-59$ & $9.69 \mathrm{E}-06 \pm 1.23 \mathrm{E}-05$ \\
\hline BMO & $3.86 \mathrm{E}-09 \pm 1.83 \mathrm{E}-09$ & $3.37 \mathrm{E}-33 \pm 2.06 \mathrm{E}-32$ & $5.23 \mathrm{E}-10 \pm 2.89 \mathrm{E}-09$ \\
\hline $\mathrm{HHO}$ & $1.09 \mathrm{E}-08 \pm 2.55 \mathrm{E}-08$ & $2.22 \mathrm{E}-21 \pm 1.73 \mathrm{E}-20$ & $1.08 \mathrm{E}-08 \pm 3.05 \mathrm{E}-08$ \\
\hline \multirow[t]{3}{*}{ SGULL } & $2.36 \mathrm{E}+00 \pm 1.32 \mathrm{E}+00$ & $1.67 \mathrm{E}-09 \pm 2.39 \mathrm{E}-10$ & $5.69 E+00 \pm 1.03 E+00$ \\
\hline & $f_{38}-$ Schwefel 2.23 & $f_{39}-$ Schwefel 2.25 & $f_{40}$-Dropwave \\
\hline & Mean \pm Std.dev & Mean \pm Std.dev & Mean \pm Std.dev \\
\hline MRFO & $9.96 \mathrm{E}+03 \pm 8.02 \mathrm{E}+04$ & $3.78 \mathrm{E}+01 \pm 8.96 \mathrm{E}+01$ & $-7.55 \mathrm{E}-01 \pm 8.51 \mathrm{E}-02$ \\
\hline CM01 & $4.78 \mathrm{E}+00 \pm 1.72 \mathrm{E}+01$ & $5.10 \mathrm{E}+01 \pm 1.55 \mathrm{E}+02$ & $-8.01 \mathrm{E}-01 \pm 8.48 \mathrm{E}-02$ \\
\hline CM02 & $9.99 \mathrm{E}-18 \pm 1.11 \mathrm{E}-17$ & $8.87 \mathrm{E}-02 \pm 2.04 \mathrm{E}-01$ & $-9.33 \mathrm{E}-01 \pm 3.67 \mathrm{E}-02$ \\
\hline CM03 & $1.05 \mathrm{E}-46 \pm 3.52 \mathrm{E}-46$ & $6.55 E+00 \pm 1.63 E+00$ & $-9.35 \mathrm{E}-01 \pm 2.16 \mathrm{E}-03$ \\
\hline CM04 & $4.01 \mathrm{E}+00 \pm 2.94 \mathrm{E}+01$ & $3.12 \mathrm{E}+01 \pm 1.17 \mathrm{E}+02$ & $-8.35 \mathrm{E}-01 \pm 7.69 \mathrm{E}-02$ \\
\hline CM05 & $0.00 \mathrm{E}+00 \pm 0.00 \mathrm{E}+00$ & $2.08 \mathrm{E}+01 \pm 5.49 \mathrm{E}+00$ & $-8.43 \mathrm{E}-01 \pm 8.21 \mathrm{E}-02$ \\
\hline CM06 & $1.10 \mathrm{E}-05 \pm 5.68 \mathrm{E}-05$ & $1.32 \mathrm{E}+01 \pm 2.67 \mathrm{E}+01$ & $-8.47 \mathrm{E}-01 \pm 7.73 \mathrm{E}-02$ \\
\hline CM07 & $7.49 \mathrm{E}-06 \pm 5.74 \mathrm{E}-05$ & $1.34 \mathrm{E}+01 \pm 4.20 \mathrm{E}+01$ & $-8.41 \mathrm{E}-01 \pm 7.21 \mathrm{E}-02$ \\
\hline CM08 & $3.42 \mathrm{E}+02 \pm 2.14 \mathrm{E}+03$ & $4.23 \mathrm{E}+01 \pm 8.68 \mathrm{E}+01$ & $-7.67 \mathrm{E}-01 \pm 7.41 \mathrm{E}-02$ \\
\hline CM09 & $1.82 \mathrm{E}-53 \pm 1.15 \mathrm{E}-53$ & $6.51 \mathrm{E}+00 \pm 1.31 \mathrm{E}+00$ & $-9.36 \mathrm{E}-01 \pm 4.04 \mathrm{E}-07$ \\
\hline CM10 & $7.89 \mathrm{E}+02 \pm 5.61 \mathrm{E}+03$ & $2.41 \mathrm{E}+01 \pm 2.71 \mathrm{E}+01$ & $-7.87 \mathrm{E}-01 \pm 8.64 \mathrm{E}-02$ \\
\hline BMO & $9.43 \mathrm{E}-76 \pm 8.36 \mathrm{E}-75$ & $1.64 \mathrm{E}+01 \pm 1.23 \mathrm{E}+00$ & $-9.39 \mathrm{E}-01 \pm 1.38 \mathrm{E}-02$ \\
\hline $\mathrm{HHO}$ & $2.87 \mathrm{E}-73 \pm 2.50 \mathrm{E}-72$ & $3.58 \mathrm{E}+00 \pm 1.08 \mathrm{E}+00$ & $-9.36 \mathrm{E}-01 \pm 6.43 \mathrm{E}-03$ \\
\hline SGULL & $6.03 E+03 \pm 1.05 E+03$ & $7.45 \mathrm{E}+03 \pm 1.94 \mathrm{E}+04$ & $-9.35 \mathrm{E}-01 \pm 2.35 \mathrm{E}-01$ \\
\hline
\end{tabular}

process air which eliminates the direct exposition of the mechanical equipment to the flowing hot exhaust air. The induced air draft coolers are the second most economical of these types after draft coolers in which the axial fans are located at the upper side of the entire cooling system to pull the process air through the tube bundles. This flowing behavior resulted from the location of the axial fans not only enables a higher control capability of the hot air but also improves the robustness of the tube bundles due to the reinforcing structural support equipment. Figure 12 shows the schematic representation of the forced and induced air draft coolers.

Practical thermal and structural design of an air-cooled heat exchanger should take into account several numbers of design factors such as heat transfer capacity of the cooling system, the imposed pressure drops on both cold and hot streams, arrangement order and physical size of the tubes, flow configuration of the running streams, etc. The conventional design process of ACHEs has been dependent upon trial-and-error procedure as it has been also practiced for shell and tube heat exchangers until the early 2000s. The procedural iterative calculation is initialized with suggesting an initial estimate for a trial overall heat transfer coefficient to obtain structural parameters of the heat exchanger which also should satisfy the imposed design constraints on the heat exchanger system. However, this solution method is significantly time-consuming and requires an excessive amount of computational power particularly when the design optimization of the system is considered. Furthermore, an increasing number of discrete design variables along with strictly defined operational conditions complicates the application of the optimization process as there is a correlated link between the possible number combinations to be explored over the search space and the number of decision parameters to be iteratively obtained. The literature survey discussed in the 


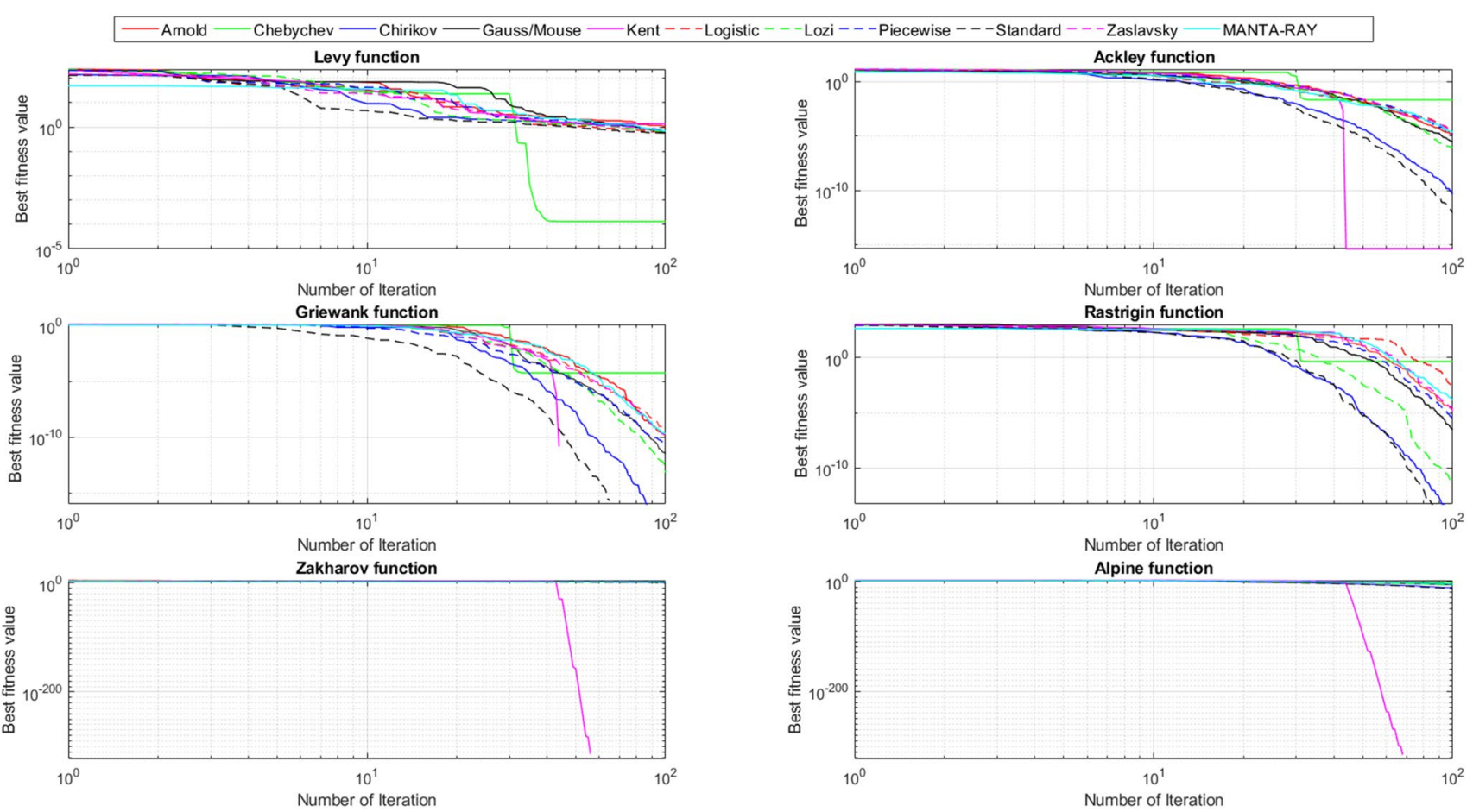

Fig. 3 Convergence curves for multimodal test functions from $f_{1}$-Levy to $f_{6}$-Alpine
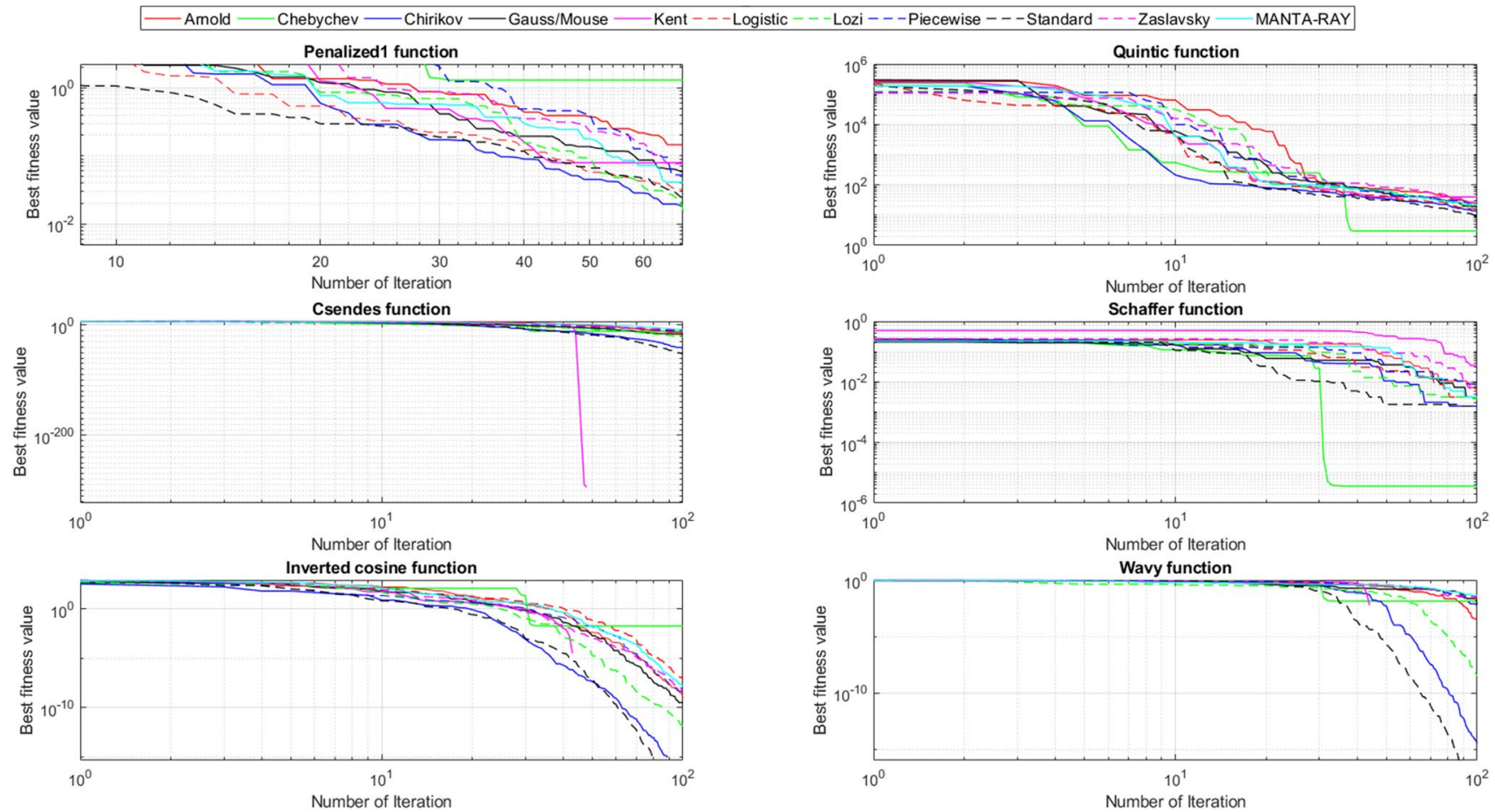

Fig. 4 Convergence curves for multimodal test functions from $f_{7}$-Penalized 1 to $f_{12}$-Alpine

introduction section suggests that stochastic algorithms can overcome the above-mentioned problem-specific difficulties faced on the course of the optimization process.
Relying on the satisfactory optimization success on constrained and unconstrained benchmark problems discussed in the previous section, this study proposes using

\section{SN Applied Sciences}



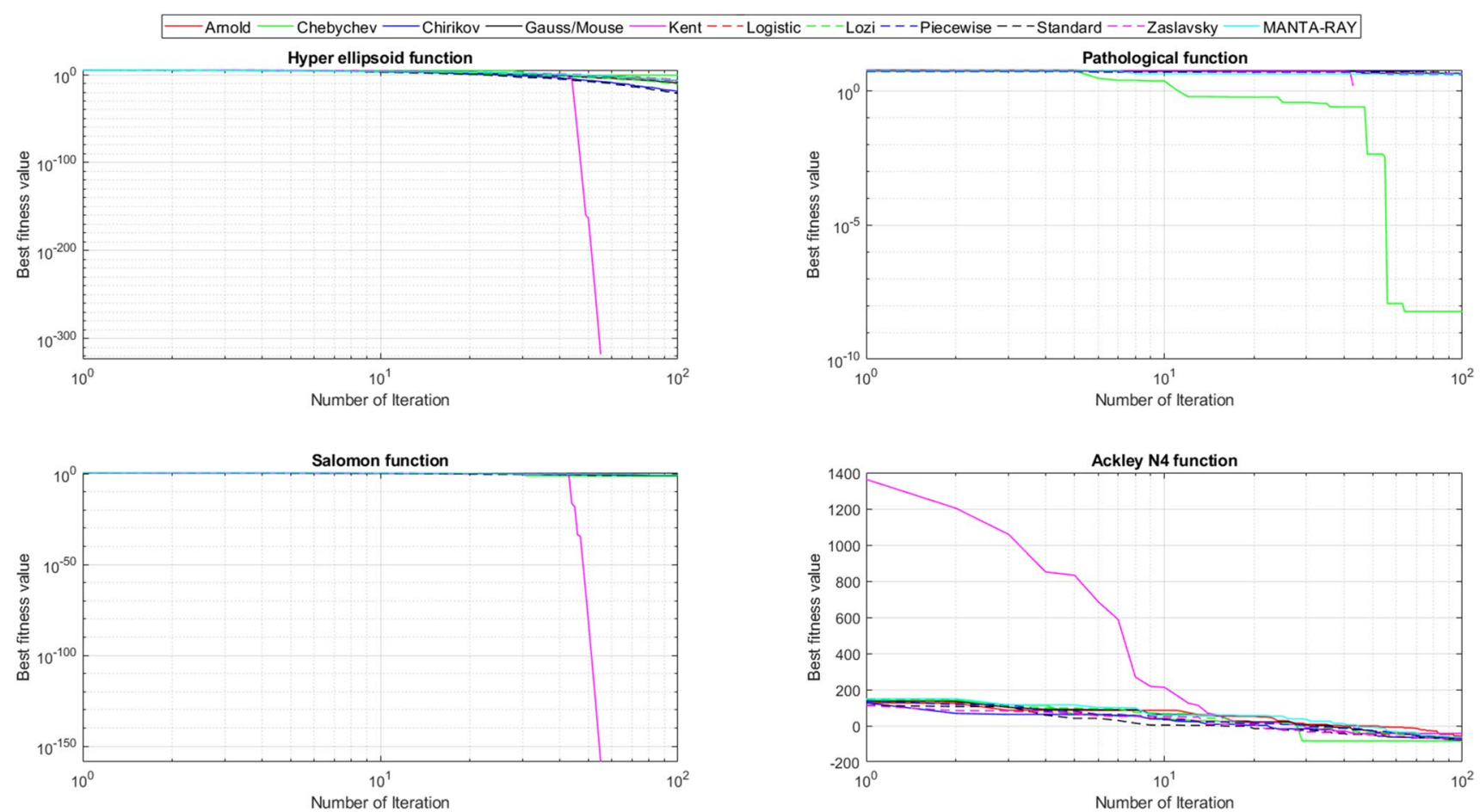

Fig. 5 Convergence curves for multimodal test functions from $f_{13}$-Hyper-ellipsoid to $f_{16}$-AckleyN4

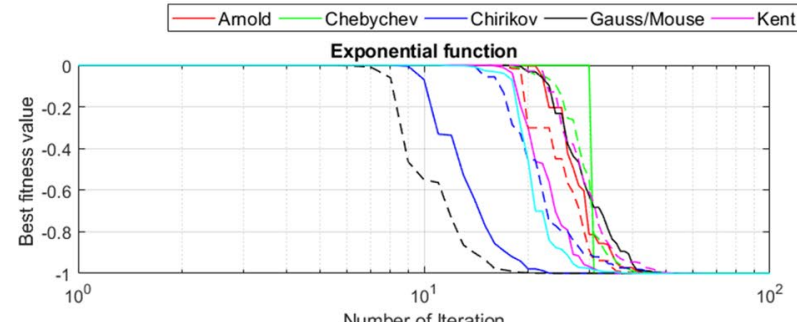

Number of Iteration
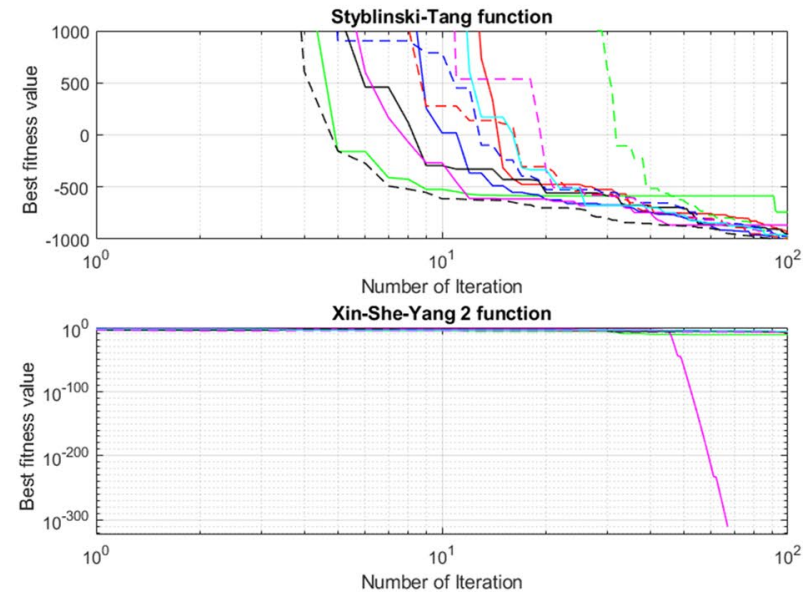

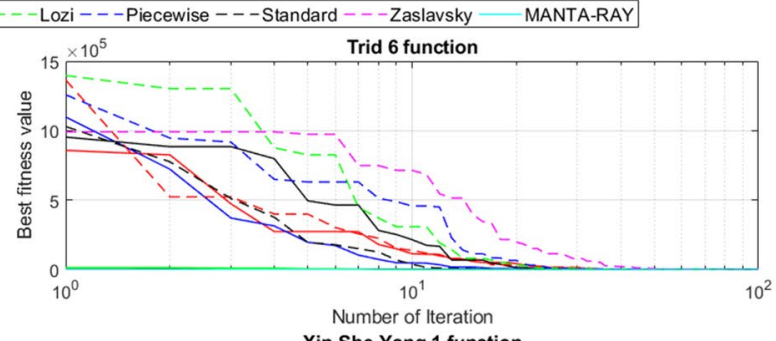

Xin-She-Yang 1 function

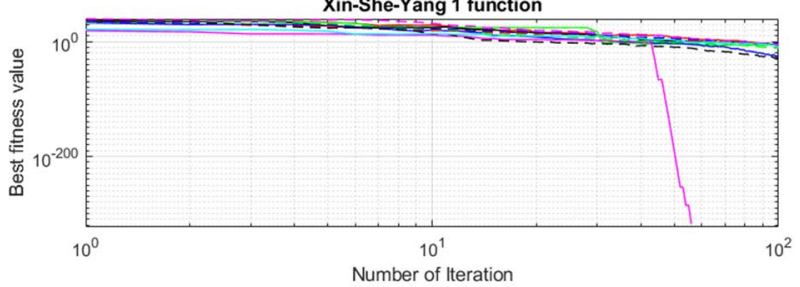

Xin-She-Yang 4 function

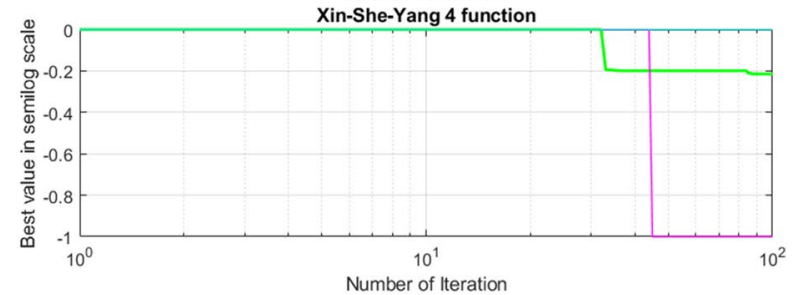

Fig. 6 Convergence curves for multimodal test functions from $f_{17}$-Exponential to $f_{22}$-Yang 4

chaotic variants of the MRFO algorithm to find optimum design variables of air-fin coolers. Below sub-sections will explain the main steps of the governing mathematical model to be utilized for design optimization purposes. 

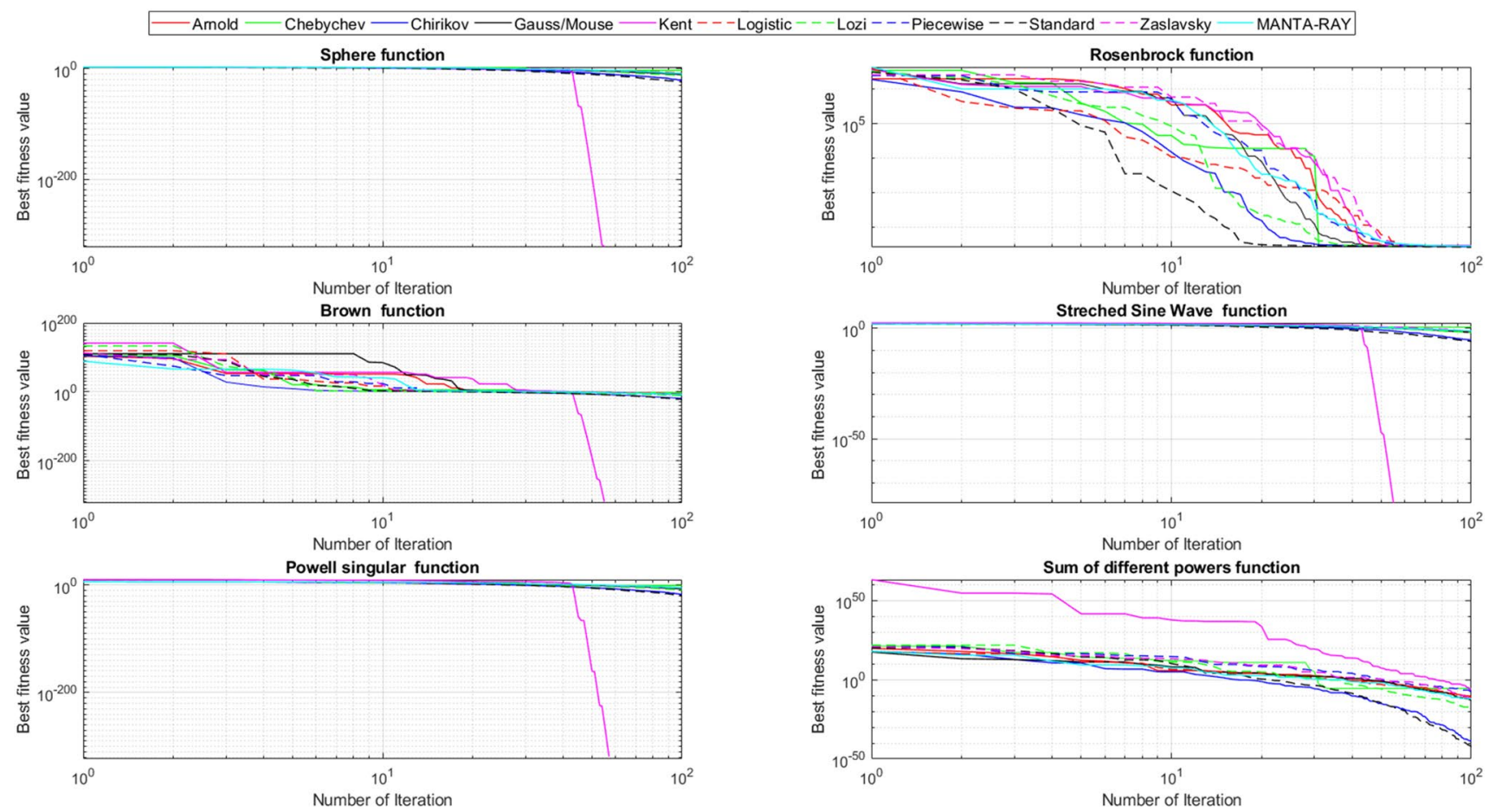

Fig. 7 Convergence curves for unimodal test functions from $f_{23}$-Sphere to $f_{28}$-Sum of different powers

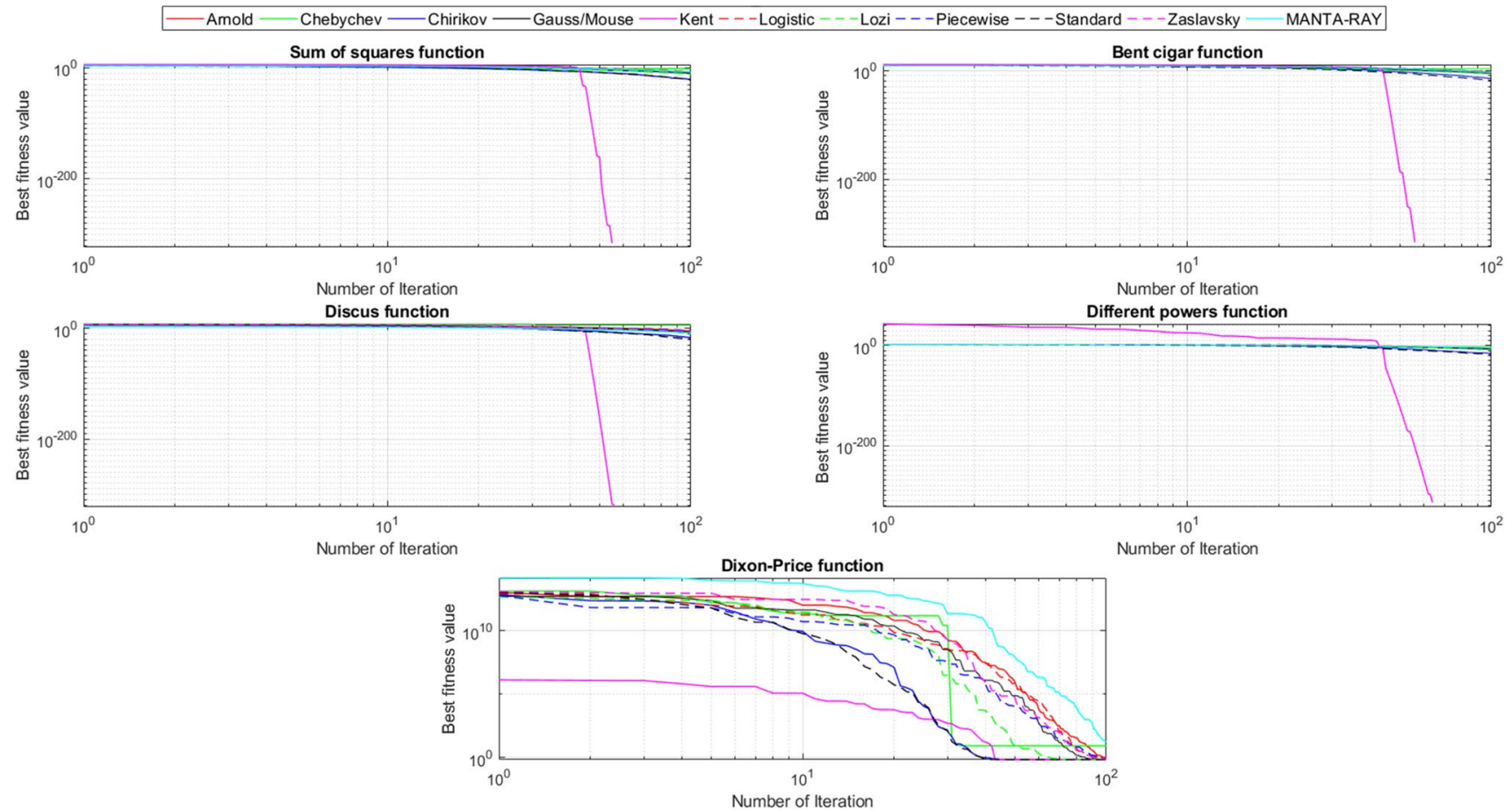

Fig. 8 Convergence curves for unimodal test functions from $f_{29}$-Sum of squares to $f_{33}$-Dixon-Price

\subsection{Design parameters and assumptions}

Design optimization addressed in this research study can be summarized by the following statement. Knowing the mass flow rate and inlet and outlet temperatures of the water to be cooled by the process air, the problem at

\section{SN Applied Sciences}



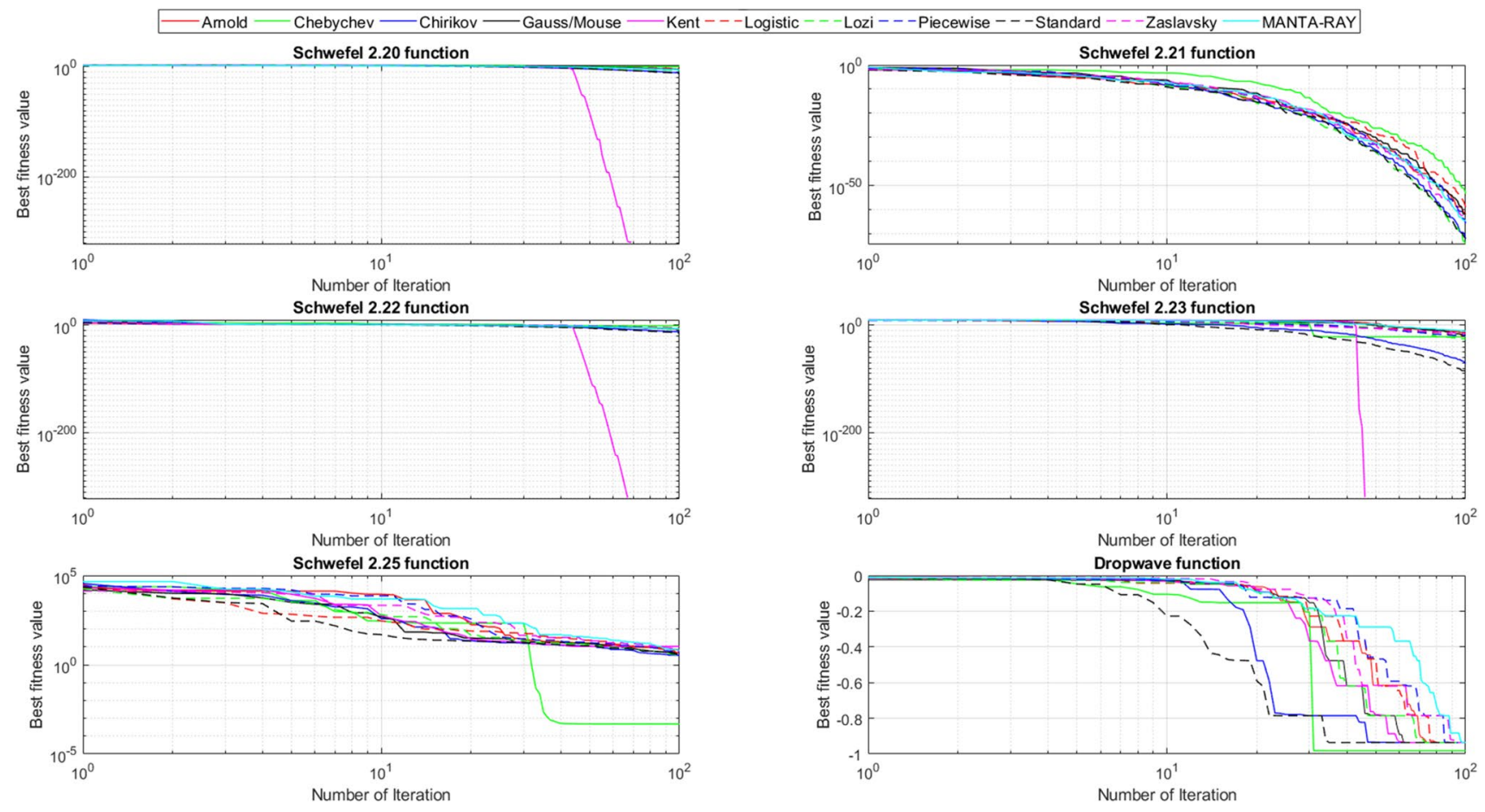

Fig. 9 Convergence curves for unimodal test functions from $f_{35}$-Schwefel 2.20 to $f_{40}$-Dropwave

hand aims to find optimal values of ten decision variables including the air cooler length $(L)$, air cooler height $(H)$, fin pitch $\left(P_{f}\right)$, tube pitch $\left(P_{t}\right)$, tube inner diameter $\left(d_{i}\right)$, tube outside diameter $\left(d_{o}\right)$, gap outside diameter $\left(d_{g}\right)$, fin inside diameter $\left(d_{b}\right)$, fin outside diameter $\left(d_{a}\right)$, and fin thickness $(\delta)$ which minimize the total annual cost of air fin cooler. The following design assumptions have been used to derive a reliable mathematical model for this optimization problem.

- Average thermophysical properties have been considered for the process air and the cooling water

- Mass flow rates, inlet and outlet temperatures, and maximum allowable pressure drops for both cold and hot streams are priorly known

- Process air passes over the tube bundle while cooling water flowing through the tubes

Considering the above-defined assumptions, the following mathematical model is developed. Heat transfer and pressure drop correlations that quantify the respective amounts of heat transfer and pressure drop taken place inside and outside of the tube banks are taken from Kraus et al. [68]

\subsection{Problem formulation}

For estimating the thermal efficiency of the air-cooled heat exchanger, $\varepsilon$-NTU method is utilized. Thermal available effectiveness of the heat exchanger with both running streams unmixed can be predicted by the following equation [68]

$\varepsilon_{\text {avail }}=1-e^{\mathrm{NTU}^{0.22} \phi / R}$

where $\phi$ is a parameter calculated by the following expression

$\phi=e^{-R(\mathrm{NTU})^{0.78}}-1$

And NTU is the number of heat transfer unit calculated by

$\mathrm{NTU}=\frac{U_{O} \times A_{\mathrm{HE}}}{C_{\min }}$

where $C_{\min }$ is the minimum mass capacity ratio between the hot and cold streams; $A_{H E}$ is the total heat exchange area, and $U_{o}$ is the overall heat transfer coefficient between two streams. The parameter $\mathrm{R}$ represents the ratio between the lower and higher mass capacitance $\left(R=C_{\min } / C_{\max }\right)$. The required effectiveness can be optionally calculated either in two ways. If the mass capacitance of the hot stream is 
Table 9 Friedmann test results for the compared algorithms

\begin{tabular}{|c|c|c|c|c|c|c|c|c|c|c|c|c|c|}
\hline \multicolumn{14}{|c|}{ CM05 versus the metaheuristic algorithm $a=0.05$} \\
\hline Functions & CM01 & CMO2 & CM03 & CM04 & CM06 & CM07 & CM08 & CM09 & CM10 & MRFO & $\mathrm{BMO}$ & $\mathrm{HHO}$ & SGULL \\
\hline$f_{1}$ & 0.061 & 0.042 & 0.078 & 0.055 & 0.052 & 0.045 & 0.060 & 0.051 & 0.047 & 0.042 & 0.065 & 0.035 & 0.002 \\
\hline$f_{2}$ & 0.008 & 0.007 & 0.022 & 0.012 & 0.009 & 0.011 & 0.011 & 0.026 & 0.005 & 0.004 & 0.006 & 0.006 & 0.008 \\
\hline$f_{3}$ & 0.004 & 0.004 & 0.003 & 0.005 & 0.006 & 0.006 & 0.008 & 0.001 & 0.004 & 0.008 & 0.050 & 0.050 & 0.009 \\
\hline$f_{4}$ & 0.002 & 0.006 & 0.005 & 0.004 & 0.002 & 0.001 & 0.006 & 0.004 & 0.002 & 0.003 & 0.050 & 0.007 & 0.006 \\
\hline$f_{5}$ & 0.003 & 0.004 & 0.003 & 0.004 & 0.004 & 0.002 & 0.005 & 0.005 & 0.004 & 0.002 & 0.008 & 0.004 & 0.005 \\
\hline$f_{6}$ & 0.011 & 0.009 & 0.007 & 0.012 & 0.008 & 0.006 & 0.008 & 0.008 & 0.009 & 0.006 & 0.014 & 0.008 & 0.009 \\
\hline$f_{7}$ & 0.053 & 0.072 & 0.064 & 0.058 & 0.052 & 0.067 & 0.054 & 0.056 & 0.067 & 0.060 & 0.051 & 0.006 & 0.012 \\
\hline$f_{8}$ & 0.052 & 0.051 & 0.047 & 0.049 & 0.055 & 0.057 & 0.064 & 0.062 & 0.065 & 0.058 & 0.054 & 0.054 & 0.002 \\
\hline$f_{9}$ & 0.008 & 0.004 & 0.005 & 0.005 & 0.003 & 0.002 & 0.006 & 0.014 & 0.008 & 0.005 & 0.020 & 0.028 & 0.004 \\
\hline$f_{10}$ & 0.072 & 0.064 & 0.058 & 0.052 & 0.062 & 0.067 & 0.069 & 0.081 & 0.074 & 0.074 & 0.058 & 0.056 & 0.052 \\
\hline$f_{11}$ & 0.008 & 0.012 & 0.011 & 0.009 & 0.007 & 0.008 & 0.009 & 0.050 & 0.010 & 0.014 & 0.011 & 0.002 & 0.004 \\
\hline$f_{12}$ & 0.010 & 0.008 & 0.005 & 0.007 & 0.004 & 0.008 & 0.002 & 0.005 & 0.009 & 0.010 & 0.014 & 0.007 & 0.005 \\
\hline$f_{13}$ & 0.014 & 0.002 & 0.008 & 0.008 & 0.009 & 0.009 & 0.006 & 0.015 & 0.007 & 0.009 & 0.004 & 0.008 & 0.001 \\
\hline$f_{14}$ & 0.008 & 0.007 & 0.007 & 0.009 & 0.012 & 0.016 & 0.008 & 0.008 & 0.015 & 0.011 & 0.007 & 0.009 & 0.016 \\
\hline$f_{15}$ & 0.005 & 0.008 & 0.006 & 0.015 & 0.014 & 0.011 & 0.017 & 0.009 & 0.008 & 0.008 & 0.012 & 0.018 & 0.017 \\
\hline$f_{16}$ & 0.047 & 0.059 & 0.057 & 0.053 & 0.058 & 0.051 & 0.072 & 0.064 & 0.063 & 0.062 & 0.057 & 0.060 & 0.014 \\
\hline$f_{17}$ & 0.045 & 0.045 & 0.048 & 0.047 & 0.048 & 0.049 & 0.043 & 0.041 & 0.048 & 0.047 & N/A & $\mathrm{N} / \mathrm{A}$ & 0.047 \\
\hline$f_{18}$ & 0.035 & 0.037 & 0.034 & 0.032 & 0.031 & 0.030 & 0.037 & 0.034 & 0.042 & 0.040 & 0.039 & 0.037 & 0.038 \\
\hline$f_{19}$ & 0.030 & 0.027 & 0.074 & 0.035 & 0.031 & 0.028 & 0.041 & 0.037 & 0.048 & 0.042 & 0.062 & 0.035 & 0.003 \\
\hline$f_{20}$ & 0.004 & 0.008 & 0.006 & 0.006 & 0.007 & 0.009 & 0.006 & 0.010 & 0.008 & 0.005 & 0.005 & 0.009 & 0.008 \\
\hline$f_{21}$ & 0.010 & 0.015 & 0.009 & 0.009 & 0.007 & 0.008 & 0.006 & 0.007 & 0.005 & 0.009 & 0.008 & 0.012 & 0.010 \\
\hline$f_{22}$ & 0.055 & 0.058 & 0.063 & 0.062 & 0.057 & 0.059 & 0.062 & 0.052 & 0.056 & 0.059 & 0.062 & 0.053 & 0.081 \\
\hline$f_{23}$ & 0.015 & 0.022 & 0.014 & 0.018 & 0.028 & 0.021 & 0.015 & 0.002 & 0.010 & 0.014 & 0.005 & 0.006 & 0.001 \\
\hline$f_{24}$ & 0.048 & 0.052 & 0.047 & 0.053 & 0.054 & 0.062 & 0.058 & 0.060 & 0.057 & 0.055 & 0.052 & 0.042 & 0.012 \\
\hline$f_{25}$ & 0.015 & 0.021 & 0.008 & 0.018 & 0.017 & 0.026 & 0.021 & 0.034 & 0.025 & 0.027 & $\mathrm{~N} / \mathrm{A}$ & 0.006 & 0.022 \\
\hline$f_{26}$ & 0.010 & 0.018 & 0.014 & 0.014 & 0.012 & 0.011 & 0.009 & 0.016 & 0.015 & 0.017 & 0.024 & 0.013 & 0.011 \\
\hline$f_{27}$ & 0.015 & 0.018 & 0.012 & 0.011 & 0.022 & 0.021 & 0.017 & 0.012 & 0.026 & 0.024 & 0.018 & 0.15 & 0.014 \\
\hline$f_{28}$ & 0.052 & 0.068 & 0.072 & 0.056 & 0.054 & 0.057 & 0.061 & 0.105 & 0.065 & 0.069 & 0.094 & 0.092 & 0.053 \\
\hline$f_{29}$ & 0.015 & 0.011 & 0.034 & 0.025 & 0.016 & 0.019 & 0.021 & 0.005 & 0.019 & 0.026 & 0.045 & 0.041 & 0.022 \\
\hline$f_{30}$ & 0.014 & 0.012 & 0.041 & 0.018 & 0.026 & 0.024 & 0.018 & 0.041 & 0.016 & 0.011 & 0.042 & 0.039 & 0.032 \\
\hline$f_{31}$ & 0.015 & 0.018 & 0.043 & 0.024 & 0.017 & 0.016 & 0.030 & 0.045 & 0.028 & 0.024 & 0.037 & 0.037 & 0.021 \\
\hline$f_{32}$ & 0.021 & 0.011 & 0.045 & 0.017 & 0.022 & 0.025 & 0.021 & 0.042 & 0.017 & 0.024 & 0.039 & 0.045 & 0.034 \\
\hline$f_{33}$ & 0.012 & 0.017 & 0.055 & 0.009 & 0.021 & 0.019 & 0.026 & 0.062 & 0.027 & 0.016 & 0.056 & 0.051 & 0.017 \\
\hline$f_{34}$ & $\mathrm{~N} / \mathrm{A}$ & $\mathrm{N} / \mathrm{A}$ & $\mathrm{N} / \mathrm{A}$ & $\mathrm{N} / \mathrm{A}$ & $\mathrm{N} / \mathrm{A}$ & $\mathrm{N} / \mathrm{A}$ & $\mathrm{N} / \mathrm{A}$ & $\mathrm{N} / \mathrm{A}$ & $\mathrm{N} / \mathrm{A}$ & $\mathrm{N} / \mathrm{A}$ & $\mathrm{N} / \mathrm{A}$ & $\mathrm{N} / \mathrm{A}$ & N/A \\
\hline$f_{35}$ & 0.012 & 0.017 & 0.009 & 0.014 & 0.018 & 0.008 & 0.020 & 0.014 & 0.011 & 0.008 & 0.015 & 0.014 & 0.022 \\
\hline$f_{36}$ & 0.041 & 0.039 & 0.002 & 0.028 & 0.025 & 0.027 & 0.035 & 0.031 & 0.035 & 0.032 & 0.033 & 0.042 & 0.005 \\
\hline$f_{37}$ & 0.012 & 0.011 & 0.024 & 0.028 & 0.034 & 0.020 & 0.014 & 0.016 & 0.025 & 0.021 & 0.028 & 0.017 & 0.004 \\
\hline$f_{38}$ & 0.011 & 0.008 & 0.035 & 0.015 & 0.012 & 0.009 & 0.021 & 0.038 & 0.017 & 0.019 & 0.042 & 0.043 & 0.015 \\
\hline$f_{39}$ & 0.032 & 0.028 & 0.072 & 0.022 & 0.053 & 0.052 & 0.030 & 0.065 & 0.042 & 0.039 & 0.058 & 0.055 & 0.034 \\
\hline$f_{40}$ & 0.048 & 0.047 & 0.044 & 0.043 & 0.053 & 0.042 & 0.058 & 0.041 & 0.038 & 0.025 & 0.052 & 0.051 & 0.026 \\
\hline
\end{tabular}

lower than that of cold stream, then the required effectiveness is obtained by the following equation

$\varepsilon_{\text {req }}=\frac{T_{\text {in }}-T_{\text {out }}}{T_{\text {in }}-t_{\text {in }}}$
On the contrary, if the mass capacitance of the hot stream is higher than that of the cold stream, the required effectiveness is calculated by

$\varepsilon_{\text {req }}=\frac{t_{\text {out }}-t_{\text {in }}}{T_{\text {in }}-t_{\text {in }}}$ 

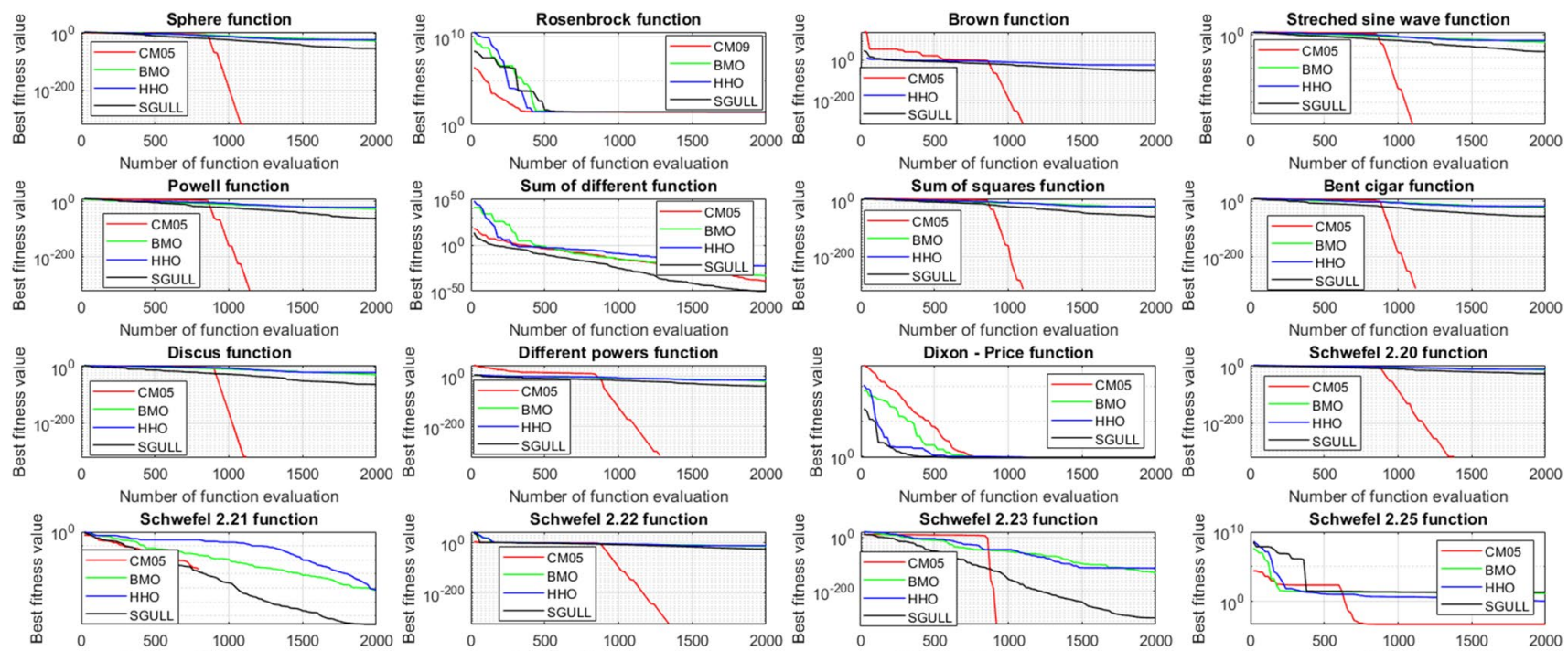

Number of function evaluation

Number of function evaluation

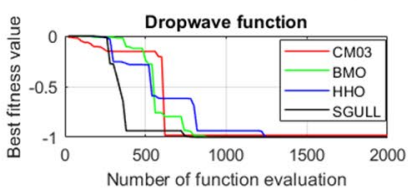

Fig. 10 Comparison of the convergence performances between the best performing chaotic variants and literature optimizers for unimodal test functions
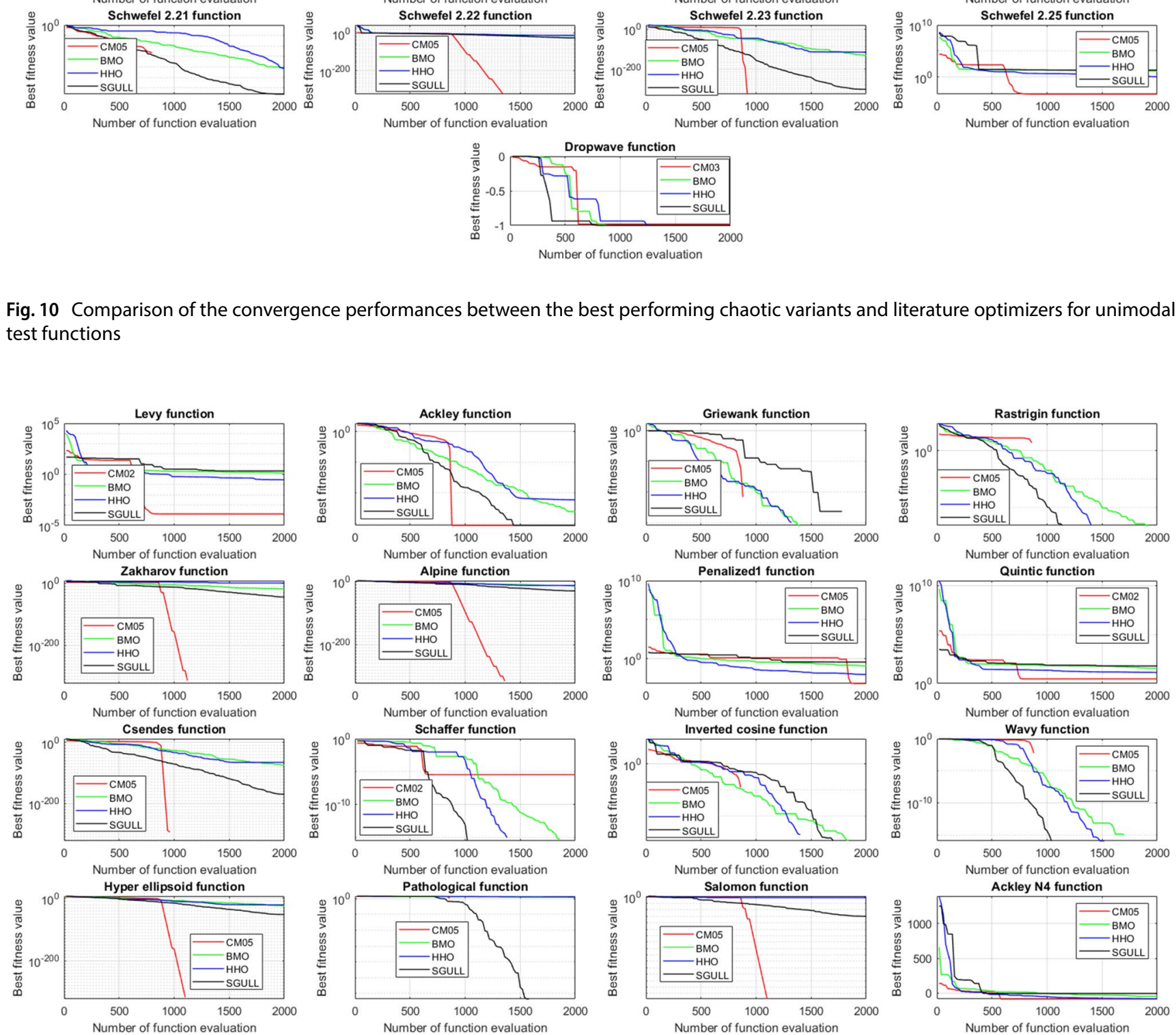

Fig. 11 Convergence histories of the best performing chaotic algorithms and literature optimizers for multimodal test functions 
Table 10 Statistical results for CEC2017 benchmark problems

\begin{tabular}{|c|c|c|c|c|c|c|c|}
\hline$F$ & Measure & EBO with CMAR [66] & jSO [67] & MRFO & CM05 & CM03 & CM09 \\
\hline \multirow[t]{2}{*}{$F 1$} & Mean & $0.00 \mathrm{E}+00$ & $0.000 \mathrm{E}+00$ & $6.862 E-29$ & $0.000 E+00$ & $0.000 E+00$ & $0.000 \mathrm{E}+00$ \\
\hline & STD & $0.00 \mathrm{E}+00$ & $0.000 \mathrm{E}+00$ & $3.963 \mathrm{E}-32$ & $0.000 \mathrm{E}+00$ & $0.000 \mathrm{E}+00$ & $0.000 \mathrm{E}+00$ \\
\hline \multirow[t]{2}{*}{$F 2$} & Mean & $0.00 \mathrm{E}+00$ & $0.000 E+00$ & $1.132 \mathrm{E}-25$ & $0.000 E+00$ & $0.000 E+00$ & $0.000 \mathrm{E}+00$ \\
\hline & STD & $0.00 E+00$ & $0.000 E+00$ & $2.764 \mathrm{E}-27$ & $0.000 E+00$ & $0.000 E+00$ & $0.000 \mathrm{E}+00$ \\
\hline \multirow[t]{2}{*}{ F3 } & Mean & $0.00 E+00$ & $0.000 E+00$ & $3.741 E+05$ & $1.248 \mathrm{E}+00$ & $2.573 E+00$ & $1.395 E+00$ \\
\hline & STD & $0.00 \mathrm{E}+00$ & $0.000 E+00$ & $2.648 \mathrm{E}+04$ & $2.785 \mathrm{E}-01$ & $3.852 \mathrm{E}-01$ & $4.843 \mathrm{E}-01$ \\
\hline \multirow[t]{2}{*}{$F 4$} & Mean & $5.65 E+01$ & $5.8670 \mathrm{E}+01$ & $1.617 E+02$ & $7.852 \mathrm{E}+01$ & $6.749 E+01$ & $6.012 \mathrm{E}+01$ \\
\hline & STD & $1.11 \mathrm{E}+01$ & 7.7797E-01 & $1.108 \mathrm{E}+01$ & $2.457 \mathrm{E}+01$ & $1.747 \mathrm{E}+01$ & $1.927 \mathrm{E}+01$ \\
\hline \multirow[t]{2}{*}{ F5 } & Mean & $2.78 \mathrm{E}+00$ & $8.5568 \mathrm{E}+00$ & $2.837 E+01$ & $1.765 E+01$ & $1.368 \mathrm{E}+01$ & $1.128 \mathrm{E}+01$ \\
\hline & STD & $1.74 \mathrm{E}+00$ & $2.0980 \mathrm{E}+00$ & $1.764 \mathrm{E}+01$ & $9.538 \mathrm{E}+00$ & $8.635 E+00$ & $7.532 E+00$ \\
\hline \multirow[t]{2}{*}{ F6 } & Mean & $0.00 \mathrm{E}+00$ & $6.0385 \mathrm{E}-09$ & $\mathrm{~N} / \mathrm{A}$ & $0.000 \mathrm{E}+00$ & $0.000 \mathrm{E}+00$ & $0.000 \mathrm{E}+00$ \\
\hline & STD & $0.00 \mathrm{E}+00$ & $2.7122 \mathrm{E}-08$ & $\mathrm{~N} / \mathrm{A}$ & $0.000 \mathrm{E}+00$ & $0.000 \mathrm{E}+00$ & $0.000 \mathrm{E}+00$ \\
\hline \multirow[t]{2}{*}{ F7 } & Mean & $3.35 \mathrm{E}+01$ & $3.8927 \mathrm{E}+01$ & $2.279 \mathrm{E}+03$ & $4.892 \mathrm{E}+01$ & $3.789 \mathrm{E}+01$ & $5.195 E+01$ \\
\hline & STD & $8.37 \mathrm{E}-01$ & $1.4594 \mathrm{E}+00$ & $1.837 E+03$ & $2.594 \mathrm{E}+00$ & $7.161 E+00$ & $1.645 \mathrm{E}+01$ \\
\hline \multirow[t]{2}{*}{ F8 } & Mean & $2.02 \mathrm{E}+00$ & $9.0918 \mathrm{E}+00$ & $1.278 \mathrm{E}+01$ & $1.076 \mathrm{E}+01$ & $1.867 E+01$ & $1.117 \mathrm{E}+01$ \\
\hline & STD & 1.32 & 1.83 & $2.569 E+00$ & $2.743 \mathrm{E}-01$ & $2.947 E+00$ & $9.362 \mathrm{E}-01$ \\
\hline \multirow[t]{2}{*}{ F9 } & Mean & $0.00 \mathrm{E}+00$ & $0.000 E+00$ & $1.879 E+01$ & $7.639 E-05$ & $9.153 \mathrm{E}-09$ & $6.398 \mathrm{E}-10$ \\
\hline & STD & $0.00 E+00$ & $0.000 E+00$ & $7.635 E+00$ & $8.528 \mathrm{E}-06$ & $8.592 \mathrm{E}-11$ & $7.729 E-15$ \\
\hline \multirow[t]{2}{*}{ F10 } & Mean & $1.41 E+03$ & 1.5277E + 03 & $1.086 \mathrm{E}+05$ & $2.794 \mathrm{E}+04$ & $9.821 \mathrm{E}+03$ & $7.762 E+03$ \\
\hline & STD & $2.15 E+02$ & $2.7716 \mathrm{E}+02$ & $2.932 E+04$ & $3.176 \mathrm{E}+03$ & $1.694 \mathrm{E}+03$ & $2.481 E+01$ \\
\hline \multirow[t]{2}{*}{$F 11$} & Mean & $4.49 E+00$ & $3.0375 E+00$ & $1.796 \mathrm{E}+01$ & $2.751 E+00$ & $2.845 E+00$ & $5.082 \mathrm{E}+00$ \\
\hline & STD & $8.88 \mathrm{E}+00$ & $2.6464 \mathrm{E}+00$ & $2.890 E+00$ & $1.823 \mathrm{E}+00$ & $1.702 \mathrm{E}+00$ & $4.565 E+00$ \\
\hline \multirow[t]{2}{*}{$F 12$} & Mean & $4.63 E+02$ & $1.7038 \mathrm{E}+02$ & $5.684 \mathrm{E}+02$ & $4.914 \mathrm{E}+02$ & $7.731 E+02$ & $1.653 E+03$ \\
\hline & STD & $2.63 E+02$ & $1.0194 \mathrm{E}+02$ & $8.938 \mathrm{E}+01$ & $1.703 E+02$ & $1.895 E+02$ & $2.991 E+02$ \\
\hline \multirow[t]{2}{*}{$F 13$} & Mean & $1.49 \mathrm{E}+01$ & $1.4840 \mathrm{E}+01$ & $1.516 E+05$ & $2.884 \mathrm{E}+02$ & $7.652 E+01$ & $9.759 E+02$ \\
\hline & STD & $6.25 \mathrm{E}+00$ & $4.8312 \mathrm{E}+00$ & $2.856 \mathrm{E}+04$ & $1.561 \mathrm{E}+01$ & $2.579 E+01$ & $5.601 \mathrm{E}+01$ \\
\hline \multirow[t]{2}{*}{ F14 } & Mean & $2.19 \mathrm{E}+01$ & $2.1834 \mathrm{E}+01$ & $4.480 E+01$ & $3.108 \mathrm{E}+01$ & $2.995 E+01$ & $2.653 \mathrm{E}+01$ \\
\hline & STD & $3.84 \mathrm{E}+00$ & $1.2458 \mathrm{E}+00$ & $7.653 E+00$ & $2.792 E+00$ & $4.732 \mathrm{E}+00$ & $1.702 \mathrm{E}+00$ \\
\hline \multirow[t]{2}{*}{$F 15$} & Mean & $3.69 E+00$ & $1.0879 \mathrm{E}+00$ & $5.685 E+01$ & $9.785 E+00$ & $1.175 E+01$ & $1.036 \mathrm{E}+01$ \\
\hline & STD & $2.15 E+00$ & $6.9133 \mathrm{E}-01$ & $1.647 E+01$ & $3.676 \mathrm{E}+00$ & $3.163 E+00$ & $4.572 \mathrm{E}+00$ \\
\hline \multirow[t]{2}{*}{ F16 } & Mean & $4.26 \mathrm{E}+01$ & $7.8923 \mathrm{E}+01$ & $3.765 E+02$ & $8.802 \mathrm{E}+01$ & $9.754 \mathrm{E}+01$ & $1.113 E+02$ \\
\hline & STD & $5.69 E+01$ & $8.4769 E+01$ & $1.649 E+01$ & $7.937 E+01$ & $4.852 \mathrm{E}+01$ & $2.763 E+01$ \\
\hline
\end{tabular}

Fig. 12 Schematic representation of the (a) Forced draft air coolers (b) Induced air draft coolers

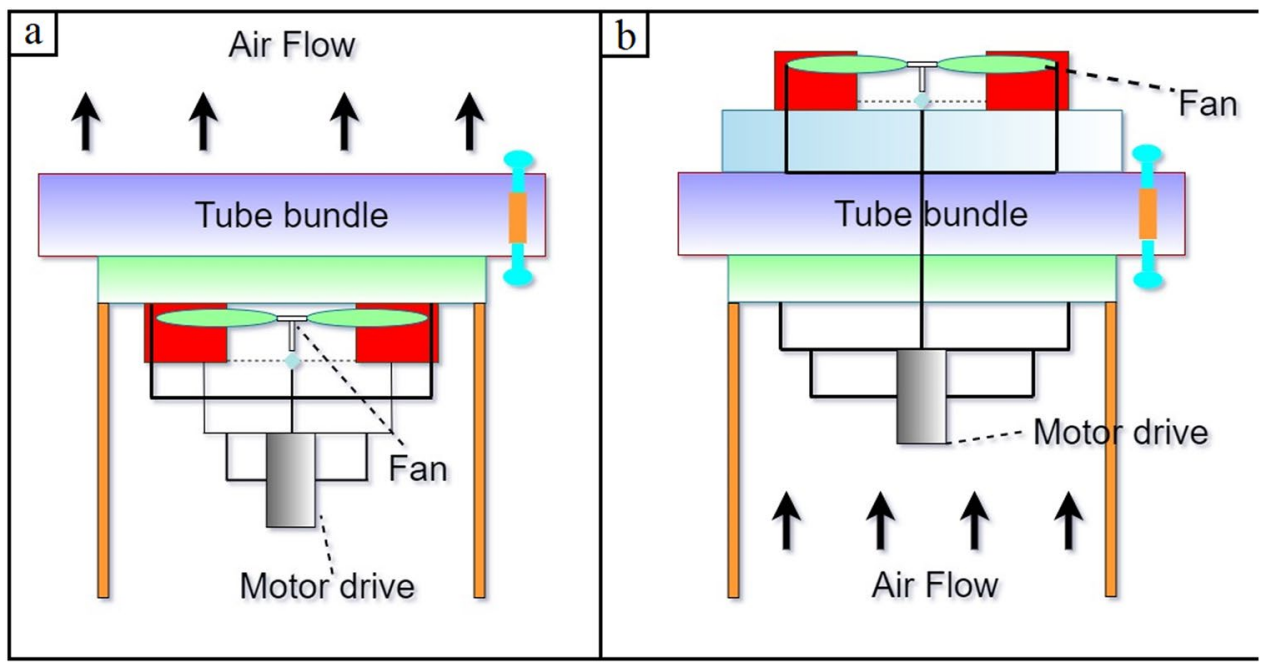


where $T_{\text {in }}$ and $T_{\text {out }}$ are respectively inlet and outlet temperatures of the hot stream while $t_{\text {in }}$ and $t_{\text {out }}$ correspondingly stand for inlet and outlet temperatures for the cold stream. Tubes in the bundle can be arranged in equilateral or staggered order. Keeping in mind that pitch arrangements across the tubes are designated by transverse pitch $P_{t}$ longitudinal pitch $P_{l}$ or diagonal pitch $P_{d}$. Diagonal pitch $P_{d}$ is the function of transverse pitch $P_{t}$ and longitudinal pitch $P_{l}$ and can be mathematically expressed by the following simple formulation

$P_{d}=\sqrt{\left[\left(\frac{P_{t}}{2}\right)^{2}+P_{t}^{2}\right]}$

Figure 13 shows the respective (a) staggered and (b) in-line tube arrangements. The total number of tubes in the bank $N$ is the multiplication of $n$ tubes in a row and $n_{r}$ tube rows. Height of the mounted fins on the tubes is computed by

$b=\frac{d_{a}-d_{b}}{2}$

where $d_{a}$ and $d_{b}$ are respectively outer and inner diameters of the fins with $\delta$ thickness. The length of the tubes in the bundle is symbolized by the $L$ parameter whose clear space between each tube is represented by the $z$ parameter. Minimum flow area $\left(A_{\min }\right)$ between tubes is a direct function of transverse pitch $P_{t}$ and can be calculated by the following procedure
If $P_{t}>\left(2 P_{d}-d_{b}-\frac{2 z \delta}{z+\delta}\right)$

$A_{\text {min }}=n L\left(P_{t}-d_{b}-\frac{2 z \delta}{z+\delta}\right)$

else if $P_{t}<\left(2 P_{d}-d_{b}-\frac{2 z \delta}{z+\delta}\right)$

$A_{\min }=2 n L\left(P_{d}-d_{b}-\frac{2 z \delta}{z+\delta}\right)$

end

The total surface area of the tubes between the fins can be calculated by

$A_{\text {tube }}=\frac{\pi N L d_{b} z}{z+\delta}$

Total heat exchange area of the fins including the tip surfaces through which heat exchange takes place is computed by the following expression

$A_{\text {fin }}=\frac{\pi \mathrm{NL}}{z+\delta}\left[0.5\left(d_{a}^{2}-d_{b}^{2}\right)+d_{a} \delta\right]$

Total heat exchange area becomes the summation of finned and bare tube area, which is expressed by

$A_{\mathrm{HE}}=A_{\text {fin }}+A_{\text {tube }}$

Convective heat transfer from tube bundles containing high fins to the process air is calculated by the correlation developed by the Briggs and Youngs [68]

$\mathrm{Nu}=\frac{h_{\text {air }} \times d_{b}}{k_{\text {air }}}=0.134 \operatorname{Re}^{0.681} \stackrel{0.333}{\operatorname{Pr}}\left[\frac{2\left(P_{f}-\delta\right)}{d_{a}-d_{b}}\right]^{0.2}\left(\frac{P_{f}-\delta}{\delta}\right)^{0.1134}$

where $R e$ is the airside Reynolds number calculated by
Fig. 13 Tube arrangements for air-fin coolers: a) Staggered tube arrangement b) In-line tube arrangement

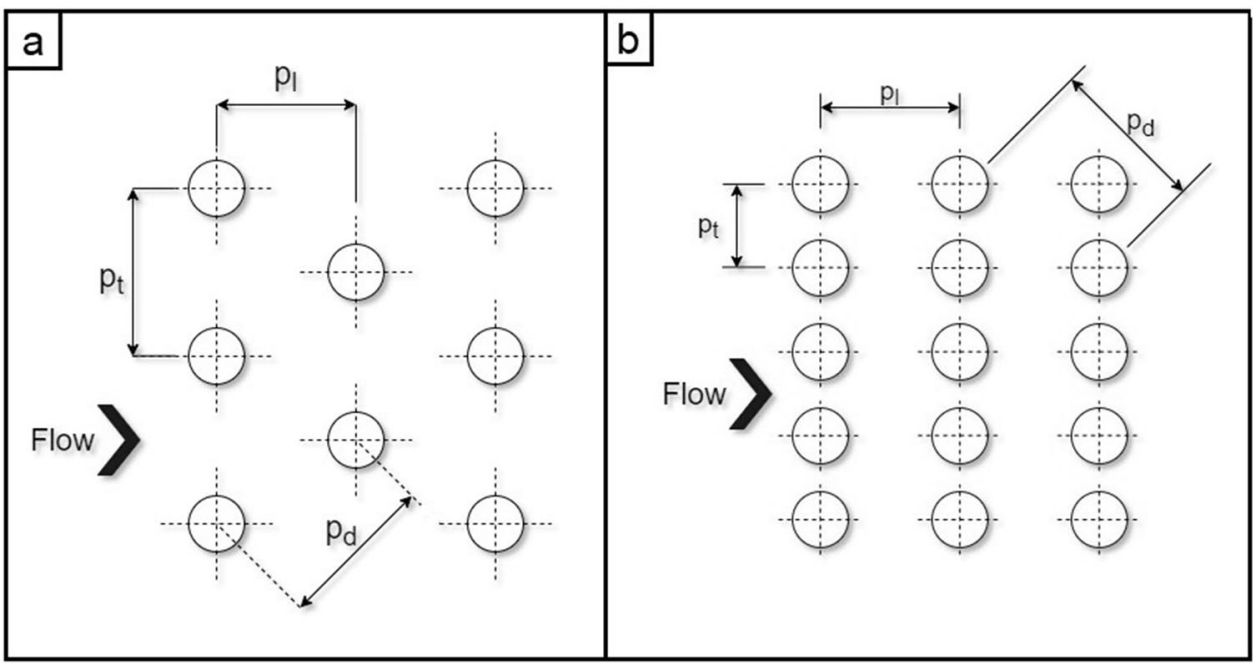

SN Applied Sciences 
$\operatorname{Re}=\frac{G_{\text {air }} \cdot d_{b}}{\mu_{\text {air }}}$

where $G_{\text {air }}$ is the mass velocity of the process air flowing over the fins and $\mu_{\text {air }}$ is the viscosity of the process air. Amount of pressure loss occurring between the staggered tube bundle is calculated by the correlation developed by Robinson and Briggs [68]

$\Delta P_{\text {air }}=18.03 \frac{G_{\text {air }}^{2}}{\rho_{\text {air }}} n_{r} \operatorname{Re}^{-0.316}\left(\frac{P_{t}}{d_{b}}\right)^{-0.927}\left(\frac{P_{t}}{P_{d}}\right)^{0.515}$

where $\rho_{\text {air }}$ is the density of the process air. For calculating the amount of tube side convective heat transfer rate, Gnielinski correlation [69] is utilized

$\mathrm{Nu}=\frac{h_{\text {tube }} \cdot d_{\text {in }}}{k}=\frac{\left(f_{\text {tube }} / 8\right)\left(\mathrm{Re}_{\text {tube }}-1000\right) \operatorname{Pr}_{\text {tube }}}{1.00+12.7 \sqrt{\left(f_{\text {tube }} / 8\right)}\left(\operatorname{Pr}_{\text {tube }}^{2 / 3}-1\right)}$

where $h_{\text {tube }}$ is the tube side convective heat transfer coefficient; $d_{i n}$ is the inner diameter of the tube; $k$ is the heat conductivity of the running in-tube fluid; $R e_{\text {tube }}$ and $P r_{\text {tube }}$ are correspondingly tube side dimensionless Reynolds and Prandtl numbers, and $f_{\text {tube }}$ is the friction factor calculated by the following expression

$f_{\text {tube }}=\frac{1}{\left(1.82 \log _{10} R e_{\text {tube }}-1.64\right)^{2}}$

And tube side pressure drop is calculated by the following equation

$\Delta P_{\text {tube }}=\frac{4 f_{\text {tube }} G_{\text {tube }}^{2}}{2 \rho} \frac{L}{d_{i}}$

For calculating the overall heat transfer coefficient between the cold and hot side streams, all different types of heat transfer resistances should be taken into account to obtain the most accurate heat transfer rates. Five different heat resistances are described and formulated as follows.

(a) Inside film resistance

$r_{f i}=\frac{1}{h_{\text {tube }}} \frac{d_{b}}{d_{i}}$

(b) Inside fouling resistance

$r_{\text {dio }}=r_{d i} \frac{d_{b}}{d_{i}}$

(c) Tube metal resistance is a function of liner diameter and tube thickness which is calculated by the following $\delta_{t h}=\frac{d_{o}-d_{i}}{2}$

and liner metal resistance is computed by

$r_{m i}=\frac{\delta_{\text {thi }}}{k_{\text {tube }}} \frac{2 d_{b}}{d_{o}+d_{i}}$

(d) Bond resistance

$r_{B d}=r_{b} \frac{d_{b}}{d_{g}}$

(e) Outer tube metal thickness is based on mean outer tube diameter and metal thickness

$r_{\text {mo }}=\frac{\delta_{\text {tho }}}{k_{\text {tube }}} \frac{2 d_{b}}{d_{b}+d_{g}}$

Figure 14 illustrates five different diameter designations to visually explain the five different inside resistances. With taking into account of all these resistances, the total resistance is summed up by the following expression

$\sum R_{\text {sum }}=r_{\mathrm{fi}}+r_{\text {dio }}+r_{\text {mi }}+r_{\text {Bd }}+r_{\text {mo }}$

It should be reminded that total resistance is based on the equivalent bare outside tube surface. So, the modified total resistance as a function of a gross outside surface can be calculated by the following

$\sum R_{\text {sum, mod }}=\sum R_{\text {sum }} \frac{A_{\mathrm{HE}}}{\mathrm{NL} \pi d_{b}}$

Outer resistance $\left(r_{\text {out }}\right)$ based on convective heat transfer is formed by airside convective heat transfer coefficient expressed by Eq. (20) and the modified fin efficiency

$r_{\text {out }}=\frac{1}{h_{\text {air }} \eta_{o}}$

where $\eta_{o}$ is the weighted fin efficiency and calculated by

$\eta_{o}=1-\frac{A_{\text {fin }}}{A_{\mathrm{HE}}}(1-\eta)$

where $\eta$ is the fin efficiency and computed by

$\eta=\frac{\tanh (m \psi)}{m \psi}$

where $m$ is a parameter given by the below term

$m=\sqrt{\frac{2 h_{\text {air }}}{k_{\text {tube }} \delta_{\text {th,fin }}}}$ 
And $\psi$ is calculated by the following

$\psi=0.5 d_{b} \frac{1-\phi}{\phi}\left(1+0.35 \ln \left(\frac{1}{\phi}\right)\right)$

where the parameter $\phi$ is the ratio between $d_{b}$ and $d_{a^{\prime}}$ that is $\phi=d_{b} / d_{a}$. Based on the defined expression and numerical definitions above, the overall heat transfer coefficient is given by the following equation

$U_{o}=\frac{1}{\sum R_{\text {sum }, \text { mod }}+r_{\text {out }}}$

\subsection{Objective function definition}

Here in this optimization case study, the utmost aim is the find optimal decision variables of an air cooler that minimizes the overall cost of a heat exchanger under predefined imposed design constraints. The overall cost of a heat exchanger is formed by two different factors including capital and operating costs. The capital cost of a system includes the expenditures regarding material, manufacturing, installation, and shipping costs, etc. An

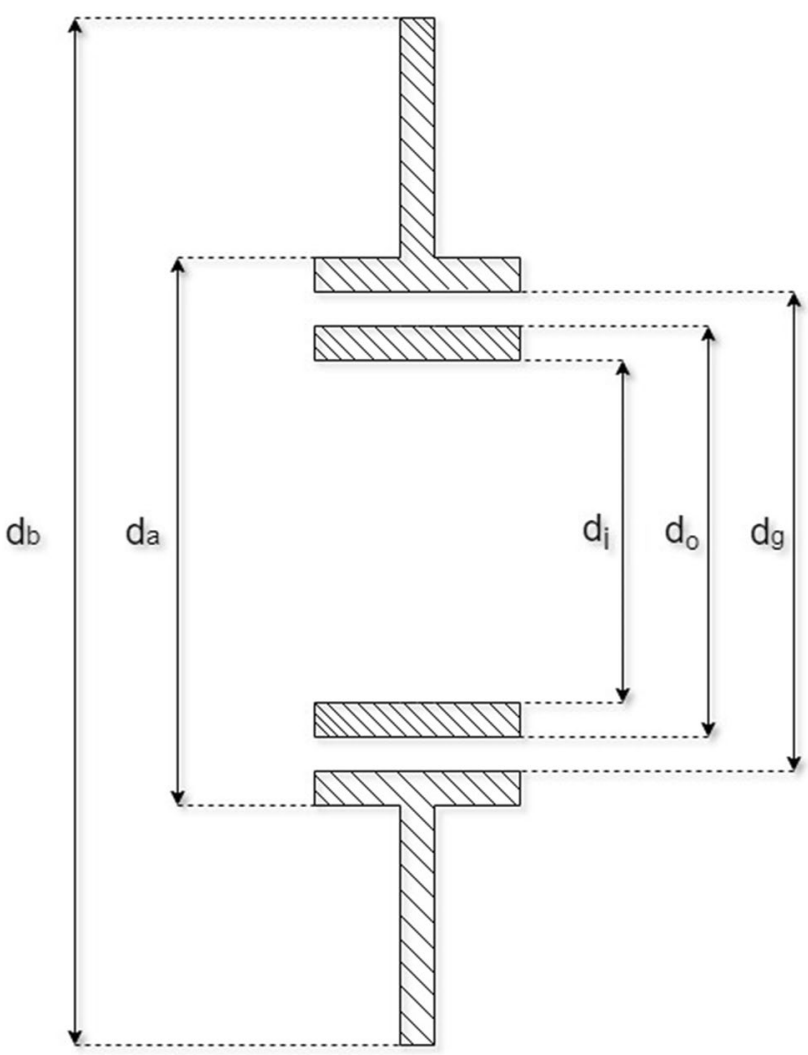

Fig. 14 Five diameter designations for the finned tube bundle insightful formulation that estimates the capital cost of air cooler can be given by [70]

$C_{\text {aircooler }}=30000\left(A_{H E} / 92.90304\right)^{0.4}$

where $A_{H E}$ is the total heat exchange surface in $\mathrm{m}^{2}$ and $C_{\text {aircooler }}$ is the capital cost in $\$$. The capital cost of the pump component is calculated the following correlated equation [71]

$C_{\text {pump }}=705.48 \cdot \dot{W}_{\text {pump }}^{0.71} \cdot\left(1+\frac{0.2}{1-\eta_{\text {pump }}}\right)$

where $C_{\text {pump }}$ is the capital cost of the pump in $\$ ; \dot{W}_{\text {pump }}$ is the pumping power calculated by the following equation

$\dot{W}_{\text {pump }}=\frac{1}{\eta_{\text {pump }}}\left(\frac{\dot{m}_{\text {cool }}}{\rho_{\text {cool }}} \Delta P_{\text {tube }}\right)$

where $\dot{m}_{\text {cool }}$ is the in-tube fluid is the flow rate in $\mathrm{kg} / \mathrm{s}$; $\rho_{\text {cool }}$ is the density of in-tube fluid; $\Delta P_{\text {tube }}$ is the pressure gradient in $\mathrm{Pa}$, and $\eta_{\text {pump }}$ is the pump efficiency which is considered as 0.8 . The capital cost of the fan equipment is computed by the correlation given below [70]

$C_{\text {fan }}=1218 \cdot f_{m} \cdot f_{p} \cdot \exp \left(a+b \ln \left(\dot{V}_{\text {air }}\right)+c\left(\ln \dot{V}_{\text {air }}\right)^{2}\right)$

where $\dot{V}_{\text {air }}$ is the volumetric flow rate of air in standard cubic feet per minute; $f_{m}$ and $f_{p}$ are respectively installation and pressure factors; numerical values of the correlation parameters $a, b$, and $c$ vary based upon the type of the running fan. A radial bladed fan is considered for this case study so corresponding values of the parameters $a, b$, and $c$ are respectively set to $0.4692,0.1203$, and 0.0931 . To determine the annual capital cost of the cooling system, the following equation is used

$C_{\text {annual,sys }}=\left(C_{\text {aircooler }}+C_{\text {pump }}+C_{\text {fan }}\right) \times C R F \times \varphi$

where $C R F$ and $\varphi$ are correspondingly cost recovery and maintenance factors. Cost recovery factor can be evaluated as a function of annual interest rate $i$ and depreciation time of the system $d t$ with using the below-defined equation

$C R F=\frac{i(i+1)^{d t}}{(i+1)^{d t}-1}$

This study aims the investigate the variational effects of the considered design variables including cooler height $(H)$, cooler length $(L)$, fin pitch $\left(P_{f}\right)$, tube pitch $\left(P_{t}\right)$, tube inner diameter $\left(d_{j}\right)$, tube outer diameter $\left(d_{o}\right)$, gap outside diameter $\left(d_{g}\right)$, fin inside diameter $\left(d_{b}\right)$ and fin outside diameter $\left(d_{a}\right)$, and fin thickness $(\delta)$ on the annual cost of an air fin cooler. 
Literature studies concerning design optimization of air fin coolers have some deficiencies while constructing the governing objective function. Theoretical investigations on air fin coolers made in some reference studies $[72,73]$ only take into account bare heat exchange without considering the influence of fin surfaces to optimize the total cost air fin cooler system. This kind of system evaluation may lead to inappropriate inferences regarding the optimal design as the fin surface plays a much important role even more than the bare heat exchange area on total investment cost rates. Furthermore, some research studies $[43,74]$ did not even consider the effects of electro fan prices as an investment cost, which is another misleading objective function formulation that may provide deceptive insights on overall cost rates as electric expenditures resulted from fan work shares plenty of portions of the total cost of the cooling system. Novelty proposed in this research study is incorporating the heat transfer resistances into overall heat transfer calculations. Nearly all case studies on air cooler design took place in the literature do not consider the heat transfer resistances occurred within gaps between fins and adjacent tube segments, which significantly affects the rate of heat transfer between flowing hot and cold streams. Equations 26, 27, $28,29,30,31$ explicitly explain the definitions and formulations of the governing heat transfer mechanisms behind the fin metal resistances. The objective function framework constructed for this research study considers all the abovementioned design aspects overlooked by the literature studies and proposes a more complex and reliable mathematical model that provides a feasible pathway to investigate the effects of each design variable on the problem objective.

\subsection{Design constraints}

The design problem is subjected to below-defined design constrained based on the structural limitations.

Fully developed turbulent flow conditions should be maintained inside the tubes, which can be realized if the intube Reynolds number is higher than 10,000

$\operatorname{Re}_{\text {tube }} \geq 10000$

Briggs and Young [68] correlation that models the convective heat transfer between the tube bundles with having high fin tubes and process air is applicable and yields reliable predictive results within the below-defined ranges

$1000<\mathrm{Re}_{\text {air }}<18000$

$11.13 \mathrm{~mm}<d_{b}<40.89 \mathrm{~mm}$

$2.84 \mathrm{~mm}<\left(d_{a}-d_{b}\right)<33.14 \mathrm{~mm}$

$0.30 \mathrm{~mm}<\delta<2.02 \mathrm{~mm}$

$24.99 \mathrm{~mm}<P_{t}<111 \mathrm{~mm}$

SN Applied Sciences

A SPRINGER NATURE journal
Optimized design variables should lie within the abovedefined ranges to ensure the accuracy and credibility of the utilized correlation. Robinson and Briggs [68] correlation used for estimating the pressure gradient along the air channels is applicable between the below-defined operation ranges

$2000<\operatorname{Re}_{\text {air }}<50000$

$18.64 \mathrm{~mm}<d_{b}<40.89 \mathrm{~mm}$

$39.68 \mathrm{~mm}<d_{a}<69.85 \mathrm{~mm}$

$42.85 \mathrm{~mm}<P_{t}<114.3 \mathrm{~mm}$

$1.5<P_{t} / d_{b}<4.6$

Pressure drop constraints for each side are given as

$\Delta P_{\text {tube }}<2000 \mathrm{~Pa}$

$\Delta P_{\text {air }}<200 \mathrm{~Pa}$

Actual available effectiveness of the air fin cooler should be higher than the below-defined value

$\varepsilon_{\text {avail }}>0.2874$

The above defined constrained complex design problem is converted into unconstrained optimization one by using static death penalty approach. A large valued penalty factor is added into the objective solution to convert infeasible solutions that violate the prescribed constraints into feasible ones. Due to its easy implementation on any kind of optimization problem, this method is considered for handling constraints in this research study. Formulate the optimization problem such that

Minimize $f(\vec{x})$

$\vec{x}=\{1,2, \ldots, D\}$

with subject to

$g_{i}(\vec{x}) \leq 0 i=1, \ldots, m$

$h_{i}(\vec{x})=0 i=m+1, \ldots, N_{\text {con }}$

where $m$ is the number of inequality constraints and $N_{\text {con }}$ stands for the total number of constraints.. Incorporating static penalty function into the defined optimization problem is a very efficient and practical method for avoding infeasible solutions in the search space. Main aim is to construct an easy-to-implement penalty function that takes into account number of prescribed problem constraints. Constrained optimization problem is converted into unconstrained problem by employing static penalty approach, as given in the below equation 


$$
\begin{aligned}
F(\vec{x})= & f(\vec{x})+\sum_{i=1}^{m} \operatorname{Pen}_{i} \max \left\{g_{i}(\vec{x}), 0\right\} \\
& +\sum_{i=m+1}^{N_{\text {con }}} \operatorname{Pen}_{i} \max \left\{h_{i}(\vec{x})-\delta, 0\right\}
\end{aligned}
$$

where $\mathrm{Pen}_{i}$ is the high valued penalty factor responsible for penalizing infeasible solutions and $\delta$ is a trial number very close to zero.

\section{Results and discussion}

\subsection{Model verification}

The proposed mathematical model describing the heat exchange mechanism occurring in an air fin cooler is compared with the heat transfer and pressure drop results obtained by Yu et al. [72]. Figure 15a shows the deviations between experimental heat transfer coefficients obtained for low fin tubes and estimations made by Briggs and Young [68] correlation for the same input parameters. It is observed experimental data agrees well with the predictive results such that maximum absolute error is no more than $12 \%$ which confirms the applicability of the proposed model. Figure 13b visualizes the estimated pressure drop values as a function of Reynolds number acquired by Robinson and Briggs correlation [68] and the experimental results of Yu et al. [75]. A good agreement is observed between the experimental data and model results as the maximum deviation error among the available data set is no more than $10.1 \%$. Outcomes of the comparative results shown in Fig. 15 verify that the proposed heat transfer model is accurate and reliable to be utilized for the objective function of the optimization problem.

\subsection{Case study}

Case study taken from Kraus et al. [68] is used as a design optimization problem solved by the best performing variant of the chaotic manta ray algorithm. The problem objective is to obtain the optimum heat exchanger design with a minimum total annual capital cost. Hot water flowing in the tube bundles with a mass flow rate of $46.5 \mathrm{~kg} / \mathrm{s}$ enters the air fin cooler at $92{ }^{\circ} \mathrm{C}$ and leaves the system at $76{ }^{\circ} \mathrm{C}$. Process air with an initial temperature of $5.0^{\circ} \mathrm{C}$ passes over the tubes at a flow rate of $124 \mathrm{~kg} / \mathrm{s}$ and cools the hot water to some degree. Allowable pressure drop values for hot and cold sides are respectively set to $2000 \mathrm{~Pa}$ and $200 \mathrm{~Pa}$ as mentioned in Eq. (49). Air cooler considers muff-type tubes with equilateral triangular pitch configuration. Thermal conductivities of liner and tubes are correspondingly 200.0 and $385.0 \mathrm{~W} / \mathrm{m}$.K. Table 11 reports the thermo-physical properties of the running fluids at bulk temperatures. Model parameters of depreciation time are considered $d t=15$, annual interest rate $i=0.14$, and maintenance factor $\varphi=1.06$. Table 12 provides the upper and lower bounds of the design variables to be optimized.

\subsection{Optimization results}

Optimization capabilities of the proposed chaotic MRFO variants will be assessed by comparing their prediction performances in attaining the minimum annualized capital cost of an air fin cooler. Table 13 reports the optimum design parameters obtained by the literature metaheuristic method of Coyote Optimization Algorithm (COYOTE) [76] and different chaotic variants along with the preliminary results of the considered case study retained from Kraus et al. [68]. One can easily see that the chaotic Kent map-based Manta-Ray algorithm (CM05) provides the minimum objective function value of $35889.14613 \$$ and outperforms the compared variants in terms of solution efficiency. Therefore, comparative evaluations between the preliminary results will be founded on optimum results found by this Kent map-based chaotic algorithm CM05. A significant decline (19.6\%) in annualized capital cost values compared to preliminary results is evident in this case. This is because of the sharp decreases in an air cooler (30.0\%) and pump (55.8\%) cost rates. Fan cost expenditure is not varied by the optimization algorithms since it is a direct function of the airflow rate as modeled in Eq. (43) which is not considered as a design variable to be optimized for this case study. As can be seen from Eq. (40), the air cooler cost is directly linked with the total heat exchange area. At the specific heat load and the temperature difference between two heat exchanging streams, it is known that the overall heat transfer coefficient is inversely proportional to the total heat transfer area of a heat exchanger. Therefore, a drastic increase $(77.3 \%)$ observed in overall heat transfer rates leads to a marked decrease in the total heat exchange area which entails a significant decline in the air cooler cost rates. Many structural design factors influence the numerical value of the overall heat transfer coefficient of a heat exchanger as suggested in Eq. (33). Heat transfer resistances play an important role in heat exchanger design; however, the majority of the literature approaches do not consider these design parameters in their proposed mathematical models and the variational influences of these different types of heat transfer resistances on the selected design objectives have not been clearly identified yet. The heat transfer model dealt with in this study explains the effect of heat resistances on overall heat transfer coefficient rates, particularly described in Eqs. (32)-(33). Proposed chaotic algorithms iteratively adjust the commanding design parameters related to fin 
Fig. 15 Comparison between the predictions obtained by heat transfer and pressure drop correlations and the actual experimental data

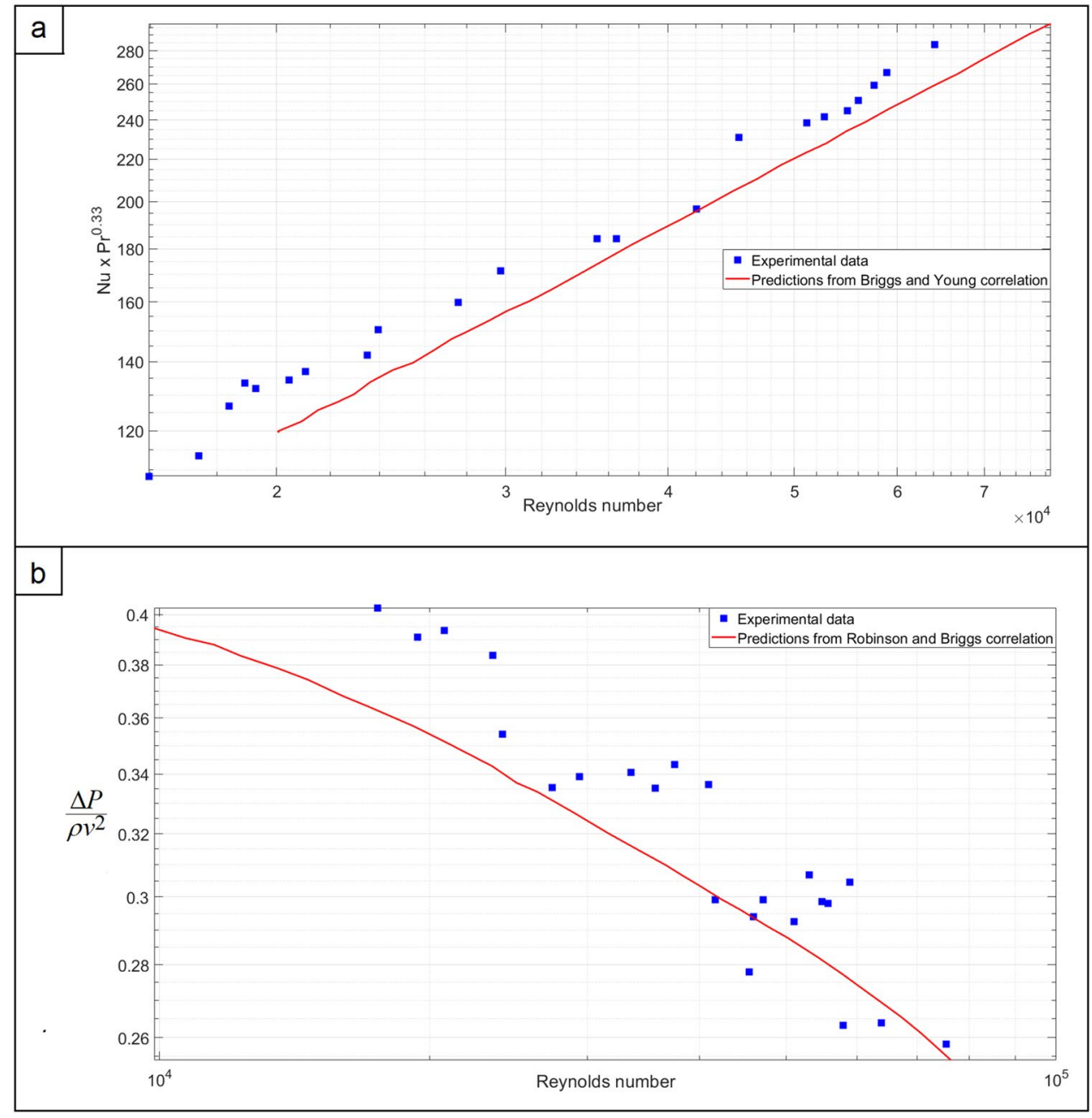

Table 11 Thermophysical properties of the running fluids at bulk temperatures

\begin{tabular}{lll}
\hline Property & In tube fluid: hot water & $\begin{array}{l}\text { Outside tube: } \\
\text { cold process } \\
\text { air }\end{array}$ \\
\hline$\mu(\mathrm{kg} \cdot \mathrm{m} / \mathrm{s})$ & $3.35 \mathrm{E}-4$ & $1.79 \mathrm{E}-5$ \\
$k(\mathrm{~W} / \mathrm{m} \cdot \mathrm{K})$ & 0.672 & 0.0255 \\
$C_{p}(\mathrm{~J} / \mathrm{kg} \cdot \mathrm{K})$ & 4206 & 1007 \\
$\rho\left(\mathrm{kg} / \mathrm{m}^{3}\right)$ & 969.4 & 1.215 \\
$\operatorname{Pr}$ & 2.19 & 0.71 \\
\hline
\end{tabular}

geometries given in Eqs. (26), (27), (28), (29), (30), (31) in such a way that the numerical value of total heat resistance formulated in Eq. (32) is minimized. Furthermore, respective increases in cooler length $-L$ by $12.1 \%$, fin inside diameters $-d_{b}$ by $21.8 \%$, accompanied by a mammoth decline in overall heat exchange area by $59.1 \%$ cause an enormous decline in modified total heat transfer resistance values given in Eq. (33). One can see the drastic decline $(66.5 \%)$ in the total fin heat exchanger area
Table 12 Upper and lower search bounds for each design variable

\begin{tabular}{lll}
\hline & Lower bound & Upper bound \\
\hline Cooler height $-H(\mathrm{~m})$ & 2.5 & 5.0 \\
Cooler length $-L(\mathrm{~m})$ & 3.0 & 7.0 \\
Fin pitch $-P_{f}(\mathrm{fin} / \mathrm{cm})$ & 2.5 & 5.0 \\
Tube pitch $-P_{t}(\mathrm{~m})$ & 0.0400 & 0.0600 \\
Inner tube diameter $-d_{i}(\mathrm{~m})$ & 0.0170 & 0.0230 \\
Outer tube diameter $-d_{o}(\mathrm{~m})$ & 0.0235 & 0.0258 \\
Gap outside diameter $-d_{g}(\mathrm{~m})$ & 0.0260 & 0.0288 \\
Fin inside diameter $-d_{a}(\mathrm{~m})$ & 0.0470 & 0.0550 \\
Fin outside diameter $-d_{b}(\mathrm{~m})$ & 0.0260 & 0.0390 \\
Fin thickness $-\delta(\mathrm{mm})$ & 0.3 & 0.6 \\
\hline
\end{tabular}

which contributes the most of the decrement in total heat exchange area, whereas bare (only tube) heat exchange surface is hugely increased by $100.1 \%$ through the chaotic MRFO variant. Variational changes in the design variables given in Eq. (18) cause this abrupt decrease in the fin surface area. A decline in cooler length $-L$, a decrease in fin 
Table 13 Comparison of the optimal results obtained by different algorithms for thermo-economic design optimization of an air-fin cooler

\begin{tabular}{|c|c|c|c|c|c|c|c|}
\hline & $\begin{array}{l}\text { Preliminary results } \\
\text { [68] }\end{array}$ & CM05 & CM09 & CM03 & CM02 & COYOTE [76] & MRFO \\
\hline $\begin{array}{l}H \text { - Cooler height } \\
\text { (m) }\end{array}$ & 3.70157 & 4.97887 & 4.98231 & 4.98721 & 4.98507 & 4.99720 & 4.99624 \\
\hline$L-$ Cooler length $(\mathrm{m})$ & 4.00000 & 4.48761 & 4.49697 & 4.40062 & 4.02567 & 4.01542 & 3.79820 \\
\hline$P_{f}-$ Fin pitch $(\mathrm{fin} / \mathrm{cm})$ & 3.00000 & 2.50000 & 2.50000 & 2.51828 & 2.50000 & 2.51005 & 2.50000 \\
\hline$P_{t}-$ Tube pitch $(\mathrm{m})$ & 0.05989 & 0.05856 & 0.05854 & 0.05864 & 0.05793 & 0.05810 & 0.05741 \\
\hline $\begin{array}{l}d_{i}-\text { Tube inner diam- } \\
\text { eter }(\mathrm{m})\end{array}$ & 0.02242 & 0.02300 & 0.02300 & 0.02300 & 0.02300 & 0.02300 & 0.02300 \\
\hline $\begin{array}{c}d_{o}-\text { Tube outer } \\
\text { diameter }(\mathrm{m})\end{array}$ & 0.02423 & 0.02390 & 0.02502 & 0.02366 & 0.02361 & 0.02366 & 0.02351 \\
\hline $\begin{array}{l}d_{g}-\text { Gap outside } \\
\text { diameter }(\mathrm{m})\end{array}$ & 0.02852 & 0.02870 & 0.02814 & 0.02879 & 0.02874 & 0.02875 & 0.02873 \\
\hline $\begin{array}{l}d_{b}-\text { Fin inside diam- } \\
\text { eter }(\mathrm{m})\end{array}$ & 0.03199 & 0.03899 & 0.03899 & 0.03876 & 0.03675 & 0.03684 & 0.03542 \\
\hline $\begin{array}{c}d_{a}-\text { Fin outside } \\
\text { diameter }(\mathrm{m})\end{array}$ & 0.04900 & 0.04700 & 0.04700 & 0.04708 & 0.04700 & 0.04710 & 0.04700 \\
\hline $\begin{array}{l}\delta-\text { Fin thickness } \\
(\mathrm{mm})\end{array}$ & 0.30000 & 0.30000 & 0.30000 & 0.30000 & 0.30000 & 0.30000 & 0.30000 \\
\hline $\begin{array}{l}\text { Total cross-sectional } \\
\text { area of the tubes } \\
\left(\mathrm{m}^{2}\right)\end{array}$ & 0.12656 & 0.21188 & 0.21188 & 0.21188 & 0.21437 & 0.21437 & 0.21687 \\
\hline $\begin{array}{l}\text { Space between fins } \\
\text { (m) }\end{array}$ & 0.00233 & 0.00369 & 0.00369 & 0.00367 & 0.00369 & 0.00368 & 0.00369 \\
\hline $\begin{array}{l}\text { Bare heat exchange } \\
\text { area }\left(\mathrm{m}^{2}\right)\end{array}$ & 82.55177 & 165.12135 & 165.43583 & 160.83614 & 141.25776 & 141.18299 & 129.94949 \\
\hline $\begin{array}{l}\text { Fin heat exchange } \\
\text { area }\left(\mathrm{m}^{2}\right)\end{array}$ & 1896.13078 & 643.81411 & 645.65413 & 659.41643 & 722.79354 & 727.06223 & 764.83191 \\
\hline $\begin{array}{l}\text { Total heat exchange } \\
\text { area }\left(\mathrm{m}^{2}\right)\end{array}$ & 1978.68255 & 808.93550 & 811.08921 & 820.25257 & 864.05130 & 868.24523 & 894.78141 \\
\hline $\begin{array}{l}\text { Tube side Reynolds } \\
\text { number }\end{array}$ & 24236.17971 & 15067.21768 & 15067.29748 & 15067.21762 & 14892.01741 & 14892.01741 & 14720.84480 \\
\hline $\begin{array}{l}\text { Tube side heat } \\
\text { transfer coefficient } \\
\left(\mathrm{W} / \mathrm{m}^{2} \mathrm{~K}\right)\end{array}$ & 3174.68466 & 2046.46821 & 2046.46962 & 2046.46821 & 2026.24048 & 2026.24048 & 2006.42913 \\
\hline $\begin{array}{l}\text { Air side Reynolds } \\
\text { number }\end{array}$ & 12147.24312 & 18547.35093 & 18513.39638 & 18486.60227 & 17755.42182 & 17770.08377 & 17254.73037 \\
\hline $\begin{array}{l}\text { Air side heat transfer } \\
\text { coefficient (W/ } \\
\mathrm{m}^{2} \mathrm{~K} \text { ) }\end{array}$ & 58.27202 & 82.54933 & 82.44671 & 82.01770 & 80.92060 & 80.63165 & 80.34587 \\
\hline $\begin{array}{l}\text { Weighted fin effi- } \\
\text { ciency }\end{array}$ & 0.92908 & 0.98699 & 0.98698 & 0.98583 & 0.97748 & 0.97744 & 0.97042 \\
\hline $\begin{array}{l}\text { Overall heat transfer } \\
\text { coefficient (W/ } \\
\mathrm{m}^{2} \mathrm{~K} \text { ) }\end{array}$ & 34.26539 & 60.77771 & 60.62075 & 59.93788 & 56.90031 & 56.63255 & 54.94762 \\
\hline Actual effectiveness & 0.36125 & 0.28736 & 0.28737 & 0.28735 & 0.28735 & 0.28738 & 0.28736 \\
\hline $\begin{array}{l}\text { Tube side pressure } \\
\text { loss }(\mathrm{Pa})\end{array}$ & 1724.67748 & 545.05044 & 546.18734 & 534.48502 & 479.12365 & 477.90425 & 443.07989 \\
\hline $\begin{array}{l}\text { Air side pressure loss } \\
\text { (Pa) }\end{array}$ & 154.26761 & 199.99921 & 199.47020 & 199.94967 & 199.99761 & 199.23001 & 199.94711 \\
\hline Air cooler cost $(\$)$ & 101967.02176 & 71297.58896 & 71373.48452 & 71694.91026 & 73202.36232 & 73344.27968 & 74232.83837 \\
\hline Pump cost $(\$)$ & 36405.27581 & 16068.36835 & 16092.15763 & 15846.59492 & 14662.88830 & 14636.38276 & 13870.84311 \\
\hline Fan cost (\$) & 120593.63731 & 120593.63731 & 120593.63125 & 120593.63125 & 120593.63125 & 120593.63125 & 12593.63125 \\
\hline $\begin{array}{l}\text { Total cost of air-fin } \\
\text { cooler system }(\$)\end{array}$ & 258965.92882 & 207959.58384 & 208059.27341 & 208135.13644 & 208458.88188 & 208574.29370 & 208697.31274 \\
\hline
\end{tabular}


Table 13 (continued)

\begin{tabular}{llllllll}
\hline & $\begin{array}{l}\text { Preliminary results } \\
{[68]}\end{array}$ & CM05 & CM09 & CM03 & CM02 & COYOTE [76] & MRFO \\
\hline $\begin{array}{l}\text { Annualized capital } \\
\text { cost }(\$ \text { /year) }\end{array}$ & 44691.69277 & 35889.14613 & 35906.34939 & 35919.44166 & 35975.31284 & 35995.23032 & 36016.46064 \\
\hline
\end{tabular}

outside diameter- $d_{a}$ and a marked increase in fin inside diameter- $d_{b}$ are the key elements that explain the considerable reduction in total fin heat exchange area. However, respective increases in the cooler length- $L$, fin inside diameters $-d_{b}$, and the parameter $z$ which represents the clear space between tubes entail an increase in the bare tube heat exchange area, as indicated in Eq. (17). Tube and air-side heat transfer coefficients are decisive parametric quantities having a direct impact on total heat transfer rates, whose respective formulations are given in Eq. (23) and Eq. (20). An increase in the air-side heat transfer coefficient $(41.6 \%)$ compensates for the decrease in tube side heat transfer coefficient values (35.5\%), those of which are closely associated with the corresponding Reynolds numbers of air and tube side streams. Corresponding decrements (37.8\%) and increments (52.6\%) in the tube and air-side heat transfer coefficient values are the main reasons behind this variational interaction. Besides, a remarkable increase (6.2\%) is observed for weighted fin efficiency, which also plays a dominant role along with the air-side heat transfer coefficient parameter on total heat transfer rates as indicated in Eq. (34). Another influencing factor on total annual cost rates is the pumping expenditures whose governing formulation is given in Eq. (41). It is seen that the pumping cost of the cooling system has a direct relation with the pumping power $-\dot{W}_{\text {pump }}$, which maintains the required amount of refrigerant water circulation along the heat exchanger tubing. Equation (42) indicates that the pressure gradient caused by the friction losses in the tubes necessitates the required pumping power. A considerable decrease (68.4\%) in pressure drop values is resulted from the variational changes of different operational parameters. Tube inner diameter $-d_{i}$ hits the allowable upper bound which allows for the resulting decreases in the mass velocity of the in-tube fluid. Increasing inner tube diameters $-d_{i}$ along with the enhanced friction losses $-f_{\text {tube }}$ resulted from the decreasing tube-side Reynolds number have a negligible effect compared to the influence of greatly reduced in-tube fluid mass flux rates as described in Eq. (25).

Figures 16 and 17 show the variational changes of the operational parameters over the design objective of the annualized capital cost of an air fin cooler. Optimum design variables obtained by CM05 are utilized for parametrical analysis and the remaining variables stay constant while the related parameter is varied between its allowable search space. It is evident that annualized capital cost rates significantly increase as cooler length $-L$ and fin pitch$P_{f}$ vary between the lower and upper search bounds. As coooler length is increased along the allowable region, bare tube area $\left(A_{\text {tube }}\right)$ and tube side pre4ssure drop $\left(\Delta P_{\text {tube }}\right)$ increase which yields an increase in capital cost rates. It is also seen that tube pitch $-P_{t}$ is inversely proportional to the annual capital cost. Increasing tube pitch values leads to a decrease in air side pressure drop rates, which eventually entails a decrease in fan cost expenditures. Objective function values tend to decrease with increasing cooler height until the cooler height reaches $4.0 \mathrm{~m}$ then this value increases with increasing cooler heights. It can be also observed from Fig. 16 that variation of the cooler length between its corresponding search space has much more impact on the change of annualized capital cost values compared to those obtained for the remaining design variables. Figure 17 visualizes the influences of varying design parameters on the objective function values. It is seen that varying gap outside diameters- $d_{g}$ and outer tube diameters $-d_{o}$ have a negligible effect on the design objective while increasing inner tube diameters and fin inside diameters reduces the annualized capital cost values. Increasing inner tube diameters leads to a decrease in tube side pressured drop rates as formulated in Eq. (25), which imposes a reduction in pumping cost rates. Due to its relatively small search span, fin thickness- $\delta$ has a limited effect over the range of solution space. Annualized capital cost values are significantly increased with increasing fin outside diameters - $d_{a}$. As Eq. (18) suggests, increasing fin outside diameters $-d_{a}$ increases the total fin heat exchange area, which consequently increases annualized cost values. On the contrary, annualized cost values decreases with increasing fin inside diameters- $d_{b}$ relying on the numerical relationship expressed in Eq. (18). It is also worth to mention that no constraint violation is observed for any defined design variable, which also idicates that all obtained optimum solutions residing in the feasible region of the search space.

\section{Conclusion}

This study proposes the chaotic Manta-Ray Foraging Optimization (MRFO) Algorithm for solving multidimensional optimization problems. Twenty-four different chaotic 

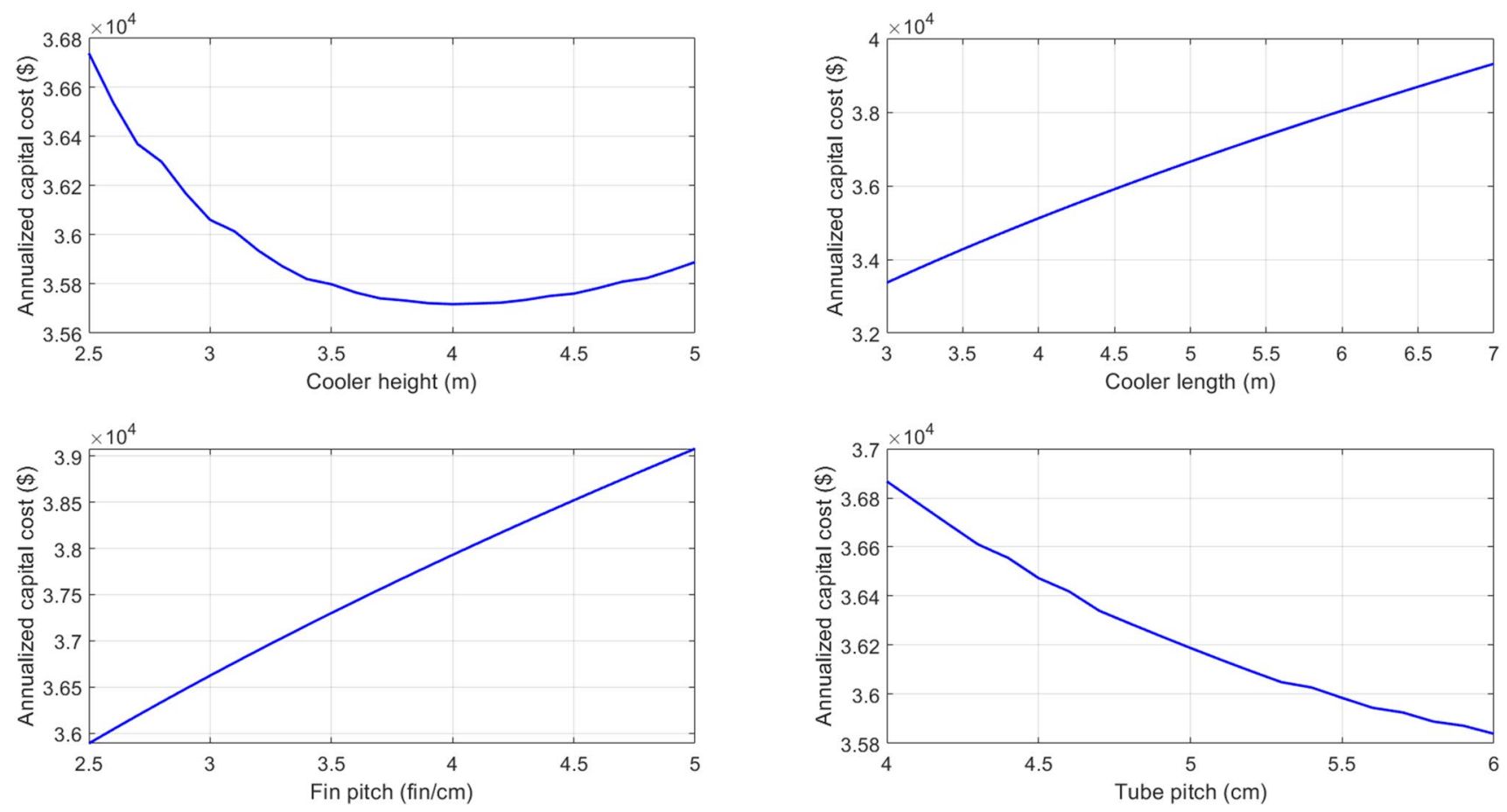

Fig. 16 Variational effects of operating parameters on the problem objective
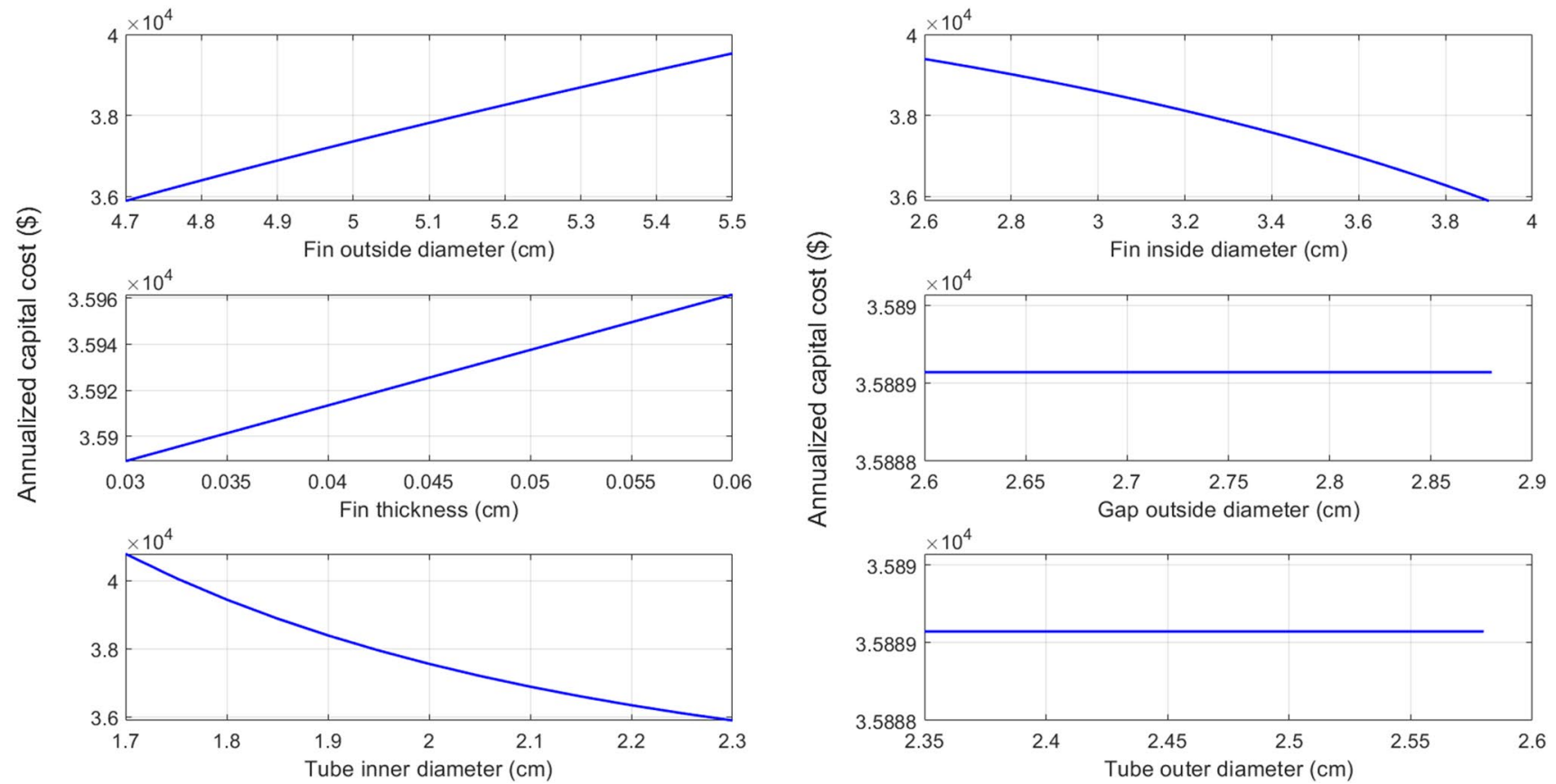

Fig. 17 Influences of design parameters on the problem objective of annualized capital cost values

maps taken from the literature studies are applied to MRFO and best performing ten chaotic maps out of twenty-four maps have been selected. The effectiveness of these ten chaotic maps is compared in terms of solution quality improvement utilizing different kinds of optimization test functions. Numerical experiments based on unconstrained multimodal and unimodal benchmark functions indicate that incorporating the chaotic maps into the the base 
metaheuristic algorithm have considerably improved the solution quality and accuracy. It is shown that Kent map (CM05), Chirikov map (CM03), and Standard map (CM09) based chaotic MRFO algorithms provide the most reliable statistical results compared to the remaining chaotic methods. The results prove that chaotic variants can significantly improve the optimization performance of MRFO by escaping the local minimum points on the search space and boosting up the convergence speed to some extent. To assess the prediction capability of the chaos enhanced algorithms over constrained test problems, a batch of sixteen benchmark cases of CEC2017 competition have been solved by three best performing above mentioned chaotic variants and respective solution outcomes have been compared with those obtained by the first and second place holders of this competition. A multidimensional real-world constrained optimization problem concerning thermo-economic design optimization of an air-fin cooler is applied to the chaotic MRFO method. Optimization results reveal that chaotic variants of MRFO can maintain a huge amount of energy-saving compared to that of the preliminary design. Total cost of the fin cooler is reduced by $19.7 \%$ compared to preliminary design when chaotic Kent Map based MRFO is employed. A sensitivity analysis is performed to investigate the variational changes of each optimized operating parameter of the air-fin cooler over the considered problem objective. It is seen that increasing cooler length, fin ptich, and fin outside diameter values increase the total cost of the heat exchanger. On the contrary, annual cost rates decrease as the design parameters increase within the defined search range. It is also observed that gap and tube outside diameters have a negligible efffect on the annual cost values. All in all, the optimization efficiency of the chaotic algorithms is verified against benchmark problems with different characteristics and it is understood that the superiority of the proposed methods is evident for the majority of the comparison case. Real-world multi-objective engineering problems can be a favorable test bench for evaluating chaotic MRFO methods for future work. An interesting idea for performance evaluation maybe their successful implementation over parallel or distributed environments. Furthermore, chaotic MRFO methods can be compared with newly emerged state-of-art metaheuristic algorithms to make a reliable conclusion on their optimization capabilities.

\section{Compliance with ethical standards}

Conflict of interest The author declares that they have no conflict of interest.
Open Access This article is licensed under a Creative Commons Attribution 4.0 International License, which permits use, sharing, adaptation, distribution and reproduction in any medium or format, as long as you give appropriate credit to the original author(s) and the source, provide a link to the Creative Commons licence, and indicate if changes were made. The images or other third party material in this article are included in the article's Creative Commons licence, unless indicated otherwise in a credit line to the material. If material is not included in the article's Creative Commons licence and your intended use is not permitted by statutory regulation or exceeds the permitted use, you will need to obtain permission directly from the copyright holder. To view a copy of this licence, visit http://creativecommons .org/licenses/by/4.0/.

\section{References}

1. Wang GG, Guo L, Gandomi AH, Hao GS, Wang H (2014) Chaotic Krill Herd algorithm. Inform Sci 274:17-34

2. Wang G, Guo L (2013) A novel hybrid bat algorithm with harmony search for global numerical optimization. J Appl Math 2013:1-21

3. Wang H, Zhao G, Li N (2012) Training support vector data descriptors using converging linear particle swarm optimization. Neural Comput Appl 21(6):1099-1105

4. Bekdaş G, Nigdeli SM, Yang XS (2018) A novel bat algorithm based optimum tuning of mass dampers for improving the seismic safety of structures. Eng Struct 159:89-98

5. Guo Y, Dai X, Jermsittiparsert K, Razmjooy N (2020) An optimal configuration for a battery and PEM fuel cell-based hybrid energy system using developed Krill herd optimization algorithm for locomotive application. Energy Rep 6:885-894

6. Fathy A, Rezk H, Mohamed Ramadan HS (2020) Recent mothflame optimizer for enhanced solid oxide fuel cell output power via optimal parameters extraction process. Energy 207:118326

7. Kennedy J, Eberhart R (1995) Particle swarm optimization. In: Proceedings of ICNN'95 - International Conference on Neural Networks 4: 1942-1948

8. Storn R, Price K (1997) Differential evolution - a simple and efficient heuristic for global optimization over continuous spaces. J Global Optim 11(4):341-359

9. Geem ZW, Kim JH, Loganathan GV (2001) A new heuristic optimization algorithm: harmony search. Simulation 76(2):60-68

10. Askarzadeh A (2016) A novel metaheuristic method for solving constrained engineering optimization problems: crow search algorithm. Comput Struct 169:1-12

11. Suleiman MH, Mustafa Z, Saari MM, Daniyal H (2020) Barnacles mating optimizer: a new bio- inspired algorithm for solving engineering optimization problems. Eng Appl Artif Intell 87:103330

12. Heidari AA, Mirjalili S, Faris $H$, Aljarah I, Mafarja M, Chen H (2019) Harris hawks optimization: algorithm and applications. Future Gener Comput Syst 97:849-872

13. Dhiman G, Kumar V (2019) Seagull optimization algorithm: theory and its applications for large-scale industrial engineering problems. Knowl Based Syst 165:169-196

14. Li S, Chen H, Wang M, Heidari AA, Mirjalili S (2020) Slime mould algorithm: a new method for stochastic optimization. Future Gener Comput Syst 111:300-323

15. Shayanfar H, Gharehchopogh FS (2018) Farmland fertility: a new metaheuristic algorithm for solving continuous optimization problems. Appl Soft Comput 71:728-746 
16. Houssein EH, Saad MR, Hashim FA, Shaban H, Hassaballah M (2020) Levy flight distribution: a new metaheuristic algorithm for solving engineering optimization problems. Eng Appl Artif Intell 94:103731

17. Patel VK, Savsani VJ (2015) Heat transfer search (HTS): a novel optimization algorithm. Inf Sci 324:217-246

18. Raja BD, Patel V, Jhala RL (2017) Thermal design and optimization of fin-and-tube heat exchanger using heat transfer search algorithm. Therm Sci Eng Prog 4:45-57

19. Patel V, Savsani V, Mudgal A (2017) Many-objective thermodynamic optimization of stirling heat engine. Energy 125:629-642

20. Sivaraj H, Gopalakrishnan G (2003) Random walk based heuristic algorithms for distributed memory model checking. Electron Notes Theor Comput Sci 89(1):51-67

21. Fu Y, Lei Z, Cai S, Lin J, Wang H (2020) WCA: a weighting local search for constrained combinatorial test optimization. Inform Software Tech 122:106288

22. Sancibrian R, Sedano A, Sarabia EG, Blanco JM (2019) Hybridizing differential evolution and local search optimization for dimensional synthesis of linkages. Mech Mach Theory 140:389-412

23. Zhang X, Kang Q, Wang X (2019) Hybrid biogeography-based optimization with shuffled frog leaping algorithm and its application to minimum spanning tree problems. Swarm Evol Comput 49:245-265

24. Yuan G, Yang W (2019) Study on optimization of economic dispatching of electric power system based on hybrid intelligent algorithms (PSO and AFSA). Energy 183:926-935

25. Alatas B (2011) Uniform big bang-chaotic big crunch optimization. Commun Nonlinear Sci 16(9):3696-3703

26. Gandomi AH, Yang XS (2014) Chaotic bat algorithm. J Comput Sci 5(2):224-232

27. Gandomi AH, Yang XS, Talatahari S, Alavi AH (2013) Firefly algorithm with chaos. Commun Nonlinear Sci 18(1):89-98

28. Arora S, Anand P (2019) Chaotic grasshopper optimization algorithm for global optimization. Neural Comput Appl 31(8):4385-4405

29. Rezaee JA (2015) A chaotic artificial immune system optimisation algorithm for solving global continuous optimisation problems. Neural Comput Appl 26(4):827-833

30. Talatahari S, Farahmand Azar B, Sheikholeslami R, Gandomi AH (2012) Imperialist competitive algorithm combined with chaos for global optimization. Commun Nonlinear Sci 17(3):1312-1319

31. Sayed Gl, Hassanien AE, Azar AT (2019) Feature selection via a novel chaotic crow search algorithm. Neural Comput Applic 31(1):171-188

32. Too J, Abdullah AR (2020) Chaotic atom search optimization for feature selection. Arab J Sci Eng 45(8):6063-6079

33. Sayed GI, Khoriba G, Haggag MH (2018) A novel chaotic salp swarm algorithm for global optimization and feature selection. Appl Intell 48(10):3462-3481

34. Sayed GI, Tharwat A, Hassanien AE (2019) Chaotic dragonfly algorithm: an improved metaheuristic algorithm for feature selection. Appl Intell 49(1):188-205

35. Mirjalili S, Gandomi AH (2017) Chaotic gravitational constants for the gravitational search algorithm. Appl Soft Comput 53:407-419

36. Zhao W, Zhang Z, Wang L (2020) Manta ray foraging optimization: An effective bio-inspired optimizer for engineering applications. Eng Appl Artif Intel 87:103300

37. Ćalasan MP, Jovanović A, Rubežić V, Mujičić $D$, Deriszadeh A (2020) Notes on parameter estimation for single-phase transformer. IEEE Trans Ind Appl 56(4):3710-3718

38. Fathy A, Rezk H, Yousri D (2020) A robust global MPPT to mitigate partial shading of triple-junction solar cell-based system using manta ray foraging optimization algorithm. Sol Energy 207:305-316

39. Selem SI, Hasanien HM, El-Fergany AA (2020) Parameters extraction of PEMFC's model using manta rays foraging optimizer. Int J Energy Res 44(6):4629-4640

40. El-Hameed MA, Elkholy MM, El-Fergany AA (2020) Three-diode model for characterization of industrial solar generating units using Manta-rays foraging optimizer: analysis and validations. Energ Convers Manag 219:113048

41. Doodman AR, Fesanghary $M$, Hosseini R (2009) A robust stochastic approach for design optimization of air cooled heat exchangers. Appl Energy 86(7):1240-1245

42. Salimpour MR, Bahrami Z (2011) Thermodynamic analysis and optimization of air-cooled heat exchangers. Heat Mass Transf 47(1):35-44

43. González MT, Petracci NC, Urbicain MJ (2001) Air-cooled heat exchanger design using successive quadratic programming (SQP). Heat Transf Eng 22(3):11-16

44. Alinia Kashani AH, Maddahi A, Hajabdollahi H (2013) Thermaleconomic optimization of an air-cooled heat exchanger unit. Appl Therm Eng 54(1):43-55

45. Karami A, Rezaei E, Shahhosseni M, Aghakhani M (2012) Optimization of heat transfer in an air cooler equipped with classic twisted tape inserts using imperialist competitive algorithm. Exp Therm Fluid Sci 38:195-200

46. Manassaldi JI, Scenna NJ, Mussati SF (2014) Optimization mathematical model for the detailed design of air cooled heat exchangers. Energy 64:734-746

47. Carvalho CB, Ravagnani MASS, Bagajewicz MJ, Costa ALH (2019) Globally optimal design of air coolers considering fan performance. Appl Therm Eng 161:114188

48. Rizzo J (2016) Ocean animals: who's who in the deep blue. National Geographic Children's Books, Washington, D.C

49. Helfman G, Burgess GH (2014) Sharks: the animal answer guide. Johns Hopkins University Press, Baltimore

50. Sjonger R, Kalman B (2005) Skates and rays. Crabtree Publishing Company, New York, NY

51. Joshi AS, Kulkarni O, Kakandikar GM, Nandedkar VM (2017) Cuckoo search optimization- a review. Mater Today 4(8):7262-7269

52. Zhang Q, Li Z, Zhou CJ, Wei XP (2013) Bayesian network structure learning based on the chaotic particle swarm optimization algorithm. Genet Mol Res 12(4):4468-4479

53. Sayed GI, Darwish A, Hassanien AE (2018) A new chaotic multiverse optimization algorithm for solving engineering optimization problems. J Exp Theor Artif In 30(2):293-317

54. Saremi S, Mirjalili S, Lewis A (2014) Biogeography-based optimisation with chaos. Neural Comput Appl 25(5):1077-1097

55. Rezaee Jordehi A (2014) A chaotic-based big bang-big crunch algorithm for solving global optimisation problems. Neural Comput Appl 25(6):1329-1335

56. Mirjalili S, Mirjalili SM, Lewis A (2014) Grey wolf optimizer. Adv Eng Softw 69:46-61

57. Bao J, Yang Q (2012) Period of the discrete Arnold cat map and general cat map. Nonlinear Dyn 70(2):1365-1375

58. Zhang Z, Wang H, Gao Y (2015) C2MP: chebyshev chaotic mapbased authentication protocol for RFID applications. Pers Ubiquit Comput 19(7):1053-1061

59. Zhang Y, Xiao D (2013) Double optical image encryption using discrete Chirikov standard map and chaos-based fractional random transform. Opt Laser Eng 51(4):472-480

60. Peitgen HO, Jürgens $H$, Saupe D (2012) Chaos and Fractals: New Frontiers of Science, 2 nd ed. 2004. Softcover reprint of the original 2nd ed. 2004 Edition, Springer

61. Feldman DP (2012) Chaos and fractals: an elementary introduction, 1st edn. Oxford University Press, Oxford 
62. May RM (1976) Simple mathematical models with very complicated dynamics. Nature 261:459-467

63. Alizadeh M, Alizadeh M, Ganjefar S (2013) Simultaneous coordinated design of PSS and SSSC using improved Lozi map based chaotic optimization algorithm (ILCOA). Neurocomput 122:181-192

64. Sprott JC (2001) Chaos and time-series analysis, 1st edn. Oxford University Press, Oxford, New York

65. Nesa N, Ghosh T, Banerjee I (2019) Design of a chaos-based encryption scheme for sensor data using a novel logarithmic chaotic map. J Inf Secur Appl 47:320-328

66. Kumar A, Misra RK, Singh D (2017) Improving the local search capability of Effective Butterfly Optimizer using Covariance Matrix Adapted Retreat Phase, In: 2017 IEEE Congress on Evolutionary Computation (CEC), pp. 1835-42

67. Brest J, Maučec MS, Bošković B (2017) Single objective realparameter optimization: Algorithm jSO, In: 2017 IEEE Congress on Evolutionary Computation (CEC), pp. 1311-8

68. Kraus AD, Aziz A, Welty JR (2001) Extended surface heat transfer. Wiley, New York

69. IncroperaFP DDP, Bergman TL, Lavine AS (2006) Fundamentals of heat and mass transfer, 6th edn. Wiley, Hoboken, NJ

70. Couper JR, Penney WR, Fair JR, Walas SM (1988) Chemical process equipment: selection and design. Butterworth-Heinemann, Boston
71. Sanaye S, Shirazi A (2013) Thermo-economic optimization of an ice thermal energy storage system for air-conditioning applications. Energ Build 60:100-109

72. Chauvel A, Fournier G (2003) Manual of process economic evaluation, new, revised, Expanded. Editions Technips, Paris

73. Peters M, Timmerhaus K, West R, Peters M (2002) Plant design and economics for chemical engineers, 5th edn. McGraw-Hill Education, New York

74. Buys JD, Kröger DG (1989) Dimensioning heat exchangers for existing dry cooling towers. Energ Convers Manag 29(1):63-71

75. Jiang-tao Y, Liu D, Tian W, Zheng MY, Wu Y, Su G, Qiu SZ (2015) Experimental and numerical investigation of heat tranfer and pressure drop in staggered arrangement helically finned-tube bundle. In: 16th International topical meeting on nuclear reactor thermal hydraulics, Chicago, United States, pp 8643-8656

76. Pierezan J, Coelho S (2018) Coyote optimization algorithm: a new metaheuristic for global optimization problems. In: Proceedings of the IEEE Congress on Evolutionary Computation (CEC), Rio de Janerio, Brazil, pp.2633-2640

Publisher's Note Springer Nature remains neutral with regard to jurisdictional claims in published maps and institutional affiliations. 